\title{
Interactions of Gliotoxin with Protein Cysteines
}

\author{
By \\ Rana Fathizargaran \\ A thesis \\ Submitted to Victoria University of Wellington \\ In fulfilment of the requirements for the degree of \\ Master of Biomedical Science
}

Victoria University of Wellington

2012 


\section{Acknowledgements}

First of all, I wish to express my sincere thanks to my supervisor Dr Bill Jordan, whose door was always open for me and always answered my questions with a smile. Without his encouragement and guidance over the course of this project I would not have made it this far.

I would like to extend my heartfelt gratitude to Danyl McLauchlan for teaching me the skills and techniques that I required for this project. The same applies to Dr Jonathan Dunne, who was very helpful and patient with my endless questions.

I am also grateful to Professor John H Miller (School of Biological Sciences, Victoria University of Wellington, New Zealand) for providing the HL-60 cells.

I also want to thank Sarah Cordiner for teaching me the skills of cell culturing. My thanks are also extended to Dr Christine Stockum and Claire Swain for providing materials and the rest of the $3^{\text {rd }}$ floor lab members of the Alan MacDiarmid Building.

Last, but not least, I would like to thanks my husband Rouhollah for his continuous support and encouragement that motivated me to study and same applies to my family in Iran who always encouraged me to study in this beautiful country. 


\begin{abstract}
Gliotoxin is a secondary metabolite that is produced by several species of fungi, and is toxic to mammalian cells. It is immunosuppressive, affects antigen presentation by macrophages, and causes apoptosis of some cells. Gliotoxin is an epipolythiodioxopiperazine molecule and contains an internal disulfide bridge that is highly reactive and essential for its toxicity. Suggested mechanisms of action include modification of thiol groups of cysteine residues in target proteins by generating oxidative stress or through covalent modification. The goal of this project was to develop mass spectrometry methods to detect protein modification by gliotoxin. Creatine kinase was used as a model protein. The measured mass of creatine kinase from 45 spectra gave a mean of $42,944 \pm 24$ which was consistent with the predicted mass of creatine kinase. A tryptic digest of creatine kinase indicated ions consistent with the predicted masses of the four cys-containing peptides including abundant ions at $\mathrm{m} / \mathrm{z}$ 794, 1130 and 2870 and an ion at low intensity at 4373 . The reaction of creatine kinase with gliotoxin showed a time dependent reaction that after $14 \mathrm{~h}$ was consistent with formation of a gliotoxin adduct. Reduction of the product with dithiothreitol released creatine kinase. Analysis of the tryptic peptides using MALDI mass spectrometry indicated complex modification of cysteines possibly including formation of a mixed disulfide adduct, intramolecular disulfides of $\mathrm{CK}$, and sulfur oxidation products. Further analysis using the ICAT (isotope-coded affinity tag) method suggested modification of Cys-254 and Cys-283 by gliotoxin. Preliminary experiments examined the effects of gliotoxin on HL-60 cells using ICAT. Proteins of gliotoxin-treated and untreated cells were labeled with Heavy and Light ICAT reagents. Potential ICAT pairs were detected in the mass spectrum as a preliminary search for proteins affected by gliotoxin. The results indicate that ICAT labeling should be an effective strategy for characterization of the protein targets of gliotoxin.
\end{abstract}




\section{Abbreviations}

ACN

Acetonitrile

CHCA

a-Cyano-4-hydroxycinnamic acid

CK

Creatine kinase

Cys

Cysteine

DMSO

Dimethyl sulfoxide

DTT

Dithiothreitol

ESI

Electrospray ionization

ETP

Epidithiodioxopiperazine

GTX

Gliotoxin

IAA

lodoacetamide

ICAT

Isotope-coded affinity tag

MALDI

Matrix assisted laser desorption ionization

MS

Mass spectrometry

MS/MS

Tandem mass spectrometry

TFA

Trifluoroacetic acid

TOF

Time of flight 


\section{TABLE OF CONTENTS}

ACKNOWLEDGMENTS.......................................................................IV

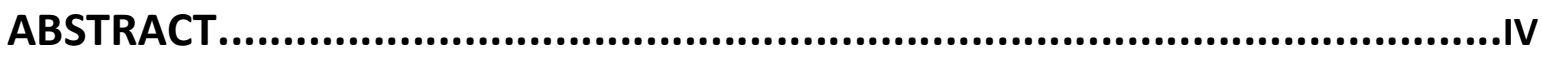

ABBREVIATIONS.....................................................................IV

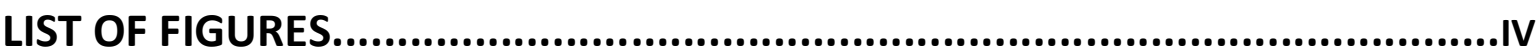

LIST OFT ABLES.........................................................................

1. INTRODUCTION.............................................................................1

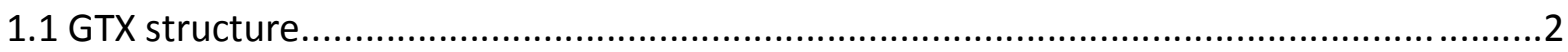

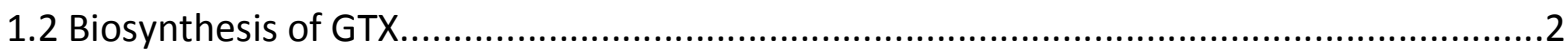

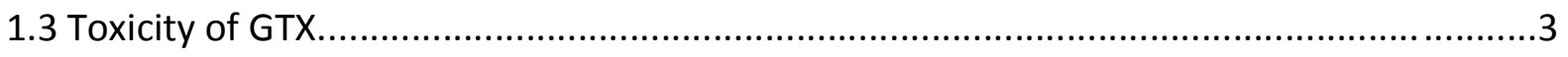

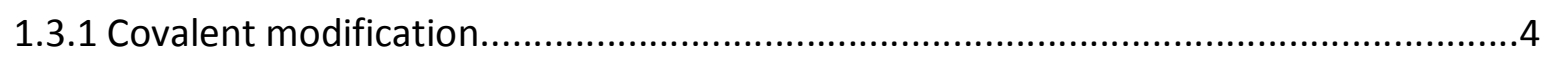

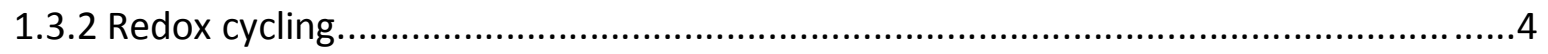

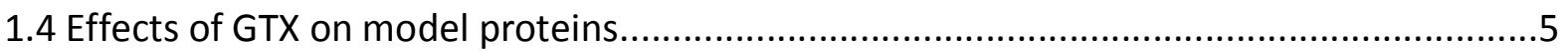

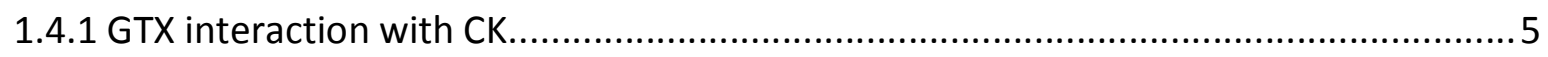

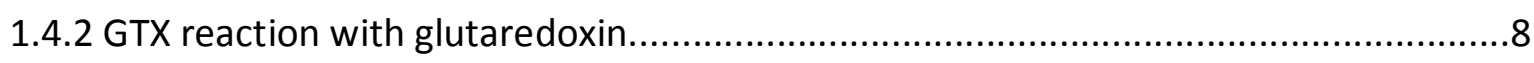

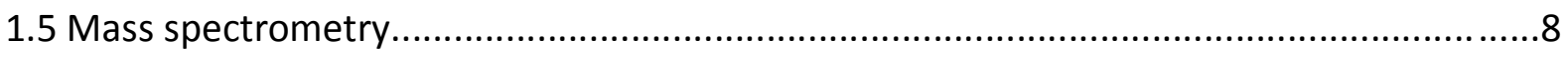

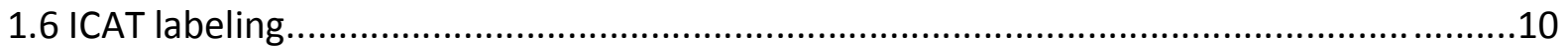

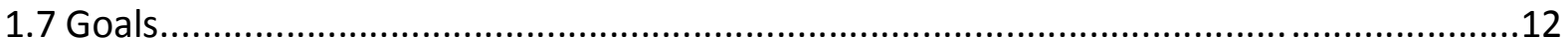

2. METHODS....................................................................................13

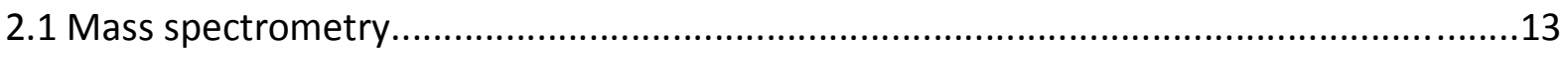

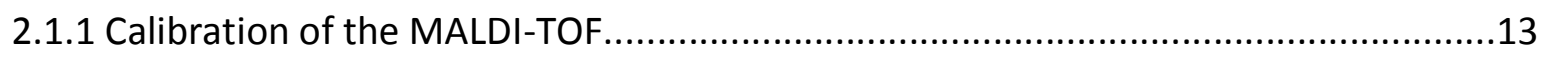

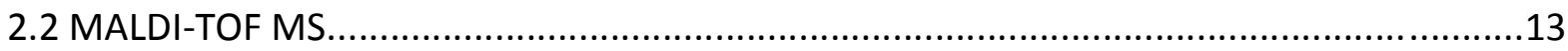

2.2.1 Preparation of CK for MALDI-TOF analysis using the dried droplet method..............13

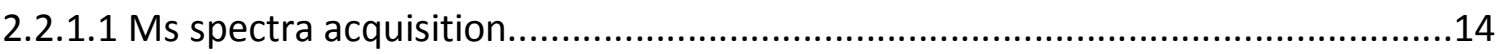

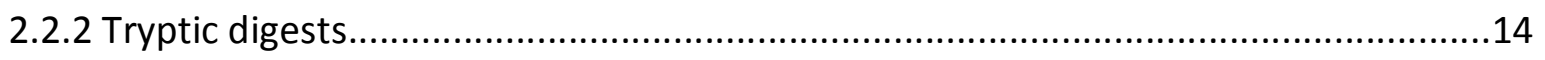

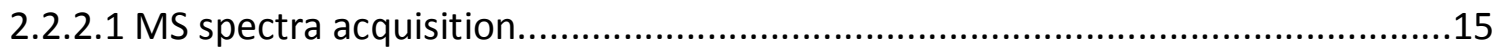




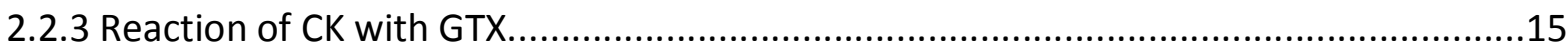

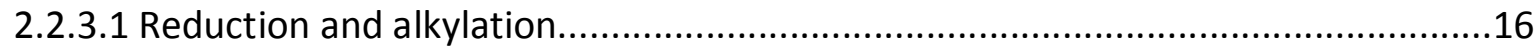

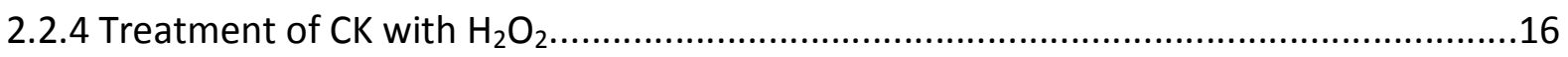

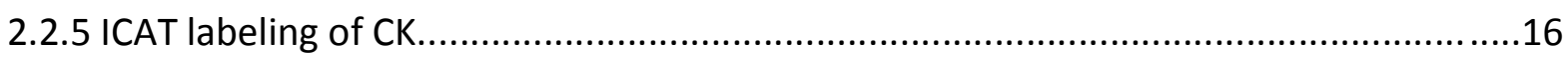

2.2.6 Purifying and concentration of peptide samples before MALDI analysis.....................17

2.2.7 Matching tryptic peptides to the CK sequences.....................................................18

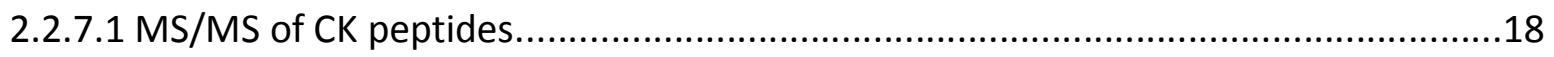

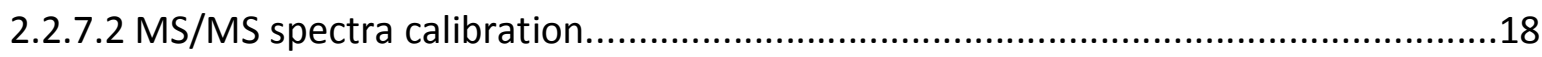

2.2.7.3 MS/MS monoisotopic precursor selection.......................................................19

2.2.7.4 Matching of peptide sequences to the NCBI database.......................................19

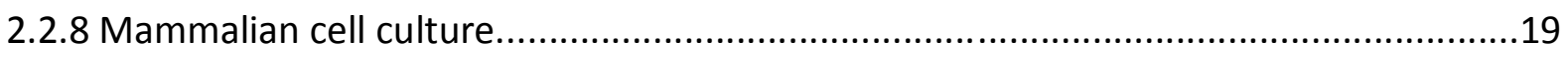

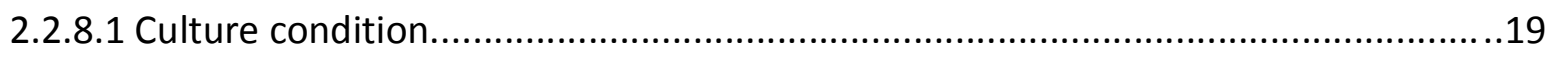

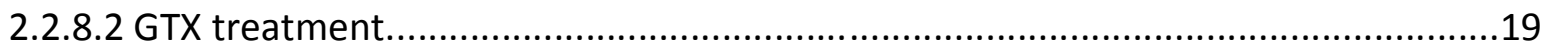

2.2.8.3 Cell viability and concentration by trypan blue exclusion....................................20

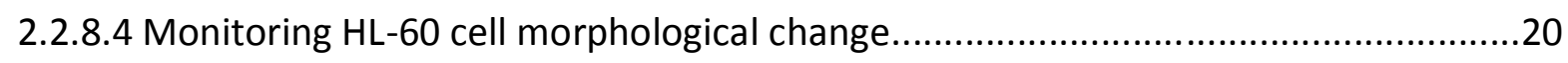

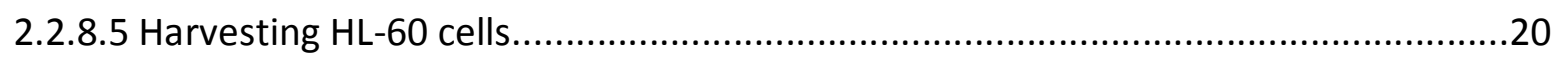

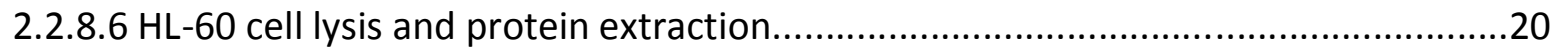

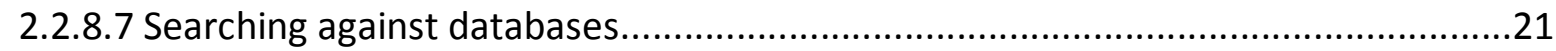

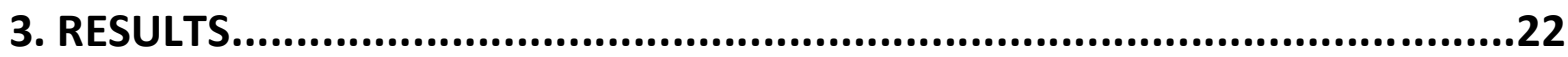

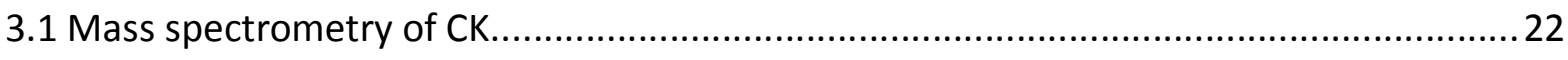

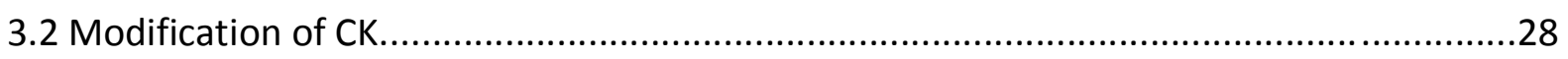

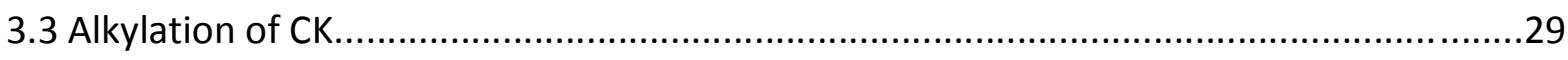

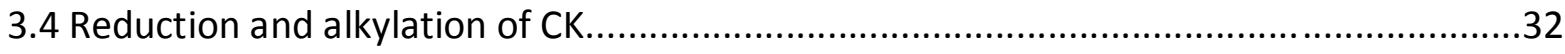

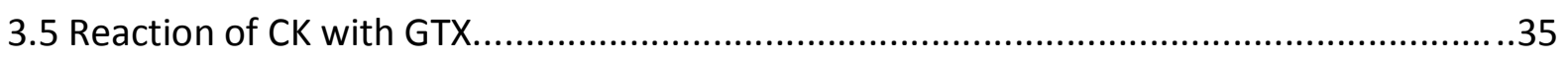

3.5.1 Comparing the tryptic peptides of CK and GTX-treated CK...................................41

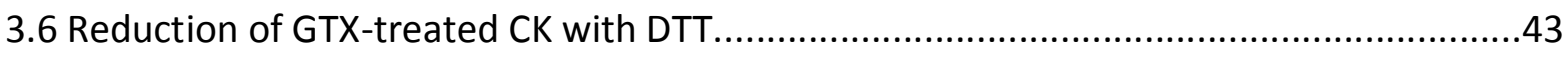

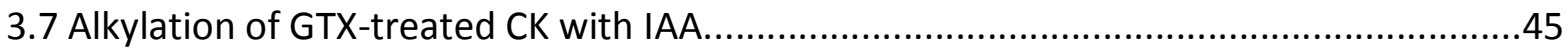

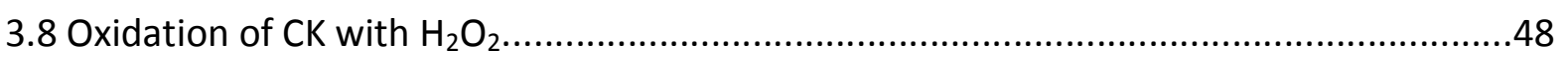




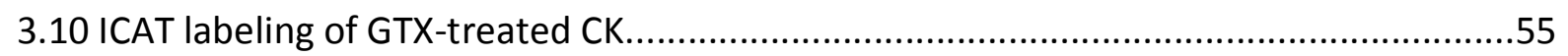

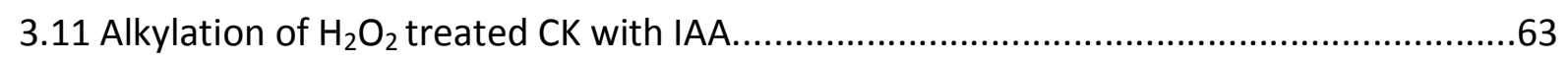

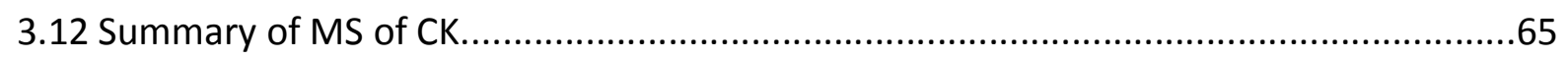

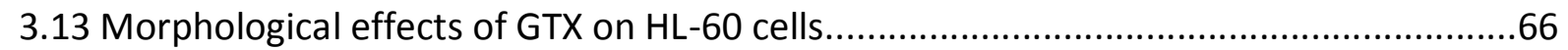

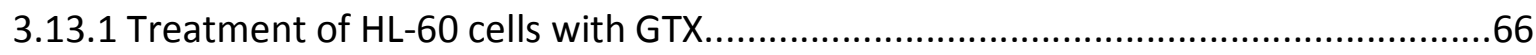

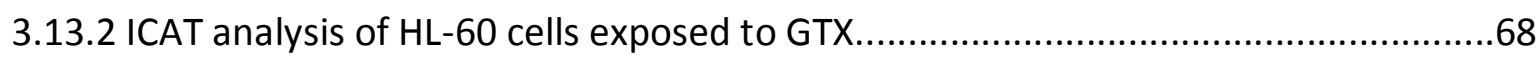

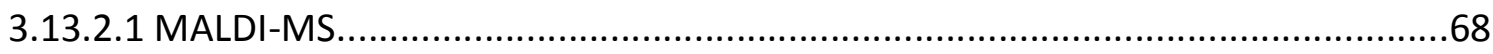

4. DISCUSSION.......................................................................70

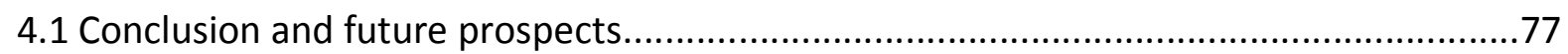

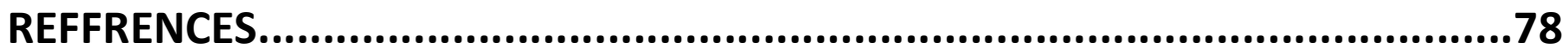

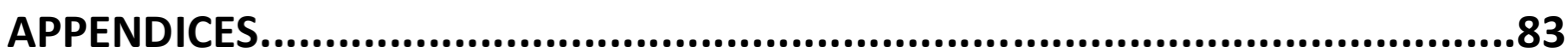

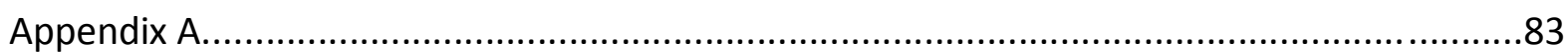

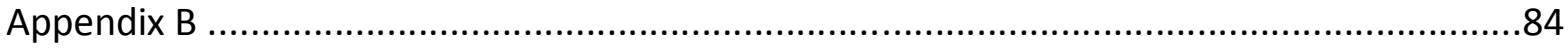

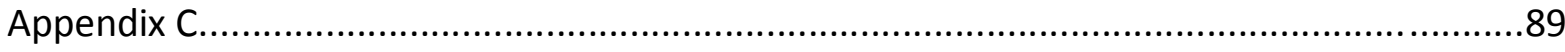

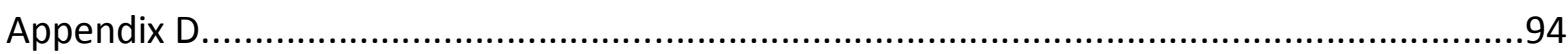




\section{LIST OF FIGURES}

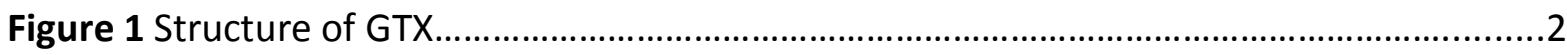

Figure 2 Schematic for covalent modification of proteins by GTX............................................

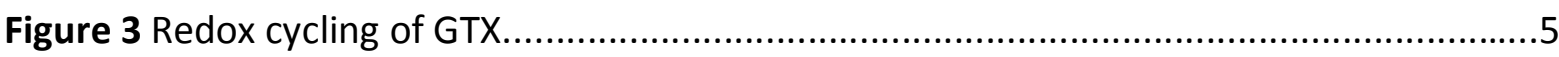

Figure 4 Structure of monomer of CK showing the positions of the cysteine residues............6

Figure 5 Proposed mechanism for CK inhabitation by GTX ......................................................

Figure 6 Schematic of a generic MS-based proteomics methodology....................................9

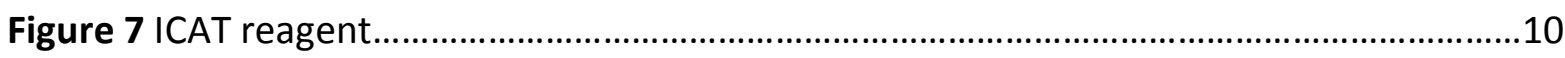

Figure 8 Schematic of a quantitative proteomic strategy using ICAT and MS.........................11

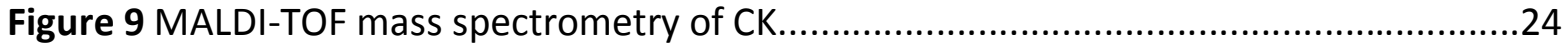

Figure 10 MALDI-TOF of peptide mass fingerprint of CK.......................................................25

Figure 11 MALDI-TOF ion corresponding to the predicted FCVGLQK peptide........................26

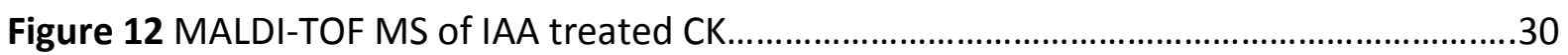

Figure 13 MALDI- TOF MS of a tryptic digest of CK alkylated with IAA ....................................31

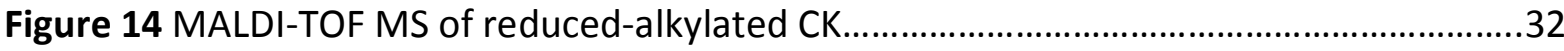

Figure 15 MALDI-TOF MS of tryptic digest of reduced and alkylated CK................................33

Figure 16 MALDI-TOF MS of tryptic digest of reduced-alkylated CK.........................................34

Figure 17 MALDI-TOF mass spectrometry of GTX-treated CK..................................................36

Figure 18 MALDI-TOF mass spectrometry of GTX-treated CK..................................................37

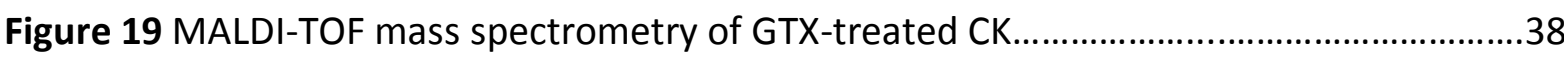

Figure 20 MALDI-TOF MS of tryptic digest of GTX-treated CK.................................................39

Figure 21 MALDI-TOF spectrum of tryptic digest of GTX-treated CK ......................................40

Figure 22 MALDI-TOF MS of tryptic digests of CK and GTX-treated CK..............................42

Figure 23 MALDI-TOF MS of GTX-treated CK reacted with DTT ...............................................43

Figure 24 MALDI-TOF MS of tryptic digest of GTX-treated CK reacted with DTT.....................44

Figure 25 MALDI-TOF mass spectrometry of GTX-treated CK reacted with IAA.....................46

Figure 26 MALDI-TOF spectrum of tryptic digest of GTX-treated CK alkylated with IAA.......47 
Figure $27 \mathrm{MALDI}$-TOF mass spectrometry of $\mathrm{H}_{2} \mathrm{O}_{2}$ treated CK. 49

Figure $28 \mathrm{MALDI}$-TOF MS of tryptic digest of $\mathrm{H}_{2} \mathrm{O}_{2}$ treated CK............................................50

Figure 29 MALDI-TOF mass spectrum of CK labeled with Light ICAT.......................................52

Figure 30 MALDI-TOF MS of tryptic digest of Light ICAT-labeled CK.......................................53

Figure 31 MALDI-TOF MS of Light ICAT-labeled CK before and after desalting and concentration .54

Figure 32 MALDI-TOF mass spectrometry of Light ICAT-labeled GTX-treated CK 56

Figure 33 ICAT spectra of a trypsin digest of a mixture of Light ICAT-labelled CK plus Heavy ICAT-labeled GTX-treated CK .57

Figure 34 MALDI-TOF MS of ICAT labeling of Cys-254 peptide ...........................................58

Figure 35 MALDI-TOF MS of ICAT labeling of Cys-146 peptide.................................................59

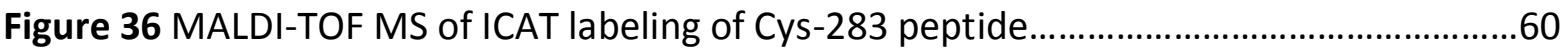

Figure 37 MALDI-TOF MS of GTX adduct on Cys-254 peptide..........................................61

Figure 38 The peptide sequence corresponding to the $\mathrm{m} / \mathrm{z} 1357.6$ ion.............................62

Figure $39 \mathrm{MALDI-TOF}$ mass spectrometry of alkylated $\mathrm{H}_{2} \mathrm{O}_{2}$ treated CK with IAA.................63

Figure 40 MALDI-TOF MS of tryptic digest of $\mathrm{H}_{2} \mathrm{O}_{2}$ treated $\mathrm{CK}$ reacted with IA......................64

Figure 41 Cultured HL-60 cells at $24 \mathrm{~h}$ after GTX treatment..............................................66

Figure 42 Cultured HL-60 cells at $24 \mathrm{~h}$ after GTX treatment..................................................67

Figure 43 MALDI-TOF MS of tryptic digest of a mixture of Light ICAT-labeled untreated HL-60 cells plus Heavy ICAT-labeled GTX-treated HL-60 cells .69 


\section{LIST OF TABLES}

Table 1 Masses of cys-containing tryptic peptides of CK and alkylated CK, with 0 or 1 missed cleavage.

Table 2 Expected mass additions for reaction of cysteine residues with IAA, GTX, or Light and Heavy ICAT reagents. 28

Table 3 Predicted masses of cys-containing peptides after modification of CK with IAA, GTX or Light and Heavy ICAT..... .28

Table 4 Theoretical and observed masses of trypsinized CK and GTX-treated CK 41

Table 5 Predicted mass change of oxidized cys-containing tryptic peptides by addition of one, two, or three oxygen molecules .48

Table 6 Predicted and observed masses of cys-containing tryptic peptides. 65 


\section{Introduction}

Gliotoxin is an immunosuppressive cytotoxin that is synthesised by diverse species of fungi including Aspergillus fumigates, Gliocladium fimbriatum, Trichoderma virens, Penicillium spp, and Candida albicans as a secondary metabolite (Gardiner, Waring \& Howlett, 2005, Rezanka, Sobotka, Spizek \& Sigler, 2006). Many filamentous fungi synthesise secondary metabolites which are not necessary for growth, although they generally have critical biological roles (Cramer et al., 2006, Munday, 1989). GTX is a hydrophobic molecule and belongs to the ETP (epipolythiodioxopiperazine) class of fungal metabolites (Chai \& Waring, 2000). ETPs are non-polar and contain an internal disulfide bridge which is crucial for their biological activity (Gardiner et al., 2005, Jones \& Hancock, 1988). The internal disulfide bridge enables ETPs to bind to the thiol group of cysteine residues of proteins or to act as a redox active molecules (Waring, Sjaarda \& Lin, 1995). ETP toxins have antibacterial, antiviral, immunosuppressive and antineoplastic activities (Jordan \& Cordiner, 1987, Gardiner et al., 2005). GTX is a virulence factor of the human pathogen $A$. fumigatus that affects $T$ cells and antigen presenting cells (Mullbacher \& Eichner, 1984, Yamada, Kataoka \& Nagai, 2000). The immunosuppressive characteristics of GTX involve effects on macrophages and mature lymphocytes (Waring, Eichner \& Mullbacher, 1988). Mullbacher and Eichner (1984) showed that GTX inhibits the phagocytotic activity of macrophages. Another study showed that treatment of macrophages with GTX resulted in DNA fragmentation and subsequently apoptosis of macrophages (Waring, Eichner, Mullbacher \& Sjaarda, 1988). GTX inhibits T cell activation by preventing antigen presentation and promoting apoptosis in monocytes. GTX also leads to apoptosis in some other cells such as hepatic stellate cells and HL-60 cell lines (Stanzani et al., 2005, Hur et al., 2008). Apoptosis may be related to interaction with mitochondrial proteins or inhibition of activation of transcription factor NFkB (Stanzani et al., 2005, Hur et al., 2008). NFKB is crucial for inflammatory immune responses and therefore inhibition of activation of this protein may be partly responsible for the immunosuppressive effects of GTX (Choi et al., 2007, Pahl et al., 1996, Gardiner et al., 2005). It has also been shown that increasing intracellular calcium levels are associated with necrosis of GTX treated thymocytes and this change may be due to interactions of GTX with redox sensitive calcium channels on the plasma membrane (Gardiner et al., 2005). 
There is evidence of morphological and cell adhesion changes in rat liver cell cultures immediately after addition of GTX (Jordan \& Pedersen, 1986). These cellular changes might be produced by interaction of GTX with membrane proteins or cytoskelatal microfilaments including actin or actin binding proteins (Jordan \& Pedersen, 1986). Orr et al. (2004) suggested that GTX has antifibrogenic and apoptosis effects on rat liver cells through a thiol redox dependent interaction.

\subsection{GTX structure}

GTX (Fig. 1) $\left(\mathrm{C}_{13} \mathrm{H}_{14} \mathrm{O}_{4} \mathrm{~N}_{2} \mathrm{~S}_{2}\right.$, molecular mass 326.4$)$ is the most studied ETP. It contains a disulfide-bridged piperazinedione ring (Fridrichsons \& Mathieson, 1967, Reeves, Murphy, Daly \& Kavanagh, 2004). The toxicity of GTX is dependent on its disulfide bond (Jordan \& Pedersen, 1986, Srinivasan et al., 2006).

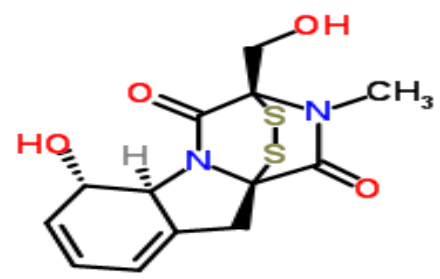

Figure 1: Structure of GTX

Structure of GTX from CSID: 5988, http://www.chemspider.com/ChemicalStructure.5988.html (accessed 05:08, Oct 27, 2012).

\subsection{Biosynthesis of GTX}

Biosynthetic ETPs are derived from at least one aromatic amino acid. GTX is derived from phenylalanine and serine as precursor amino acids (Gardiner et al., 2005). Secondary metabolites of fungi that have more than one amino acid are generally produced by nonribosomal peptide synthetases. The complete genome sequence of $A$. fumigatus showed that the non-ribosomal peptide synthetase enzymes that synthesise GTX usually have genes clustered in the genome (Gardiner et al., 2005). Several genes (gli genes) have been identified related to the biosynthesis of GTX (Balibar \& Walsh, 2006) including gliZ, a transcriptional regulator of GTX production that encodes the $\mathrm{Zn}(\mathrm{II})_{2} \mathrm{Cys}_{6}$ binuclear 
transcription factor. Substitution of the gliz gene with a marker gene caused no detectable GTX biosynthesis and failure to express the other gli cluster genes (Bok et al., 2006, Schrettl et al., 2010). Additionally mutation in the gliP gene resulted in failure to make GTX (Fox \& Howlett, 2008). These genes are activated when secondary metabolism commences in fungi (Rementeria et al., 2005). LeaA is a methyltransferase that possibly is involved in regulation of these genes (Stack, Neville \& Doyle, 2007). It has been shown that gli genes are repressed in the absence of GTX, indicating that GTX regulates its own biosynthesis (Cramer et al., 2006).

\subsection{Toxicity of GTX}

Understanding of the mechanism of action of ETPs and factors affecting their reactivity is important because it might provide insight into new approaches to control the toxic effects of ETPs (Jones \& Hancock, 1988). The toxicity characteristic of ETPs like GTX are because of the internal disulfide bridge that is suggested to act in two ways: (1) covalent modification by formation of mixed disulfides with proteins that contain susceptible thiol groups (Fig. 2) and/or (2) formation of reactive oxygen species (Fig. 3) through redox cycling (oxidative stress) (Munday, 1989, Waring et al., 1995). 


\subsubsection{Covalent modification}

GTX interacts with some proteins through the formation of disulfide bonds with thiol residues. Known target proteins include creatine kinase (Hurne, Chai \& Waring, 2000), alcohol dehydrogenase (Waring et al., 1995), and glutaredoxin (Srinivasan et al., 2006).

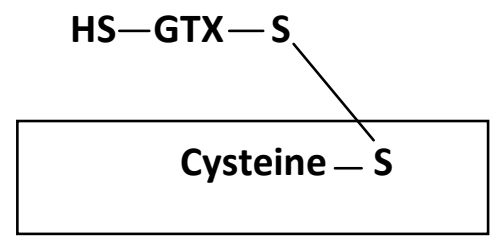

\section{Figure 2: Schematic for covalent modification of proteins by GTX}

The figure shows the proposed covalent modification of proteins by GTX. GTX interacts with proteins via covalent binding to the thiol group of cysteine. One sulfur of GTX is adducted to the cysteine forming a mixed disulfide. The second sulfur of GTX may be present as free thiol.

GTX is known to possess antibacterial, antiviral and antifungal properties that are thought to be dependent on the disulfide bond (Fukuyama, Nakatsuka \& Kishi, 1981). The toxicity of GTX for bacteria has been proposed to involve selective binding to thiol groups of proteins on the cytoplasmic membrane. A study by Jones and Hancock (1988) of the antibiotic activity of GTX showed that a Salmonella typhimurium mutant with a deficiency in synthesis of outer-membrane polysaccharide was sensitive to GTX, and they proposed that GTX binds to cytoplasmic membranes. GTX prevents viral RNA replication through the inhibition of reverse transcriptase in viruses (Miller, Milstrey \& Trown, 1968).

\subsubsection{Redox cycling}

Munday (1989) proposed that the toxicity of ETPs is dependent on redox cycling of the disulfide in the presence of oxygen and subsequent generation of reactive oxygen species such as superoxide or hydrogen peroxide $\left(\mathrm{H}_{2} \mathrm{O}_{2}\right)$ (Fig. 3) that can directly damage DNA and 
proteins and subsequently stimulate apoptosis. Superoxide $\left(\mathrm{O}_{2}{ }^{--}\right)$can give rise to hydrogen peroxide and hydroxyl radical (HO) which is thought to be the most toxic species.

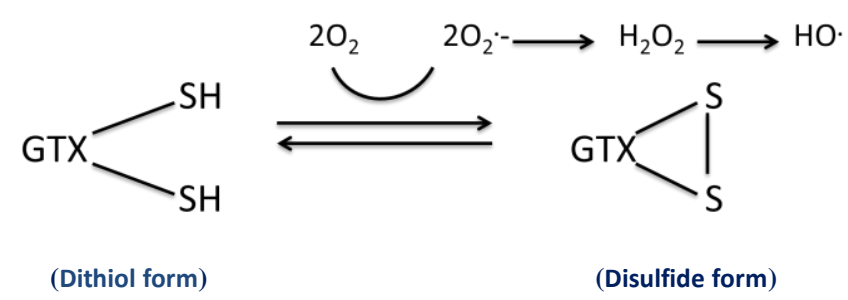

\section{Figure 3: Redox cycling of GTX}

Proposed scheme for recycling of GTX between the disulfide and dithiol is accompanied by production of superoxide, hydrogen peroxide and finally hydroxyl radical (adapted from Gardiner et al., 2005).

GTX exists almost exclusively in its reduced form in animal cells (Bernardo, Brasch, Chai \& Waring, 2003). Oxidation of intracellular GTX resulted in its rapid efflux from the cell and its entry to neighbouring cells (Bernardo et al., 2003). The disulfide bridge is vital for GTX toxicity, thus any alterations to it such as removing sulfur atoms prevents its activity (Gardiner et al., 2005). For example, treatment with reducing agents such as glutathione or dithiothreitol (DTT) resulted in loss of GTX activity (Grovel et al., 2006). In contrast to the proposed production of superoxide by redox cycling, Choi et al. (2007) demonstrated antioxidation effects of GTX that they proposed to be due to interactions with thioredoxin.

\subsection{Effects of GTX on model proteins}

\subsubsection{GTX reaction with CK}

Creatine kinase (CK) is an essential enzyme in cellular energy homeostasis and metabolism (Zhao, Yan, Liu \& Zhou, 2007). CK is expressed by a variety of cells and tissues. It catalyses the reversible reaction of the conversion of creatine and consumes ATP to produce phosphocreatine and ADP (Zhao et al., 2007, Wu et al., 2011). Therefore, CK has an important role in the formation and maintenance of phosphocreatine that can be converted to ATP in a short time in cells (Cantwell et al., 2001). The CK homodimer has eight SH groups 
in its structure and it is thought that two of these $\mathrm{SH}$ groups are more reactive than others (Hou \& Zhou, 1996). The activity of CK can be inhibited by thiol specific agents and reactive oxygen species (Hurne et al., 2000). Therefore, in this project CK from rabbit muscle was used as an experimental model protein for use of mass spectrometry to examine interaction of GTX with protein cysteine residues. CK from rabbit muscle functions as a non-covalently bound dimer that comprises two identical monomers containing 4 cysteines (Cys-74, Cys146, Cys-254 and Cys-283) in each of its $42 \mathrm{kDa}$ monomers (Hurne et al., 2000). The monomers show non-identical behaviour because the thiol groups on the two monomers react at different rates (Price \& Hunter, 1976). Cys-283 is the only reactive cysteine in CK that is close to the active site of the enzyme (Hurne et al., 2000). The crystal structure of CK shows that Cys-283 and Cys-74 are physically close (Fig. 4).

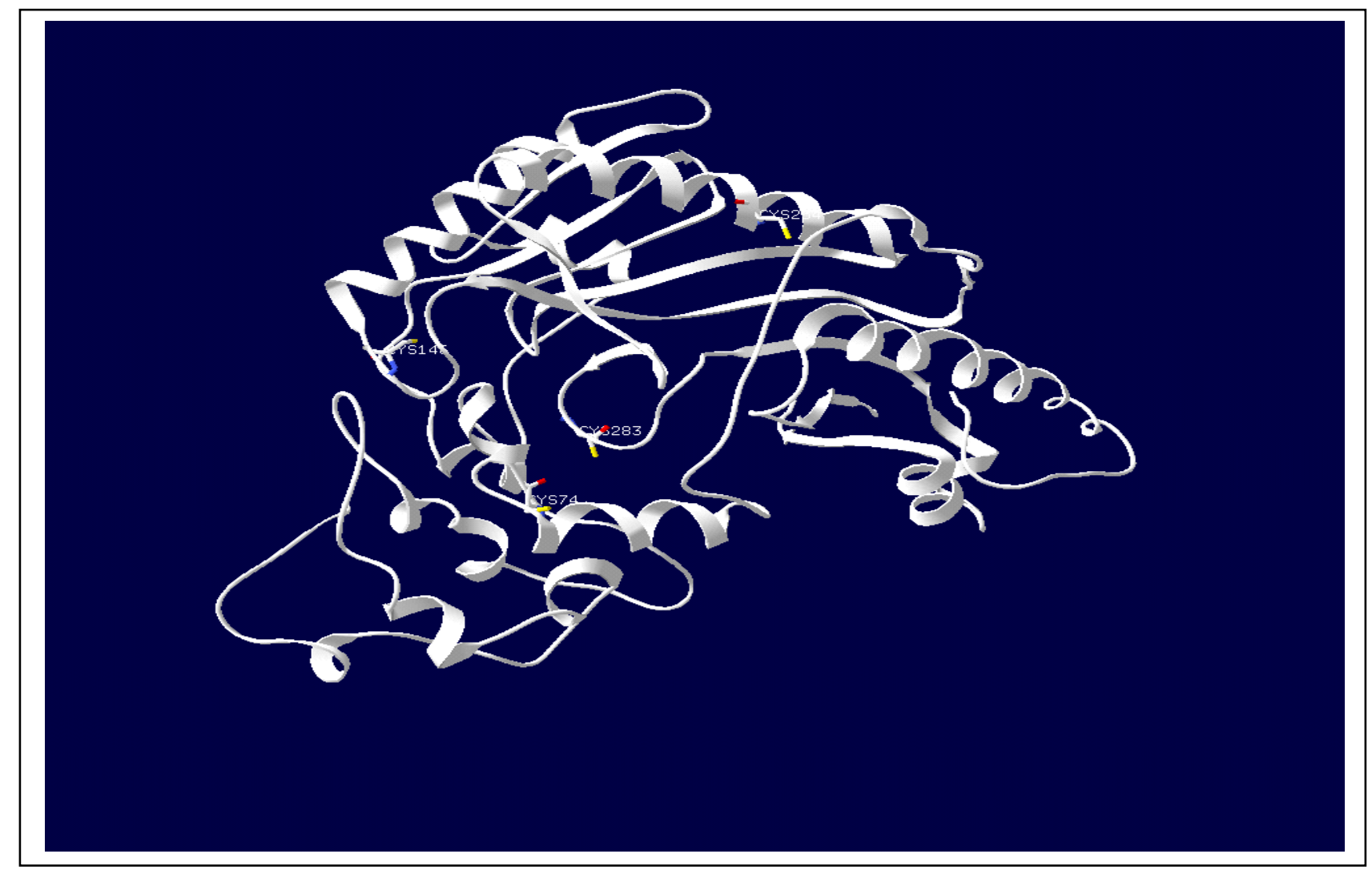

Figure 4: Structure of monomer of CK showing the positions of the cysteine residues

The image was produced using the spdbv.exe programme. The crystal structure of CK suggests that Cys-283 is near to the active site of the protein. Cys-74 is located between $\alpha$ helices 4 and 5, Cys-283 is located between $\beta$ sheets 7 and 8 , Cys-254 is in $\alpha$ helix 10, and Cys-146 is found between $\beta$ sheets 1 and 2 (Rao, Bujacz \& Wlodawer, 1998). 
Inactivation of CK by GTX is a complex process, potentially involving formation of a GTX-CK mixed disulfide that can also act as an intermediate to form intramolecular disulfides of CK. Hurne et al. (2000) proposed that inactivation of the enzyme occurs because of disulfide bond formation on two cysteines of CK. They postulated that an initial mixed disulfide can give rise to a fully oxidized CK internal disulfide between Cys-283 and 74. They proposed that GTX initially binds to a thiol of CK as an intermediate (A) (Fig. 5) and then reacts with an adjacent thiol to make a disulfide bond in CK (B). Tryptic digests of CK that had reacted with $\left[{ }^{35} \mathrm{~S}\right] \mathrm{GTX}$ contained radiolabeled peptides from reaction with Cys-254, to a lesser extent with Cys-283, and with Cys-146 in lower amounts. No reaction with Cys-74 was detected. Reducing agents such as DTT prevent inactivation of CK by GTX via direct reduction of GTX (Grovel et al., 2006), or possibly by reduction of the protein-GTX mixed disulfide.

(A)

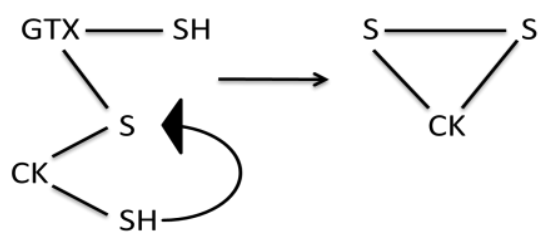

Figure 5: Proposed mechanism for CK inhibition by GTX

Proposed formation of a mixed disulfide between CK Cys-283 and GTX followed by formation of an internal disulfide between Cys-283 and 74. Adapted from Hurne et al. (2000). 


\subsubsection{GTX reaction with glutaredoxin}

Glutaredoxin (GRX1) is an antioxidant enzyme that exhibits specific catalysis of reduction of protein-glutathionyl mixed disulfides, and it has important roles in homeostasis of intracellular thiol status (Biswas, Chida \& Rahman, 2006). GTX is both a substrate and an inhibitor of GRX1. In the presence of GSH, GTX forms a mixed disulfide with GSH that may be a possible substrate for GRX1. In the absence of GSH, GTX inhibits GRX1 in a time and concentration dependent reaction that requires reduced GRX1 (dithiol), oxidized GTX and oxygen (Srinivasan et al., 2006). Analysis of the reaction product by mass spectrometry showed the production of an adduct consistent with a disulfide between one molecule of GRX1 and one molecule of GTX. This reaction product was $64 \mathrm{Da}$ less than the expected mass, indicating elimination of two sulfur atoms either in the mass spectrometer, or lost during the enzyme initiated reaction. Inhibition of GRX1 was reversed by denaturation of GRX1 with urea and then reduction with DTT, suggesting the breakage of the mixed disulfide bound between GRX1 and GTX. It is thought that the reaction initiates between GTX sulfurs and Cys-22 in the active site of GRX1 (Srinivasan et al., 2006).

\subsection{Mass spectrometry}

Mass spectrometry (MS) can be used to identify proteins and their post translational modifications and to measure changes in protein abundance between different samples (Ashcroft, 2003, Mann \& Kelleher, 2008). Mass spectrometry uses size-based separation of charged molecules. In MS, gas phase ions in a vacuum are separated based on their mass to charge $(\mathrm{m} / \mathrm{z})$ ratio. Two techniques are commonly used to produce protein or peptide ions in the gas phase for MS analysis: matrix assisted laser desorption ionization (MALDI) and electrospray ionization (ESI) (Ashcroft, 2003). ESI ionizes proteins or peptides out of solution and generates multiply charged ions for each protein or peptide (Aebersold \& Mann, 2003). In the MALDI method, a protein or peptide sample is mixed with a UV absorbing matrix and co-crystallised onto a MALDI target plate and then the sample is irradiated with a UV laser in the mass spectrometer to generate mainly singly charged ions in the gas phase. In time of flight (TOF) analysis the ion masses can be measured based on the time taken to reach the detector (Vanlaere et al., 2008). 
Two methods are used for protein identification using mass spectrometry (Fig. 6). Peptide mass fingerprinting (PMF) is carried out by digesting proteins (trypsin is often the enzyme of choice) and matching a list of experimental peptide masses obtained from MS with the masses present in a database (Siepen, Keevil, Knight \& Hubbard, 2007). Tandem mass spectrometry (MS/MS) includes isolation of generated peptide ions and fragmentation by energetic collision with gas molecules in the mass spectrometer to give sequence-based ions that can be interpreted either de novo or searched against sequence databases (Aebersold \& Mann, 2003).

Trypsin cleaves peptides after lysine or arginine residues except when these residues are subsequent to a proline residue (Siepen et al., 2007). Tryptic digestion is suitable for MALDI analysis because the generated peptides have positively charged C-terminal lysine or arginine amino acids that migrate as $[\mathrm{M}+1]$ ions in a mass spectrometer. Arginine containing peptides typically provide better signals in MALDI compared to lysine containing peptides (Siepen et al., 2007) because of ionization differences between these two amino acids (Ashcroft, 2003).

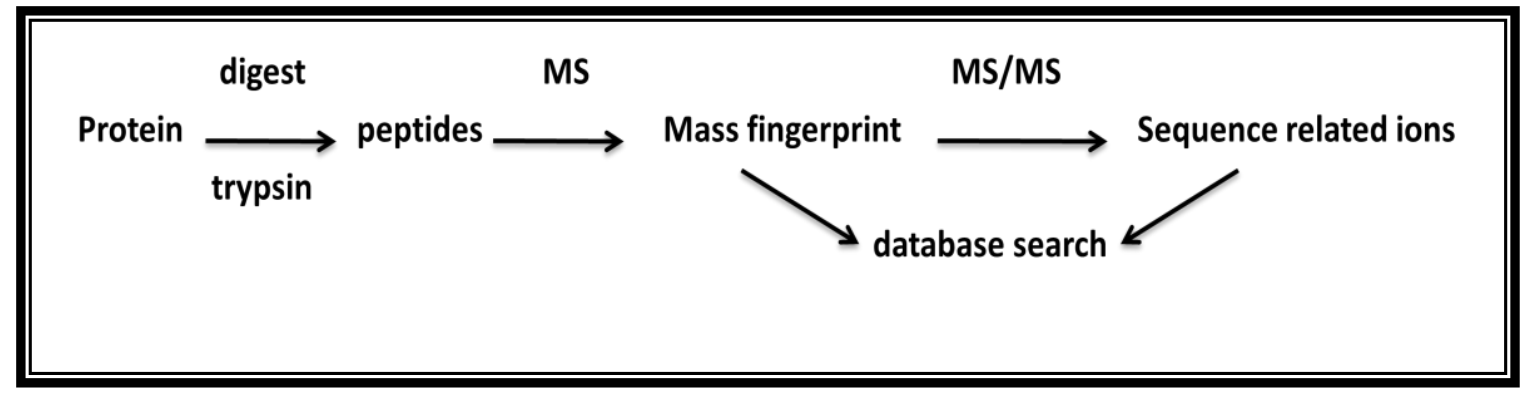

Figure 6: Schematic of a generic MS-based proteomics methodology

The figure shows a common approach for identification of proteins. Initially purified protein is digested (often with trypsin) to produce peptide fragments. The generated peptides are analyzed by MS to measure peptide masses, or by MS/MS, and resultant masses are searched against databases to identify proteins. 


\subsection{ICAT labeling}

ICAT (isotope-coded affinity tag) reagents are used in a gel free and MS based approach to identify and quantify proteins and oxidant sensitive thiols in proteins (Sethuraman et al., 2004). The ICAT reagent has a reactive iodoacetamide group that reacts with free cysteine thiols. In this method, two protein samples are labeled with either Heavy or Light ICAT reagents that have four components (Fig. 7): (1) a biotin affinity tag that helps selection of cysteine-containing peptides and simplifies the peptide mixture; (2) cleavable linker, the biotin tag is removed by cleaving the linker with acid and the ICAT-labeled peptides are purified using an avidin cartridge; (3) the isotope coded tag which identifies labeled proteins with Heavy reagent tag including 9 heavy isotopes or Light reagent tag containing no heavy isotope, this mass difference ( $9 \mathrm{Da}$ ) allows comparison of free thiols in samples by means of MS; (4) an iodoacetamide group that reacts with cysteine sulfhydryls (Fu et al., 2008).

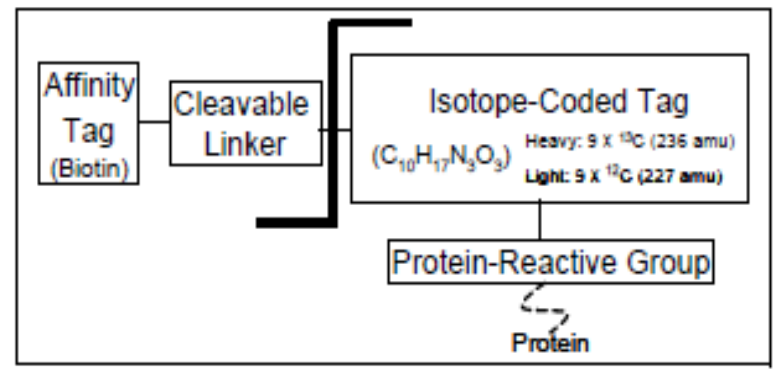

Figure 7: ICAT reagent

The figure shows the components of ICAT reagent. (Image source: Handbook for Methods of Applied Biosystems ICAT reagents).

After labeling of proteins with acid cleavable ICAT reagents, the labeled samples are combined and then digested with typsin and purified by chromatographic methods (cation exchange and avidin chromatography). The resolution of the separation improves by increasing either the number of fractions or the number of chromatographic separations (Hsu \& Chen, 2005). Subsequently peptides are analyzed by MS to identify and quantify free labeled cysteines, while modified cysteines lose ICAT labels, therefore this method 
measures the relative abundance of cysteinyl peptides by measuring the signal intensities in MS (Page, Griffiths, Bleackley \& MacGillivray, 2006, Hood, Veenstra \& Conrads, 2004) (Fig. 8). Tandem MS can then be used to identify the peptides and the parent proteins. ICAT has been used to examine the oxidation of $\mathrm{CK}$ by $\mathrm{H}_{2} \mathrm{O}_{2}$ (Sethuraman et al., 2004). Cys-283, but not Cys-146 was shown to be sensitive to oxidation by $\mathrm{H}_{2} \mathrm{O}_{2}$. This result was similar to the conclusion of Hurne et al. (2000) that GTX reacts with Cys-283 of CK.

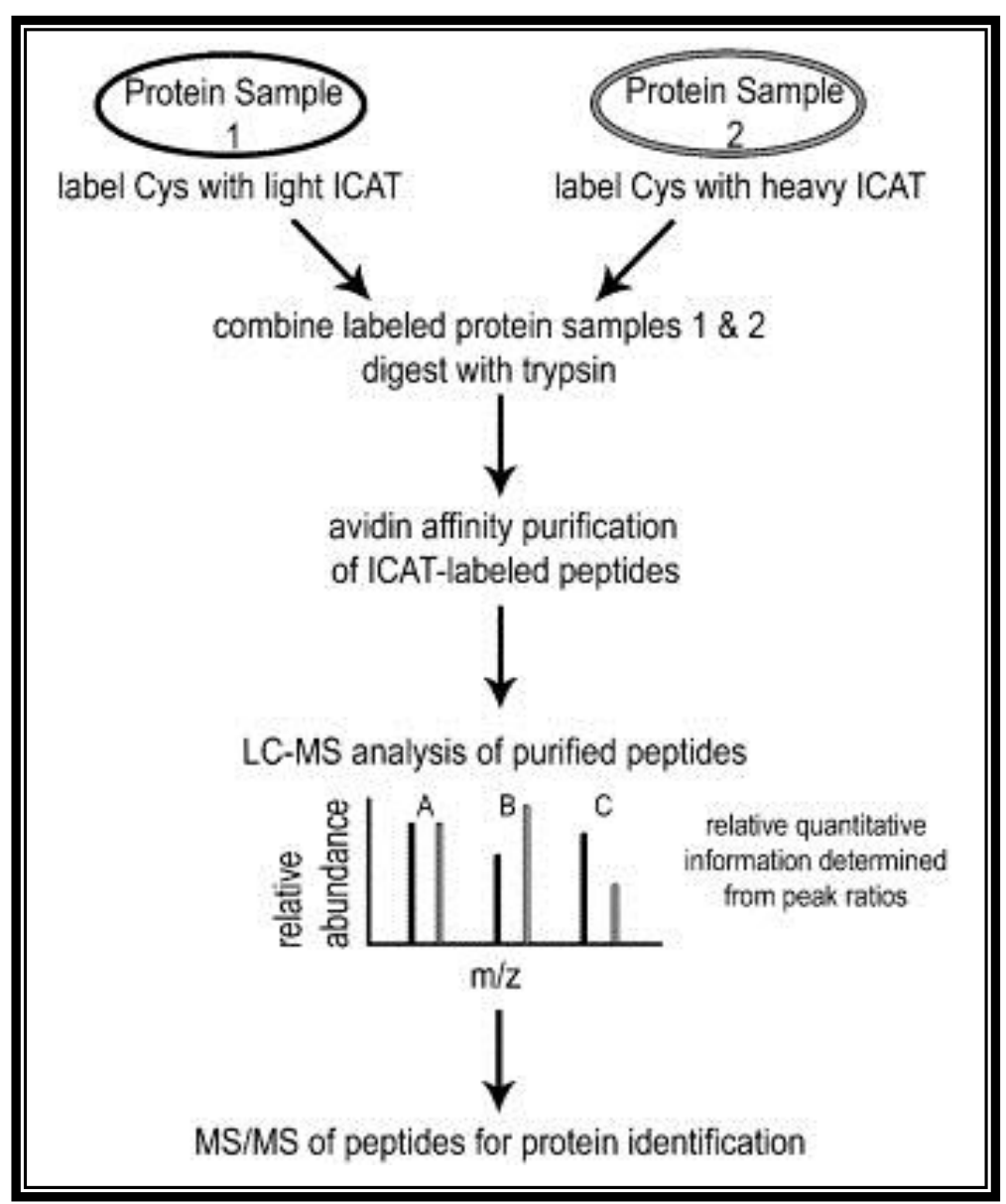

Figure 8: Schematic of a quantitative proteomic strategy using ICAT and MS (Page et al., 2006). License Number for permission: 3022281111339 


\subsection{Goals}

The goal of this project was to use MS and ICAT to examine the reaction of GTX with protein cysteines. The enzyme CK was selected as a model to examine the reaction of protein cysteines with GTX. CK was exposed to GTX, and MS was used to examine the reaction products. DTT was used as a reducing agent to test reversal of the modification. Based on previous results (Hurne et al., 2000) it was expected that Cys-283 would be reactive including formation of a mixed disulfide adduct with GTX, and that Cys-74 might also show change due to formation of a Cys-283-Cys-74 internal disulfide. $\mathrm{H}_{2} \mathrm{O}_{2}$ was used as an oxidant to identify oxidant-sensitive cysteines of CK. Preliminary experiments were carried out to establish conditions for use of ICAT to detect proteins modified by GTX in HL-60 cells. 


\section{Methods}

\subsection{Mass spectrometry}

Analysis of proteins and peptides was carried out using an AB SCIEX TOF/TOF ${ }^{\mathrm{TM}} 5800$ mass spectrometer (Applied Biosystems, Foster City, CA) controlled by TOF/TOF ${ }^{\mathrm{TM}}$ Explorer $^{\mathrm{TM}}$ software. MALDI spectra were obtained by mixing tryptic digests of proteins with CHCA ( $\alpha$ cyano-4-hydroxycinnamic acid) matrix, or proteins with sinapinic acid (3, 5-dimethoxy-4hydroxycinnamic acid) matrix, followed by crystallisation of a $\mu \mathrm{L}$ of the sample on a target MALDI plate. The samples were irradiated with UV light in the vacuum chamber of the MALDI mass spectrometer.

\subsection{Calibration of the MALDI-TOF}

The MALDI mass spectrometer was calibrated using standard peptides and proteins of known molecular weight. For each analysis spectra were obtained first for calibrant and then for samples on the same plate (external calibration). The spectra were analyzed using Data Explorer software version 5.1 (Applied Biosystems, Foster City, CA).

\subsection{MALDI-TOF MS}

\subsubsection{Preparation of CK for MALDI-TOF analysis using the dried droplet method}

CK from rabbit muscle was purchased from Roche Diagnostics GmbH (Penzberg, Germany; catalogue number 10127566001) and prepared in water as a $1 \mathrm{mg} / \mathrm{mL}$ solution (approximately $25 \mu \mathrm{M}$ according to the $43 \mathrm{kDa}$ mass of $\mathrm{CK}$ ). Native CK was reduced by addition of DTT (Merck, Darmstadt, Germany) $(3 \mathrm{mg} / \mathrm{mL}$ ) to a final concentration of $20 \mathrm{mM}$, followed by incubation at $50{ }^{\circ} \mathrm{C}$ for $30 \mathrm{~min}$. In some experiments, the product was then alkylated by addition of iodoacetamide (IAA) (GE Healthcare, Buckinghamshire, UK) (9.25 $\mathrm{mg} / \mathrm{mL}$ ) to a final concentration of $50 \mathrm{mM}$ and incubation at room temperature for $30 \mathrm{~min}$ in the dark. The samples of native CK, alkylated CK, and reduced-alkylated CK were prepared in sinapinic acid matrix by mixing $1 \mu \mathrm{L}$ of sample with $1,2,5$ or $10 \mu \mathrm{L}$ of sinapinic acid matrix solution. Aliquots $(1 \mu \mathrm{L})$ were then spotted onto a MALDI plate and left to dry allowing crystal formation before inserting the sample plate into the MALDI vacuum chamber. The 
sinapinic acid matrix solution was prepared by suspending $10 \mathrm{mg}$ of matrix in $1 \mathrm{~mL} A C N$ (acetonitrile) (minimum 99.5\%, Sigma Chemical Company, MO): 0.1 \%TFA (trifluoroacetic acid, Fluka Chemie GmbH, Switzerland) (1:1). This mixture was then centrifuged at full speed $(12,100 \times \mathrm{g})$ for $5 \mathrm{~min}$ in a MiniSpin (Eppendorf) centrifuge. The supernatant was transferred to a clean tube and the remaining sediment containing undissolved crystals was discarded.

Sinapinic acid matrix was used to analyze proteins because it generates less fragment ions than CHCA and therefore facilitates measurement of masses greater than $10 \mathrm{kDa}$. For calibration of protein masses, $1 \mu \mathrm{L}$ of the Cal 3 peptide mixture (Applied Biosystems) was suspended in $100 \mu \mathrm{L}$ of the sinapinic acid matrix and $1 \mu \mathrm{L}$ aliquots were then spotted onto the MALDI plate. The spectra were calibrated against Cal 3 containing thioredoxin $(11,674$ $\mathrm{m} / \mathrm{z})$, apomyoglobin (horse) $(16,952 \mathrm{~m} / \mathrm{z})$, and apomyoglobin $(33,904 \mathrm{~m} / \mathrm{z})$. Peak matching conditions for calibration of MALDI spectra were a signal to noise ratio greater than or equal to 10 , mass tolerance of $\pm 90 \mathrm{Da}$, and a minimum of 2 matched calibrants.

\subsubsection{MS spectra acquisition}

To obtain spectra, the MALDI mass spectrometer was used in the positive ion linear mode with detector voltage of $1.950 \mathrm{kV}$, laser pulse rate $400 \mathrm{~Hz}$, delay time $2430 \mathrm{nsec}$, and velocity $600 \mu \mathrm{m} / \mathrm{sec}$. The spectra were acquired over a mass range of 10,000 to $100,000 \mathrm{Da}$ using 1000 shots per spectrum with an approximate laser intensity range of 5500 to 6200 .

\subsubsection{Tryptic digests}

Samples of native CK, alkylated CK, and reduced-alkylated CK were digested with trypsin (Modified sequencing grade, Roche Diagnostics $\mathrm{GmbH}$, catalogue number 11418025001). A $1 \mu \mathrm{g}$ aliquot of trypsin was reconstituted in $20 \mu \mathrm{L}$ of $50 \mathrm{mM}$ ammonium bicarbonate. Fivefold diluted samples were prepared by adding $10 \mu \mathrm{L}$ of native CK, alkylated CK, and reducedalkylated CK to $40 \mu \mathrm{L}$ of ammonium bicarbonate. Ten microliters of these dilutions were mixed with $2 \mu \mathrm{L}$ of trypsin followed by incubation at $37{ }^{\circ} \mathrm{C}$ for at least $3 \mathrm{~h}$ or overnight. The tryptic digests were prepared in CHCA matrix (Sigma) by mixing $1 \mu \mathrm{L}$ of digests with $1,2,5$ or $10 \mu \mathrm{L}$ of CHCA matrix solution, followed by spotting $1 \mu \mathrm{L}$ aliquots onto the MALDI plate. The CHCA matrix was made by mixing $10 \mathrm{mg}$ of CHCA in $1 \mathrm{~mL} \mathrm{ACN:} 0.1 \%$ TFA (1:1). This was 
centrifuged at full speed in a MiniSpin centrifuge for $5 \mathrm{~min}$. The supernatant was removed and transferred to a clean tube and the remainder with undissolved crystals was discarded.

CHCA is a "hot" matrix that is appropriate for peptide detection (less than $4 \mathrm{kDa}$ ). To achieve accurate calibration of monoisotopic peptide masses from tryptic digests of CK, or modified $\mathrm{CK}$, Cal 2 standard (Sigma) was used as a calibrant. This was done by adding $1 \mu \mathrm{L}$ of Cal 2 to $100 \mu \mathrm{L}$ of CHCA matrix and then $1 \mu \mathrm{L}$ aliquots were spotted onto the MALDI plate. The acquired spectra were calibrated against the Cal 2 spectra containing a bradykinin fragment 1-7 (monoisotopic $\mathrm{m} / \mathrm{z}$ 757.3997), human angiotenisin II (monoisotopic $\mathrm{m} / \mathrm{z}$ 1046.5423), $\mathrm{P}_{14} \mathrm{R}$ (synthetic peptide) (monoisotopic $\mathrm{m} / \mathrm{z}$ 1533.8582), human ACTH fragment 18-39 (monoisotopic $\mathrm{m} / \mathrm{z}$ 2465.1989), and bovine insulin oxidized B chain (monoisotopic $\mathrm{m} / \mathrm{z}$ 3494.6513). Peak matching conditions for calibration of MALDI-MS were a signal to noise ratio greater than or equal to 200 , mass tolerance of $\pm 0.5 \mathrm{~m} / \mathrm{z}$, a minimum of 4 matched peaks, and maximum outlier error was 3 ppm.

\subsubsection{MS spectra acquisition}

To obtain spectra for spotted peptides, the MALDI-TOF mass spectrometer was used in positive ion reflector mode with CID off, final detector voltage $1.800 \mathrm{kV}$, laser pulse rate 400 $\mathrm{Hz}$, delay time $140 \mathrm{nsec}$, and velocity $600 \mu \mathrm{m} / \mathrm{sec}$. The spectra were acquired in a mass range of 700 to 5000 Da with 400 shots per spectrum. The laser was fired in a random and uniform pattern with an approximate intensity range of 2900 to 3500 .

\subsubsection{Reaction of CK with GTX}

In order to examine the effects of GTX on CK, GTX (from Gliocladium fimbriatum) was used (Sigma Chemical Company, MO, catalogue number G9893). CK was prepared in water as a $25 \mu \mathrm{M}$ solution and GTX was made as a $15 \mathrm{mM}$ solution by dissolving $5 \mathrm{mg}$ of GTX in $1 \mathrm{~mL}$ of DMSO (dimethyl sulfoxide). The reaction of the CK with GTX was carried out using CK (25 $\mu \mathrm{g})$ incubated with GTX $(10 \mu \mathrm{g})$ at $37{ }^{\circ} \mathrm{C}$ in a water bath overnight. The control was CK incubated with DMSO. 


\subsubsection{Reduction and alkylation}

In some experiments CK or modified CK was alkylated with IAA. An aliquot (1 $\mu \mathrm{L})$ of IAA $(9.25 \mathrm{mg} / \mathrm{mL})$ was added to $10 \mu \mathrm{L} \mathrm{CK}$ solution followed by incubation at room temperature for $30 \mathrm{~min}$ in the dark. To examine reduced $\mathrm{CK}, 10 \mu \mathrm{L}$ of DTT $(3 \mathrm{mg} / \mathrm{mL})$ was added to CK followed by incubation at $50{ }^{\circ} \mathrm{C}$ for $30 \mathrm{~min}$. GTX-treated CK, reduced GTX-treated CK and alkylated GTX-treated CK were prepared in sinapinic acid matrix by mixing $1 \mu \mathrm{L}$ of samples with $1,2,5$ or $10 \mu \mathrm{L}$ of sinapinic acid matrix solution. Then $1 \mu \mathrm{L}$ aliquots were placed on the MALDI plate and allowed to dry.

GTX-treated CK and alkylated GTX-treated CK were digested with trypsin (see Section 2.2.2). Tryptic digests were prepared in CHCA matrix by mixing $1 \mu \mathrm{L}$ of digests with 1, 2, 5 or $10 \mu \mathrm{L}$ of CHCA matrix solution and were then subjected to MALDI analysis.

\subsubsection{Treatment of $\mathrm{CK}$ with $\mathrm{H}_{2} \mathrm{O}_{2}$}

Hydrogen peroxide $\left(\mathrm{H}_{2} \mathrm{O}_{2}\right)$ 30\% (Perhydrol ${ }^{\circledR}$ ) was purchased from Merck (Darmstadt, Germany, catalogue number 107209) new for this project. CK (100 $\mu \mathrm{g})$ was incubated with $10 \mu \mathrm{L}$ of hydrogen peroxide at room temperature for $10 \mathrm{~min}$, with untreated CK as control. The reaction was stopped by addition of $0.1 \mu \mathrm{g}$ of bovine liver catalase (Sigma) prepared as a $1 \mathrm{mg} / \mathrm{mL}$ solution. In some experiments, the sample was alkylated by mixing $10 \mu \mathrm{L}$ of the reaction product with $1 \mu \mathrm{L}$ of IAA $(9.25 \mathrm{mg} / \mathrm{mL})$ and reacted at room temperature for $1 \mathrm{~h}$ in the dark.

\subsubsection{ICAT labeling of CK}

ICAT reagents were from Applied Biosystems (Cleavable ICAT $^{\circledR}$ Reagent Kit for protein labeling, Monoplex Version). CK was made up in $50 \mathrm{mM}$ Tris ( $\mathrm{pH} 8.3$ ) as a $25 \mu \mathrm{M}$ solution (1 $\mathrm{mg} / \mathrm{mL}$ ). A $15 \mathrm{mM} \mathrm{GTX}$ solution was made by dissolving $5 \mathrm{mg}$ of GTX in $1 \mathrm{~mL}$ of DMSO. CK $(25 \mu \mathrm{g})$ was exposed to GTX $(10 \mu \mathrm{g})$ or control conditions at $37{ }^{\circ} \mathrm{C}$ overnight, approximately $14 \mathrm{~h}$. The entire sample of the GTX-treated CK was transferred into a vial of Heavy ICAT reagent in ACN $(20 \mu \mathrm{L})$ and the control CK was transferred into a vial of Light ICAT reagent. 
These two vials were incubated at $37{ }^{\circ} \mathrm{C}$ for $2 \mathrm{~h}$ in a water bath in the dark. The ICAT-labeled protein samples were mixed to give a 1:1 ratio sample and then digested with $25 \mu \mathrm{g}$ of trypsin by incubating at $37{ }^{\circ} \mathrm{C}$ for $10-14 \mathrm{~h}$. The tryptic peptides were purified using a cation exchange cartridge (Part Number: 4326752) according to the Applied Biosystems Cleavable ICAT $^{\circledR}$ Reagent protocol to remove excess labeling reagents and trypsin. The ICAT-labeled peptides were collected from the cation exchange column by eluting the peptides with a cation exchange buffer (collecting a single fraction). The collected peptides were then further purified using an avidin affinity cartridge (Part Number: 4326746) for selective isolation of ICAT-labeled peptides. The unlabeled peptides were washed from the affinity cartridge with an ICAT affinity buffer wash and the ICAT-labeled peptides were then eluted with an affinity buffer. The eluted affinity-purified ICAT-labeled peptides were evaporated to dryness in a centrifugal vacuum concentrator then suspended in ICAT cleavage reagents. The cleaving reagent $A$ and the cleaving reagent $B$ were mixed in a 95:5 ratio then $90 \mu \mathrm{L}$ of this was added to the ICAT-labeled peptides followed by incubating at $37{ }^{\circ} \mathrm{C}$ for $2 \mathrm{~h}$. The sample was once again dried by evaporation and peptides were suspended in $20 \mu \mathrm{L}$ of $0.1 \%$ TFA. The unlabeled peptides were also dried and dissolved in $20 \mu \mathrm{L}$ of $0.1 \%$ TFA. The peptide samples were used either directly for MALDI analysis or after desalting and concentrating using Eppendorf PerfectPure ${ }^{\circledR}$ C-18 Tips.

\subsubsection{Purifying and concentration of peptide samples before MALDI analysis}

The samples of labeled and unlabeled peptides were cleaned up and desalted using $10 \mu \mathrm{L}$ Eppendorf PerfectPure ${ }^{\circledR}$ C-18 Tips. First, the tips were washed by aspirating $100 \%$ ACN solution through the tips and discarding the solvent at least three times. The tip was then washed by aspirating and discarding 50\% ACN/ $0.1 \%$ TFA in HPLC-grade water solution three times, followed by washing with $0.1 \%$ TFA. Next, the peptides were bound to the tip by aspirating and dispensing at least 15 times. The tip was washed by aspirating and discarding $0.1 \%$ TFA in HPLC-grade water four times. Finally, the peptides were eluted into $1.5 \mu \mathrm{L}$ of $70 \% \mathrm{ACN} / 0.1 \%$ TFA in HPLC-grade water by aspirating and expelling 15 times to maximize retrieval of the original peptides. This sample was dried in a centrifugal vacuum concentrator. For MALDI analysis, the dried peptides were dissolved in $20 \mu \mathrm{L}$ of $0.1 \%$ TFA 
and then were prepared in the CHCA matrix by mixing $1 \mu \mathrm{L}$ of peptides with $1,2,5$ or $10 \mu \mathrm{L}$ of the CHCA matrix.

\subsubsection{Matching tryptic peptides to the CK sequences}

CK was identified by means of peptide mass fingerprinting. CK was digested with trypsin to generate peptide fragments, and then tryptic peptide fragments were desalted using C-18 Zip Tips (see Section 2.2.6). The peptides were separated by HPLC (Tempo ${ }^{\text {TM }}$ LC MALDI). For HPLC analysis, the dried peptides were dissolved in $20 \mu \mathrm{L}$ of buffer $\mathrm{A}, 98 \% \mathrm{H}_{2} \mathrm{O} / 0.1 \%$ TFA/ 2\% ACN. This was centrifuged at full speed for $10 \mathrm{~min}$ and then transferred to an autosampler vial in the Tempo ${ }^{\mathrm{TM}}$ LC Spotter. The Tempo performs one gradient capillary HPLC separation and automatically spots the sample along with matrix onto a MALDI target plate for analysis. The obtained sequences were searched against the NCBI non-redundant database via Mascot algorithm version 2.3 (see the search result in Appendix D).

\subsubsection{MS/MS of CK peptides}

To acquire MS/MS (tandem mass spectrometry) spectra for tryptic peptides of CK, the MALDI was used in $1 \mathrm{kV}$ positive reflector mode, with CID and metastable suppressor on. The laser was fired in a random and uniform pattern with intensity of 4662 and a pulse rate of $1000 \mathrm{~Hz}$. Once five sub-spectra were collected the acquisition of spectra was stopped and the final spectra were collected after a total of 500 laser shots per spectrum.

\subsubsection{MS/MS spectra calibration}

The MS/MS spectra were calibrated against the known fragment ion masses from the monoisotopic human ACTH fragment 18-39 (2465.1989 Da), which is an isolated precursor ion. Peak matching parameters for calibration included a signal to noise ratio of 50 , mass tolerance of $200 \mathrm{ppm}$, a minimum of 15 matched peaks, final detector voltage of $1.950 \mathrm{kV}$, and maximum outlier error of $2 \mathrm{Da}$. 


\subsubsection{MS/MS monoisotopic precursor selection}

The criteria selected for the interpretation method for MS/MS included minimum mass of 800 and maximum mass of $3000 \mathrm{Da}, 20$ maximum precursors, and excluded precursors within 200 resolution. The exclusion list is shown in Appendix A.

\subsubsection{Matching of peptide sequences to the NCBI database}

Peptide mass fingerprints and acquired sequences from MS/MS were imported into Protein Pilot ${ }^{\mathrm{TM}}$ software and searched against the NCBI non- redundant protein sequence database using the Mascot algorithm. The search parameters included mammalian taxonomy, monoisotopic masses, a +1 peptide charge, one missed trypsin cleavage, variable modification by methionine oxidation, MS/MS fragment tolerance of $0.1 \mathrm{Da}$, and precursor tolerance of $0.05 \mathrm{Da}$.

\subsubsection{Mammalian cell culture}

\subsubsection{Culture conditions}

HL-60 human promyelocytic leukemic cells were obtained from Professor John H. Miller's group, School of Biological Sciences, Victoria University of Wellington and were cultured in DMEM/F12 (Dulbecco's Modified Eagle Medium Nutrient Mixture F-12 (Ham)) $\left(\mathrm{GIBCO}^{\circledR}\right.$, Grand Island, NY, USA) supplemented with 10\% FCS in the presence of 100 units $/ \mathrm{mL}$ penicillin and 100 units $/ \mathrm{mL}$ streptomycin. The cells were maintained in a humidified atmosphere at $37{ }^{\circ} \mathrm{C}$ in $5 \% \mathrm{CO}_{2}$ in air and were passaged when they reached about $80 \%$ confluency.

\subsubsection{GTX treatment}

GTX (from Gliocladium fimbriatum) stock solution $5 \mathrm{mg} / \mathrm{mL}$ in DMSO was stored at $-20{ }^{0} \mathrm{C}$. When cultured HL-60 cells reached approximately $80 \%$ confluency, the cells were seeded into flasks containing $9 \times 10^{6}$ cells, each with a total volume of $10 \mathrm{~mL}$. Some flasks were treated with 2, 10 or $50 \mu$ g of GTX. Control flasks included DMSO or untreated controls. 


\subsubsection{Cell viability using trypan blue exclusion}

To evaluate the cytotoxicity of GTX in HL-60 cultures the viability of cells was determined using a hemocytometer and a trypan blue exclusion test. To examine the viability of cells, 10 $\mu \mathrm{L}$ of HL-60 cells were stained with $10 \mu \mathrm{L}$ of $0.4 \%$ trypan blue dye and then $10 \mu \mathrm{L}$ of this mixture was added to the hemocytometer. Dead cells took up dye and were blue but live cells excluded dye.

\subsubsection{Monitoring HL-60 cell morphological change}

Morphological changes of HL-60 cells were examined at 0, 1, 2 and $24 \mathrm{~h}$ after GTX treatment using phase contrast microscopy and photographed with 10x and 20x objectives using a CC12 Soft Image System camera that was connected to an Olympus IX51 microscope, and Olympus Cell A Imaging software.

\subsubsection{Harvesting HL-60 cells}

Cells were centrifuged at $300 \mathrm{~g}$ for $5 \mathrm{~min}$. Supernatants were removed and discarded and cell pellets resuspended in $2 \mathrm{~mL}$ of ice-cold PBS that had been flushed with nitrogen to displace oxygen. Cells were centrifuged again, supernatants were removed, and the cells were resuspended in $1 \mathrm{~mL}$ of PBS and transferred into $1.5 \mathrm{~mL}$ microcentrifuge tubes. Cells were centrifuged at $300 \mathrm{~g}$ (SIGMA 1-14 Laboratory Table Top Microcentrifuge) for $5 \mathrm{~min}$, supernatants were removed and nitrogen was flushed gently into the tubes. Cell pellets were stored at $-80{ }^{\circ} \mathrm{C}$ until required.

\subsubsection{HL-60 cell lysis and protein extraction}

The cell pellets were resuspended in lysis buffer (30 mM Tris-Cl, $7 \mathrm{M}$ urea, $2 \mathrm{M}$ thiourea, 4\% (w/v) CHAPS) with an approximate volume of $60 \mu \mathrm{L}$ per $3.6 \times 10^{6}$ cells and vortexed for 30 $\min$ at $4{ }^{\circ} \mathrm{C}$. Samples were then centrifuged at $16,000 \mathrm{~g}$ for $15 \mathrm{~min}$ at $4{ }^{\circ} \mathrm{C}$. Supernatants were removed and stored at $-20{ }^{0} \mathrm{C}$ for later use. Twenty five micrograms of the obtained proteins from untreated (control) and $10 \mu \mathrm{g}$ GTX-treated samples were reconstituted with the labeling buffer and labeled using Light and Heavy ICAT respectively using the methods described in Section 2.2.5. Free cysteine residues were directly labeled in the control and GTX-treated samples without the reduction of disulfide bonds to maintain the thiol redox- 
states. The ICAT-labeled peptides were dried, cleaned up by Zip Tipping and then were analyzed by MALDI MS.

\subsubsection{Searching against databases}

MS/MS and parent ion data was exported into peaklist format and imported into PEAKS software for de novo sequencing (Zhang et al., 2011). The data was then refined, correcting the mass and charge states of the precursor ions. De novo sequencing was carried out on each spot with an error tolerance of $1 \mathrm{Da}$ for parent ions and 0.33 Da for fragment ions. Post-translational modifications used when analysing the peak values were: fixed for ICAT Light chain (M 227), ICAT Heavy chain (M 236), ICAT Heavy plus GTX (M 562), and GTX (M 326). The peaks and the de novo sequences were searched against the UniProtKB 2012-11 Homo Sapiens (Human) Proteome Reference Set (68,079 sequences). 


\section{Results}

All results presented in this project were repeated at least three times. The ABSCIEX 5800 specification for mass accuracy in the linear mode, which is used to measure proteins, is 500 $\mathrm{ppm}$ with external calibration, this corresponds to a mass accuracy of approximately $20 \mathrm{Da}$ for a $40 \mathrm{kDa}$ protein. The mass accuracy specification for measurement of peptide masses in reflector mode is $25 \mathrm{ppm}$ external.

\subsection{Mass spectrometry of CK}

Fig. 9 shows representative MALDI spectra of native CK. CK was analyzed in the positive ion linear mode. External calibration was carried out using thioredoxin $(M+1,11674)$, apomyoglobin $(M+1,16952)$ and apomyoglobin $(2 M+1,33903)$. The measured mass of $C K$ from 45 spectra gave a mean of $42,944 \pm 24$ for the expected $1^{+}(M+1)$ ion, although this mass was greater than the calibrant masses. The spectra also contained an approximately $21 \mathrm{kDa}$ mass corresponding to the $2^{+}(\mathrm{M}+2)$ ion, and an approximately $86 \mathrm{kDa}$ mass that may represent a CK dimer or two CK molecules sharing a proton $(2 \mathrm{M}+1)$. The protein size was also calculated from the average mass of the $M+2$ ions resulting in 43,012 as the average mass. The UniProtKB (www.uniprot.org) search result for rabbit CK (Entry P00563) gives a predicted average mass 43,112 Da for the full length sequence, or 42,981 if the $\mathrm{N}$-terminal methionine is removed. The measured $\mathrm{m} / \mathrm{z} 42,944 \pm 24$ therefore suggests the presence of the $\mathrm{N}$-terminally processed protein assuming the accuracy of the calibration. The nomenclature for peptides used in this thesis, however, assumes the protein contains the Nterminal methionine, for example the peptide ECVGLQK (residues 253-259) contains Cys254. In subsequent experiments CK and its reaction products were analyzed in the same batch.

Fig. 10 shows the MALDI spectrum of a tryptic digest of CK. Arrows indicate ions consistent with the predicted masses of the four cys-containing peptides. Appendix B lists the predicted masses of all tryptic peptides of CK including peptides resulting from one missed cleavage or oxidation of methionine. Table 1 summarizes the predicted masses of the cyscontaining peptides, including allowance for up to two missed tryptic cleavages, and shows that all four peptides were detected in the MALDI spectra. Abundant ions at 794.43 , 
1130.55 and 2870.37 (Fig. 10) correspond to peptides containing Cys-254, 146 and 283 respectively. Fig. 11 shows the Cys-254 ion. A minor peak at 4372.92 corresponds to the predicted $\mathrm{m} / \mathrm{z}$ of the peptide containing Cys-74 in residues $46-86$ but the signal to noise ratio was low and larger ions such as this generally give weak spectra in CHCA matrix. An ion at $\mathrm{m} / \mathrm{z} 950.54$ is consistent with the presence of the peptide R.FCVGLLQK resulting from one missed cleavage of the Cys-254 tryptic peptide. 

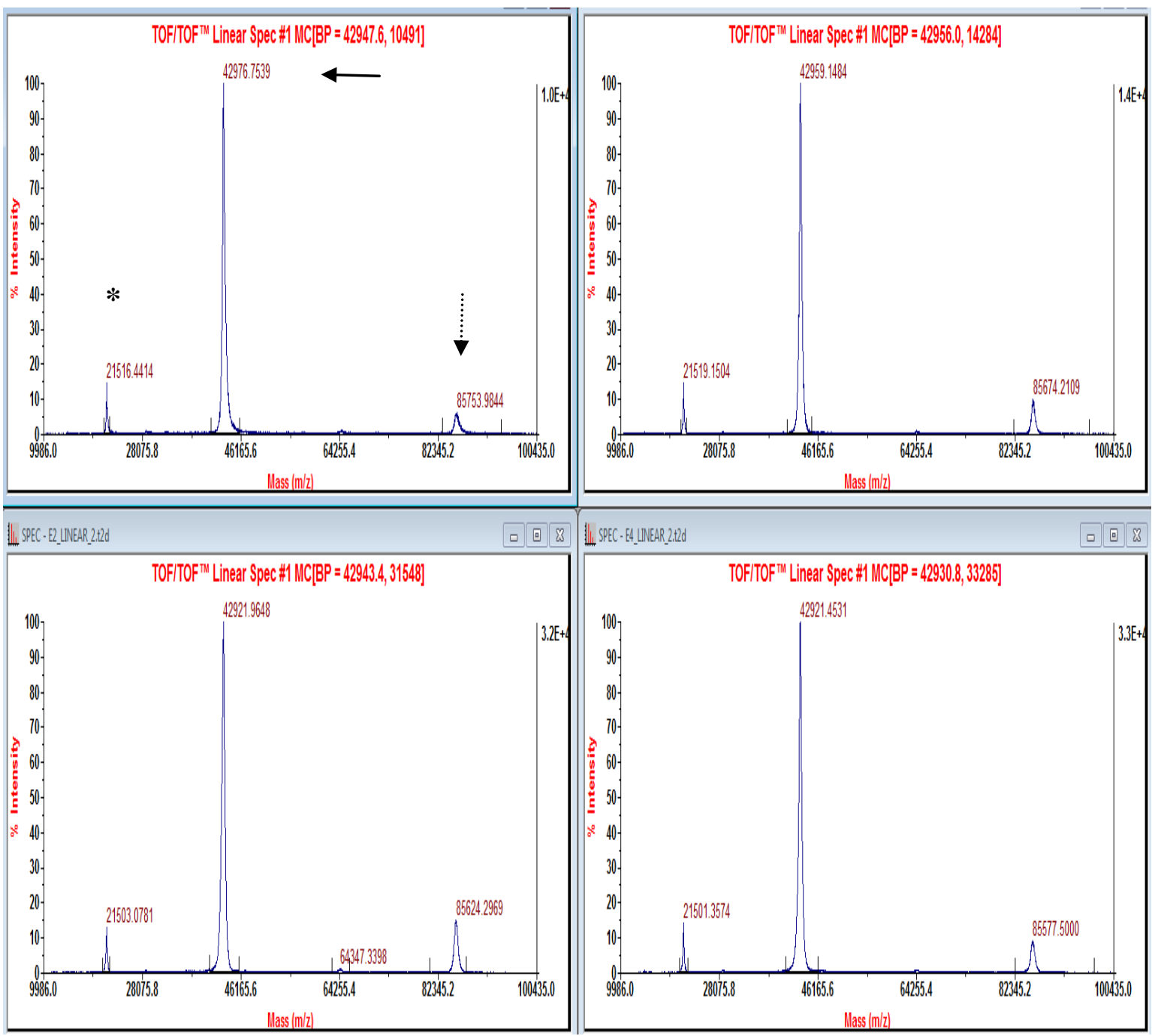

Figure 9: MALDI-TOF mass spectrometry of CK

The MALDI spectra of CK in sinapinic acid matrix show the approximately $43 \mathrm{kDa}$ mass of CK (arrow). The dotted arrow indicates a mass that could be a $2 \mathrm{M}+1$ or a dimer of CK. The asterisk indicates the probable $2^{+}(\mathrm{M}+2)$ ion of $\mathrm{CK}$. 


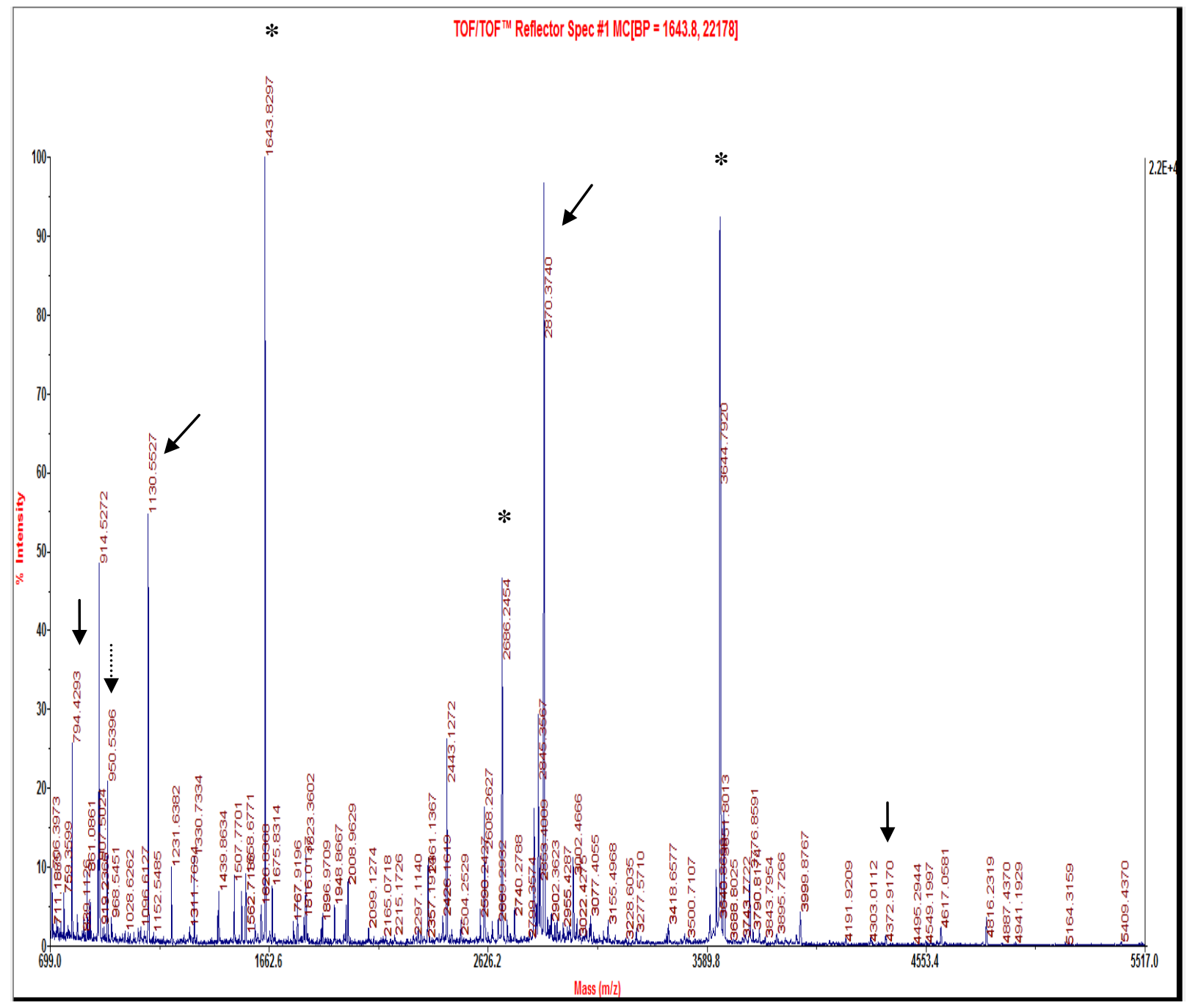

Figure 10: MALDI-TOF of peptide mass fingerprint of CK

This mass spectrum was acquired from CK after digestion with trypsin and preparation in CHCA matrix. Arrows indicate ions consistent with the cys-containing peptides with zero missed cleavage and the dotted arrow is consistent with the Cys-254 peptide with one missed cleavage. Asterisks indicate ions that correspond to other predicted tryptic peptides of CK whose masses are listed in Appendix B. 


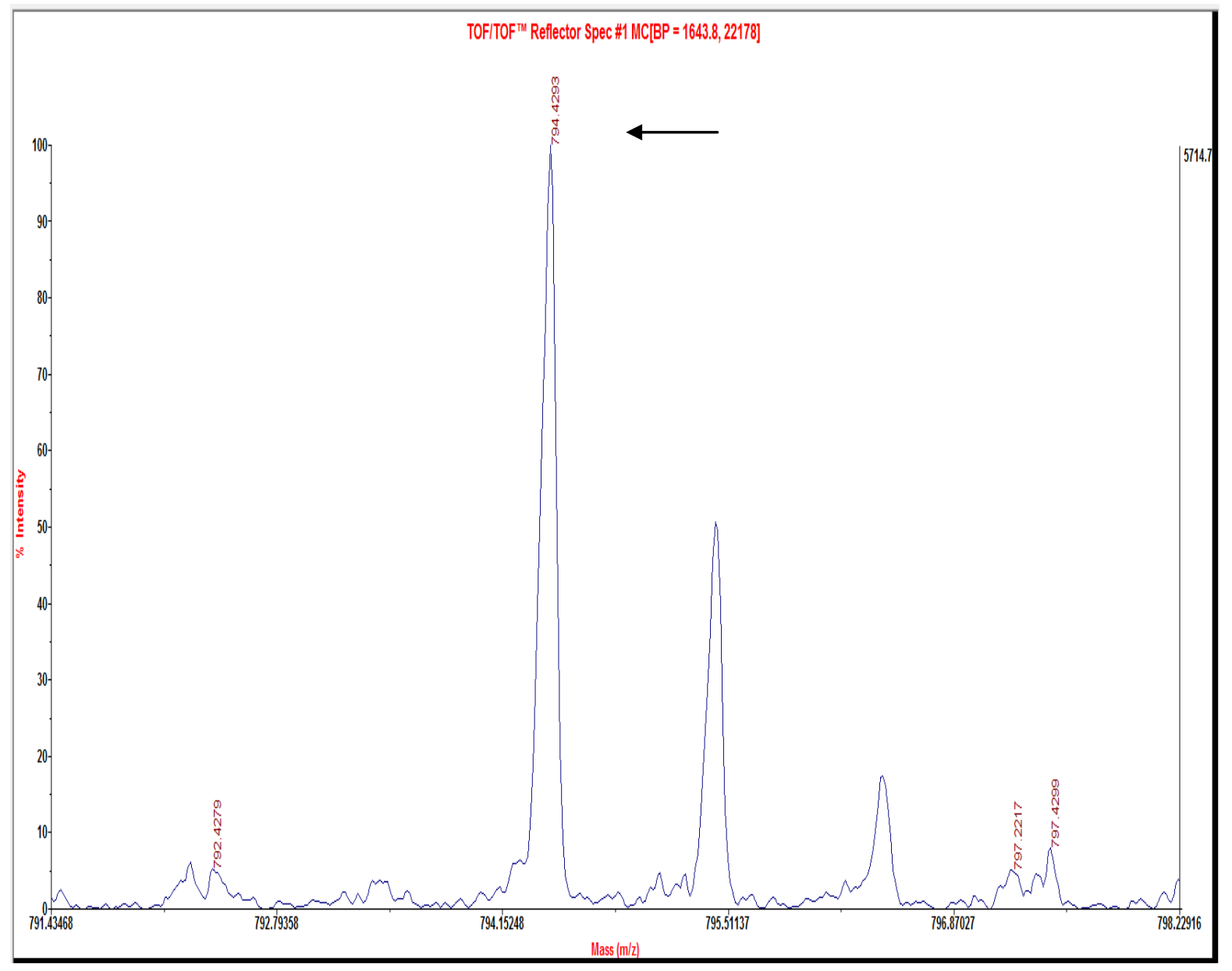

Figure 11: MALDI-TOF ion corresponding to the predicted FCVGLQK peptide

The arrow indicates the ion that corresponds to the predicted $\mathrm{m} / \mathrm{z}$ of the Cys-254 containing peptide. The spectrum shows resolution of the isotopic peaks. 


\begin{tabular}{|c|c|c|c|c|c|}
\hline $\begin{array}{l}\text { Cysteine } \\
\text { residue } \\
\text { (peptide) }\end{array}$ & $\begin{array}{l}\text { Missed } \\
\text { Trypsin } \\
\text { cleavages }\end{array}$ & $\begin{array}{l}\text { Predicted } \\
\mathrm{m} / \mathrm{z}\end{array}$ & Sequence & CK & $\begin{array}{l}\text { Alkylated } \\
\text { CK }\end{array}$ \\
\hline Cys-74 & 0 & 4373.02 & $\begin{array}{l}\text { ETPSGFTLDDVIQTGVDNPG } \\
\text { HPFIMTVGCVAGDEESYTVFK }\end{array}$ & $4373 ?$ & - \\
\hline & 1 & 4616.15 & $\begin{array}{l}\text { DK.ETPSGFTLDDVIQTGVDN } \\
\text { PGHPFIMTVGCVAGDEESYTVFK }\end{array}$ & - & - \\
\hline \multirow[t]{3}{*}{ Cys-146 } & 0 & 1130.54 & GYTLPPHCSR & $1130 \checkmark$ & $1187 \checkmark$ \\
\hline & 1 & 1458.75 & SIK.GYTLPPHCSR & - & - \\
\hline & 1 & 1472.71 & GYTLPPHCSR.GER & - & - \\
\hline \multirow[t]{3}{*}{ Cys-283 } & 0 & 2870.39 & AGHPFMWNEHLGYVLTCPSNLGTGLR & $2870 \checkmark$ & $2927 \checkmark$ \\
\hline & 1 & 2998.48 & K.AGHPFMWNEHLGYVLTCPSNLGTGLR & - & $3055 \checkmark$ \\
\hline & 1 & 3447.72 & AGHPFMWNEHLGYVLTCPSNLGTGLR.GGVHVK & - & - \\
\hline \multirow[t]{3}{*}{ Cys-254 } & 0 & 794.42 & FCVGLQK & $794 \checkmark$ & $851 \checkmark$ \\
\hline & 1 & 950.52 & R.FCVGLQK & $950 \checkmark$ & - \\
\hline & 1 & 1553.84 & FCVGLQK.IEEIFK & - & - \\
\hline
\end{tabular}

Table 1: Masses of cys-containing tryptic peptides of CK and alkylated CK, with 0 or 1 missed cleavage. Ticked masses represent peptides which were observed in the MALDI spectra. The expected mass accuracy using external calibration from peptide standards on the same MALDI plate is 25 ppm or 0.025 per 1000 Da peptide. 


\subsection{Modification of CK}

In subsequent experiments the masses of $\mathrm{CK}$ and its tryptic peptides were measured after reaction of the protein with GTX, and with iodoacetamide or ICAT reagents that alkylate cysteine residues. Table 2 summarizes the expected mass increments, and Table 3 summarizes the predicted masses of any resulting cys-containing peptides in the tryptic digests. The predicted addition for GTX is calculated to be the same as the molecular weight of oxidized GTX if GTX disulfide reacts with an accessible cysteine thiol (Fig. 2).

\begin{tabular}{||l|l||}
\hline Reactant & Expected mass addition \\
\hline IAA & 57 \\
\hline GTX & 326.4 \\
\hline Light ICAT & 907.5 \\
\hline Heavy ICAT & 916.5 \\
\hline Cleaved Light ICAT & 227.13 \\
\hline Cleaved Heavy ICAT & 236.16 \\
\hline \hline
\end{tabular}

Table 2: Expected mass additions for reaction of cysteine residues with IAA, GTX, or Light and Heavy ICAT reagents. ICAT masses are shown before or after cleavage of the biotin tag.

\begin{tabular}{||l|l|l|l|l|l|l|l|l||}
\hline \hline \multicolumn{1}{||l}{$\begin{array}{l}\text { Cys-containing tryptic } \\
\text { peptides }\end{array}$} & \multicolumn{6}{l||}{ Predicted mass $\left(\mathbf{M + H ^ { + } )}\right.$} \\
\hline Mass (m/z) & Peptide & IAA & GTX & $\begin{array}{l}\text { GTX + } \\
\text { Heavy ICAT }\end{array}$ & Light ICAT & Heavy ICAT & $\begin{array}{l}\text { Cleaved } \\
\text { Light ICAT }\end{array}$ & $\begin{array}{l}\text { Cleaved } \\
\text { Heavy ICAT }\end{array}$ \\
\hline 794.4 & $253-259$ & 851.4 & 1120.8 & 1356.96 & 1701.9 & 1710.9 & 1021.53 & 1030.56 \\
\hline 1130.5 & $139-148$ & 1187.6 & 1456.9 & 1693.06 & 2037.9 & 2047 & 1357.63 & 1366.66 \\
\hline 2870.4 & $267-292$ & 2927.4 & 3196.8 & 3432.96 & 3777.8 & 3786.9 & 3097.53 & 3106.56 \\
\hline 4373 & $46-86$ & 4430 & 4699.4 & 4935.56 & 5280.5 & 5289.5 & 4600.13 & 4609.16 \\
\hline \hline
\end{tabular}

Table 3: Predicted masses of cys-containing peptides after modification of CK with IAA, GTX, or Light and Heavy ICAT (before or after cleavage of the biotin tag). 


\subsection{Alkylation of CK}

Reaction of CK with iodoacetamide is expected to alkylate accessible cysteine residues, resulting in a mass addition of 57 for each alkylated cysteine. The size of alkylated CK was $43,020 \pm 18$ Da (Fig. 12) which indicated modification of approximately one cysteine per CK molecule. Analysis of the tryptic peptides from alkylated CK (Fig. 13) indicated the presence of unmodified and alkylated peptides (Table 1). The tryptic digest of alkylated CK contained ions at $\mathrm{m} / \mathrm{z} 851,1187$, and 2927 corresponding to mass additions of 57 to the Cys-254, 146, and 283 peptides. An ion at $\mathrm{m} / \mathrm{z} 1130$ corresponding to unmodified Cys-254 was also present indicating partial reaction of this cysteine. An ion at $\mathrm{m} / \mathrm{z} 3055$ is consistent with the Cys-283 peptide with one missed cleavage and a 57 Da adduct $(2998+57)$. The presence of multiple alkylated peptides in the tryptic digest was not consistent with the smaller mass addition to the protein (Fig. 12), although one explanation is that some alkylation of peptides continued during the tryptic digestion. 


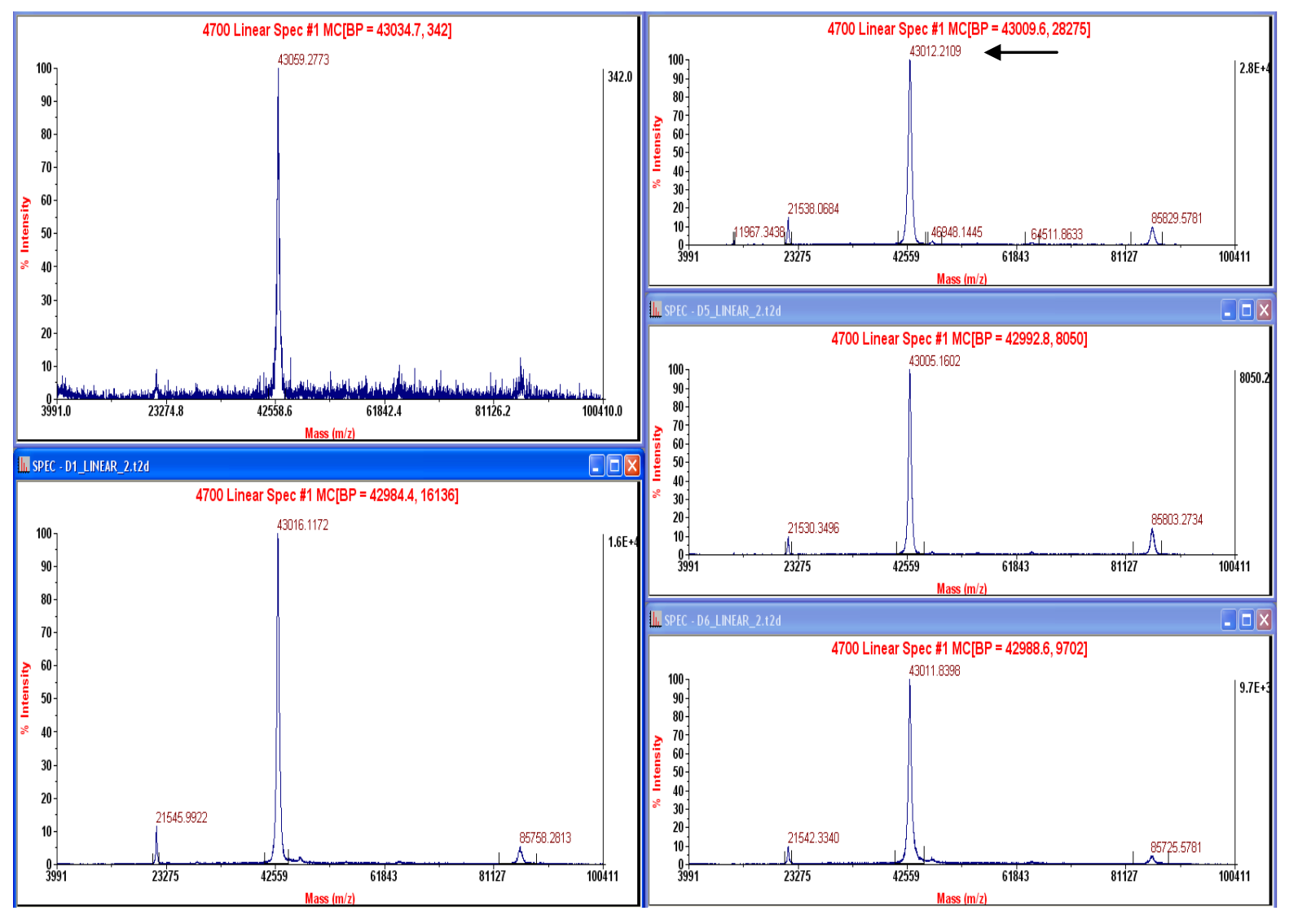

Figure 12: MALDI-TOF MS of IAA treated CK

Figure shows the spectra of CK alkylated with IAA. Sample was prepared in sinapinic acid as the matrix. The acquired spectra were calibrated using Cal 3 standard. The mean mass was $43,020 \pm 18$. 


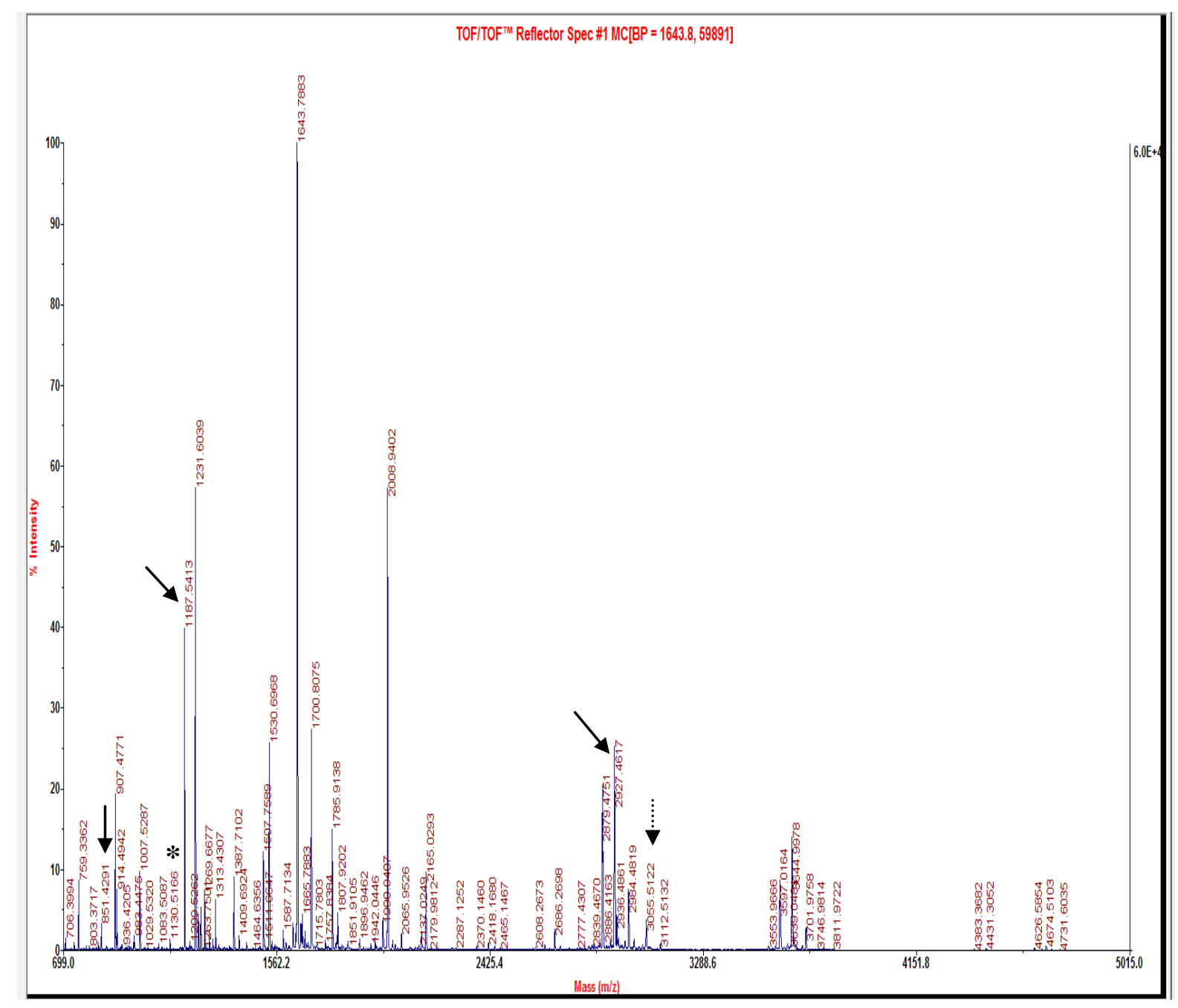

Figure 13: MALDI-TOF MS of a tryptic digest of CK alkylated with IAA

The solid arrows indicate cys-containing peptides with a 57 Da addition. Dotted arrow indicates Cys-283 with one missed cleavage that has a $57 \mathrm{Da}$ addition, and the asterisk indicates a mass consistent with the unmodified Cys-146 containing peptide. 


\subsection{Reduction and alkylation of CK}

To further examine the accessibility of CK cysteines to alkylation, CK was first treated with DTT and then reacted with IAA. DTT reduces disulfide bonds and therefore facilitates the reaction of IAA with cysteine residues. Fig. 14 shows the MALDI spectra of the protein product. The result of 10 experimental measurements gave a mean of $43,178 \pm 26$ Da that is consistent with alkylation of three to four cysteines of CK (an addition of about $197 \mathrm{Da}$ ). The mass fingerprint of the tryptic digest of this sample is shown in Fig. 15. The spectrum contains ions at $\mathrm{m} / \mathrm{z}$ 851, 1187, and 2927 corresponding to the Cys-254, 146, and 283 peptides each with a mass addition of 57 . The spectrum also contains ions at $\mathrm{m} / \mathrm{z} 3055$ and 4673 which are consistent with Cys-283 and 74 with one missed cleavage that have a $57 \mathrm{Da}$ addition $(2998+57=3055),(4616+57=4673)$. The ion at $\mathrm{m} / \mathrm{z} 1130$ corresponds to an unreacted Cys-146 peptide.

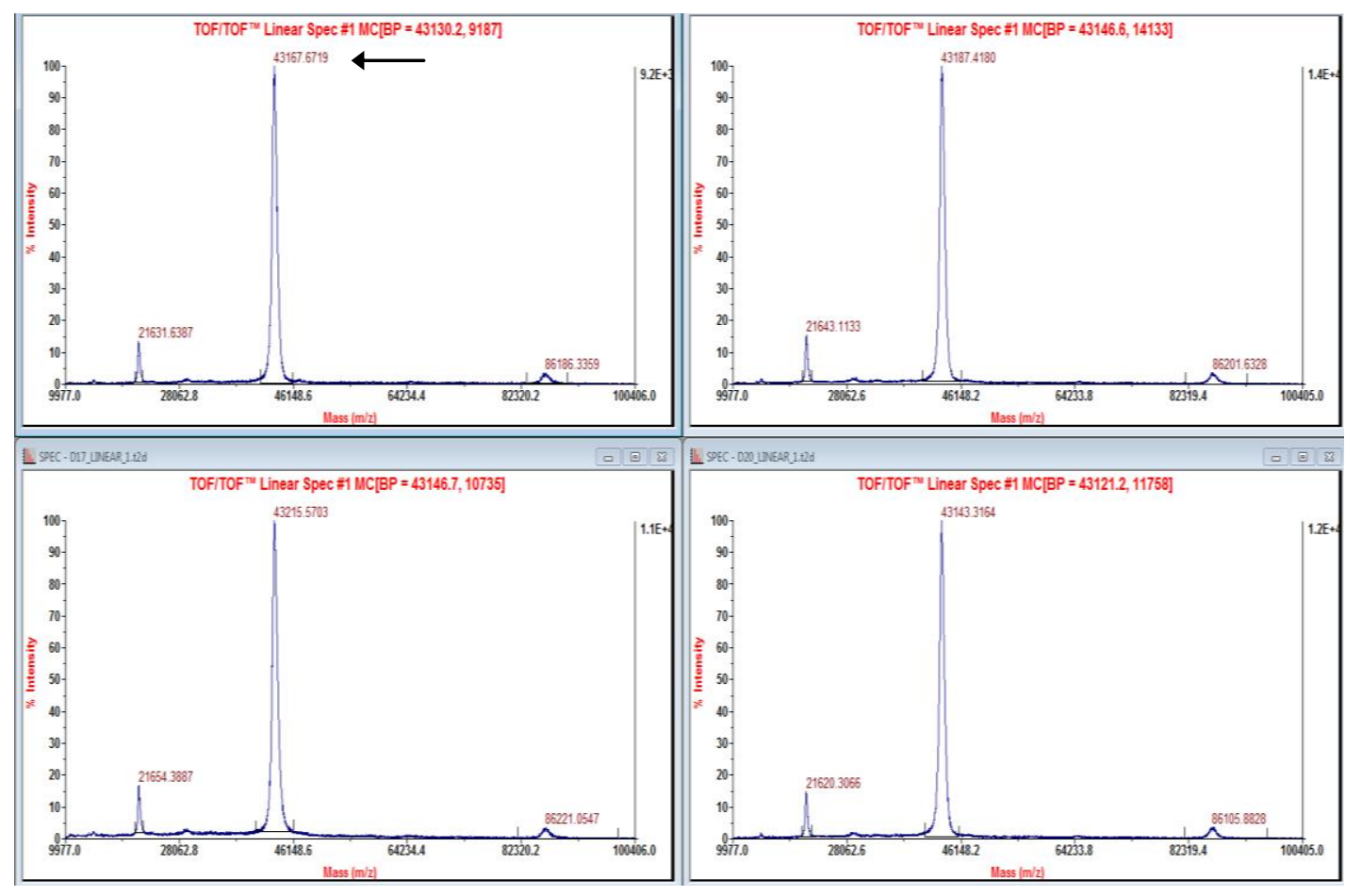

Figure 14: MALDI-TOF MS of reduced-alkylated CK

The reaction products of reduced and alkylated CK in sinapinic acid matrix (arrowhead) show a mean of $43,178 \pm 26 \mathrm{~m} / \mathrm{z}$. 


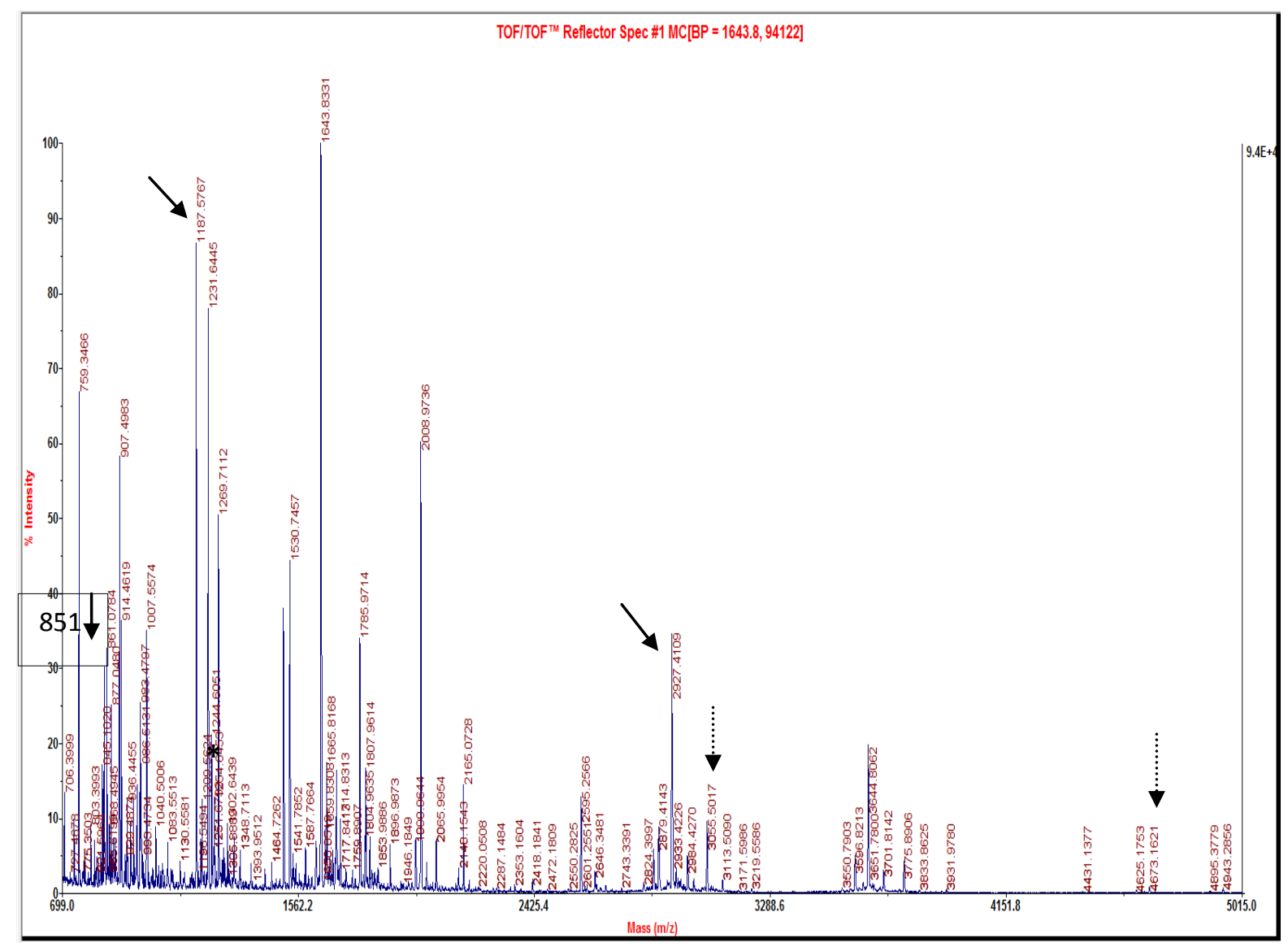

Figure 15: MALDI-TOF MS of tryptic digest of reduced and alkylated CK

Mass spectrum of reduced-alkylated CK digested with trypsin. Solid arrows indicate the cyscontaining peptides that have an addition of $57 \mathrm{Da}$. The dotted arrows indicate the cyspeptides with one missed cleavage that have a $57 \mathrm{Da}$ addition and the asterisk indicates an ion consistent with unmodified Cys-146 containing peptide. Detail of the $\mathrm{m} / \mathrm{z} 851.4$ ion is shown in Fig. 16. 


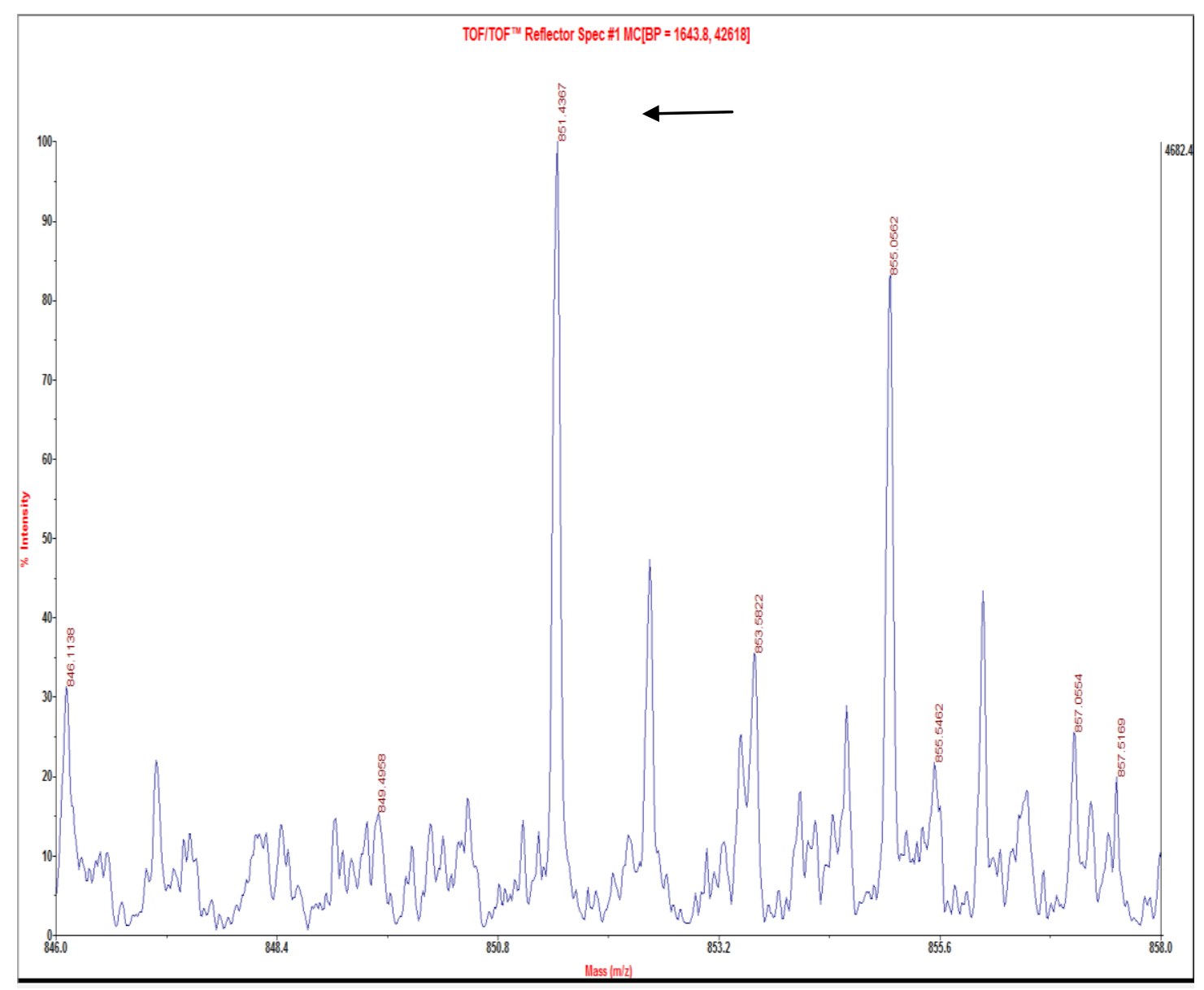

Figure 16: MALDI-TOF MS of tryptic digest of reduced-alkylated CK

Region of the $\mathrm{m} / \mathrm{z} 851.4$ ion corresponding to a Cys-254 peptide with a $57 \mathrm{Da}$ addition.

34 


\subsection{Reaction of CK with GTX}

To examine the effects of GTX on CK, CK was reacted with GTX and analyzed by MALDI MS. To determine if the reaction of GTX with CK was time dependent, CK was subjected to reaction with GTX for 2,14 , and $24 \mathrm{~h}$ at $37{ }^{\circ} \mathrm{C}$. The reaction products are shown in Figs. 17, 18 and 19. Fig. 17 illustrates the reaction products of CK treated with GTX for $2 \mathrm{~h}$. The obtained masses with a mean of $42,843 \pm 30$ indicated that CK had not reacted with GTX in 2 h. Fig. 18 shows the reaction products of CK treated with GTX for $14 \mathrm{~h}$. The spectra show the mean mass of $43,268 \pm 44$ which indicates that CK has reacted with GTX. The spectrum for the tryptic digest of this sample (Fig. 20) shows a minor ion at $\mathrm{m} / \mathrm{z} 1120$ which is consistent with Cys-254 with a GTX adduct and also contains an ion at $\mathrm{m} / \mathrm{z} 1162.5$ which is consistent with oxidized Cys-146 $\left(\mathrm{SO}_{2}\right)$. An ion corresponding to a GTX adduct of the Cys-283 peptide (expected adduct mass 3196.8) was not detected. Fig. 19 shows the reaction products of CK and GTX after $24 \mathrm{~h}$. The detected masses have a mean of $43,400 \pm 97$ indicating that CK has a product which is more than the mass of one GTX but less than the mass of two GTX molecules. Possible explanations include a GTX adduct plus oxidation of some cysteines at $24 \mathrm{~h}$. 


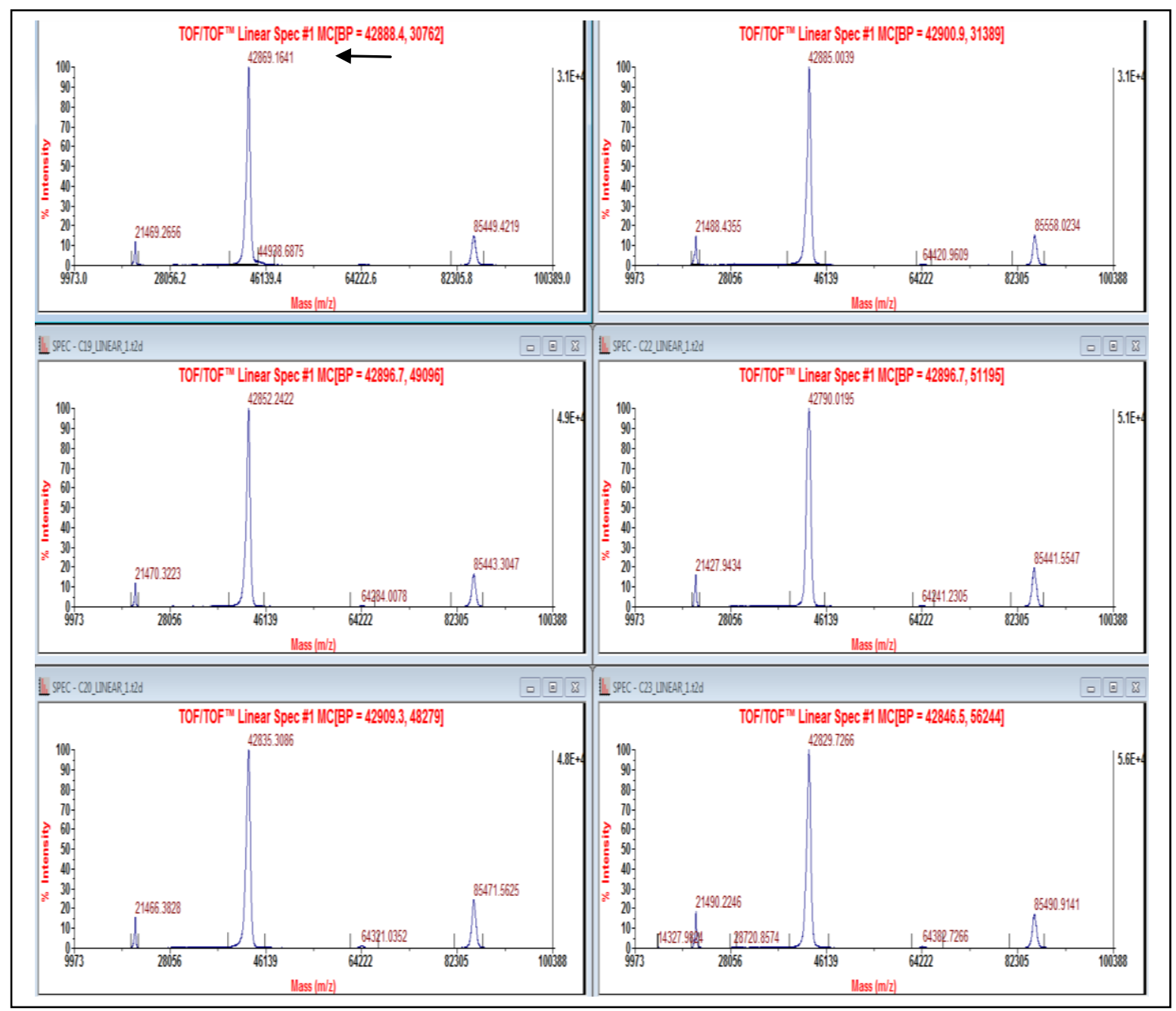

Figure 17: MALDI-TOF mass spectrometry of GTX-treated CK

The spectra show the reaction products of CK reacted with GTX for $2 \mathrm{~h}$ that was prepared in sinapinic acid matrix. The acquired spectra show a mean of $42,843 \pm 30$. 

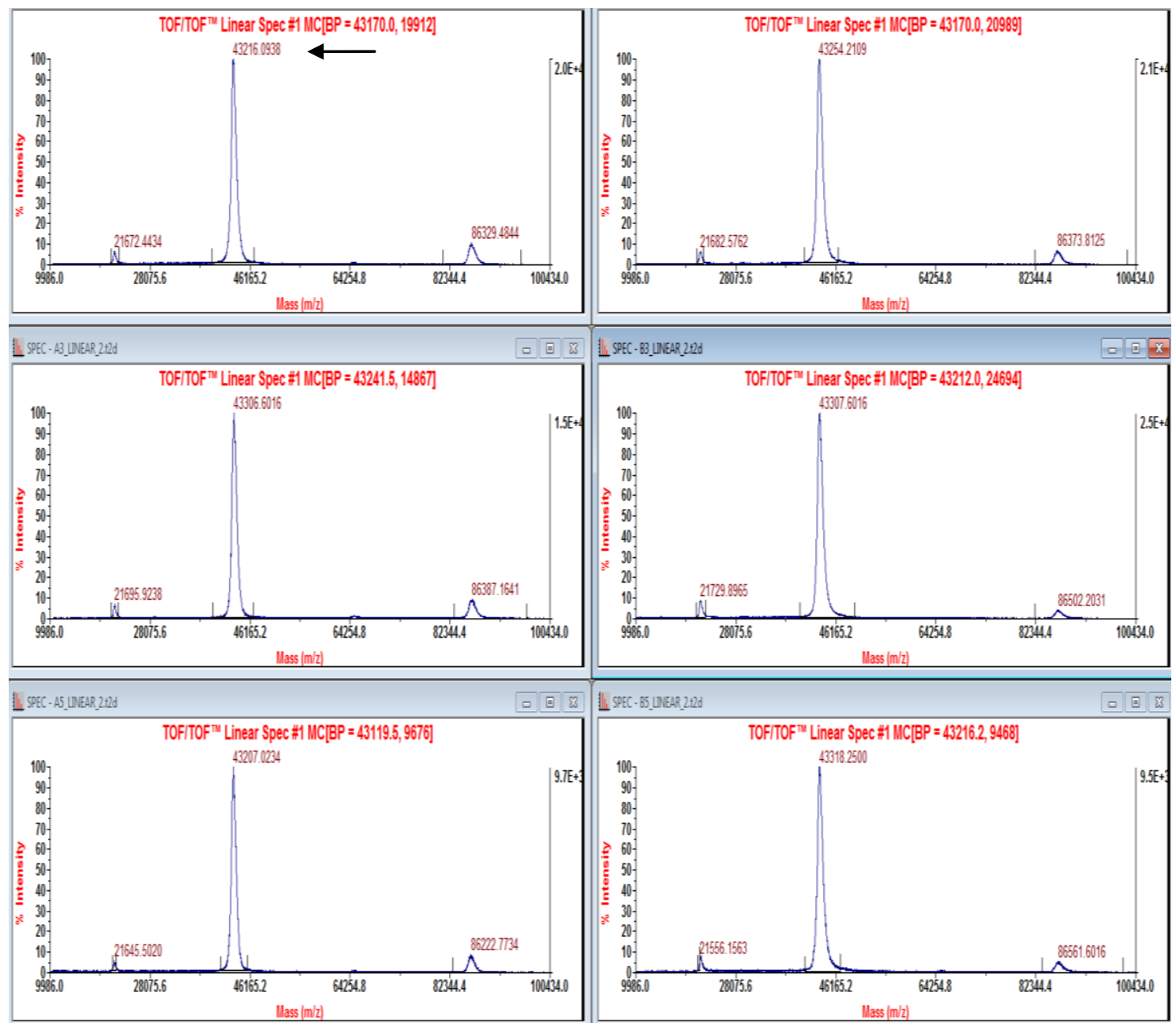

Figure 18: MALDI-TOF mass spectrometry of GTX-treated CK

The spectra show the reaction products of CK reacted with GTX for $14 \mathrm{~h}$. The obtained masses show a mean of $43,268 \pm 44$. 

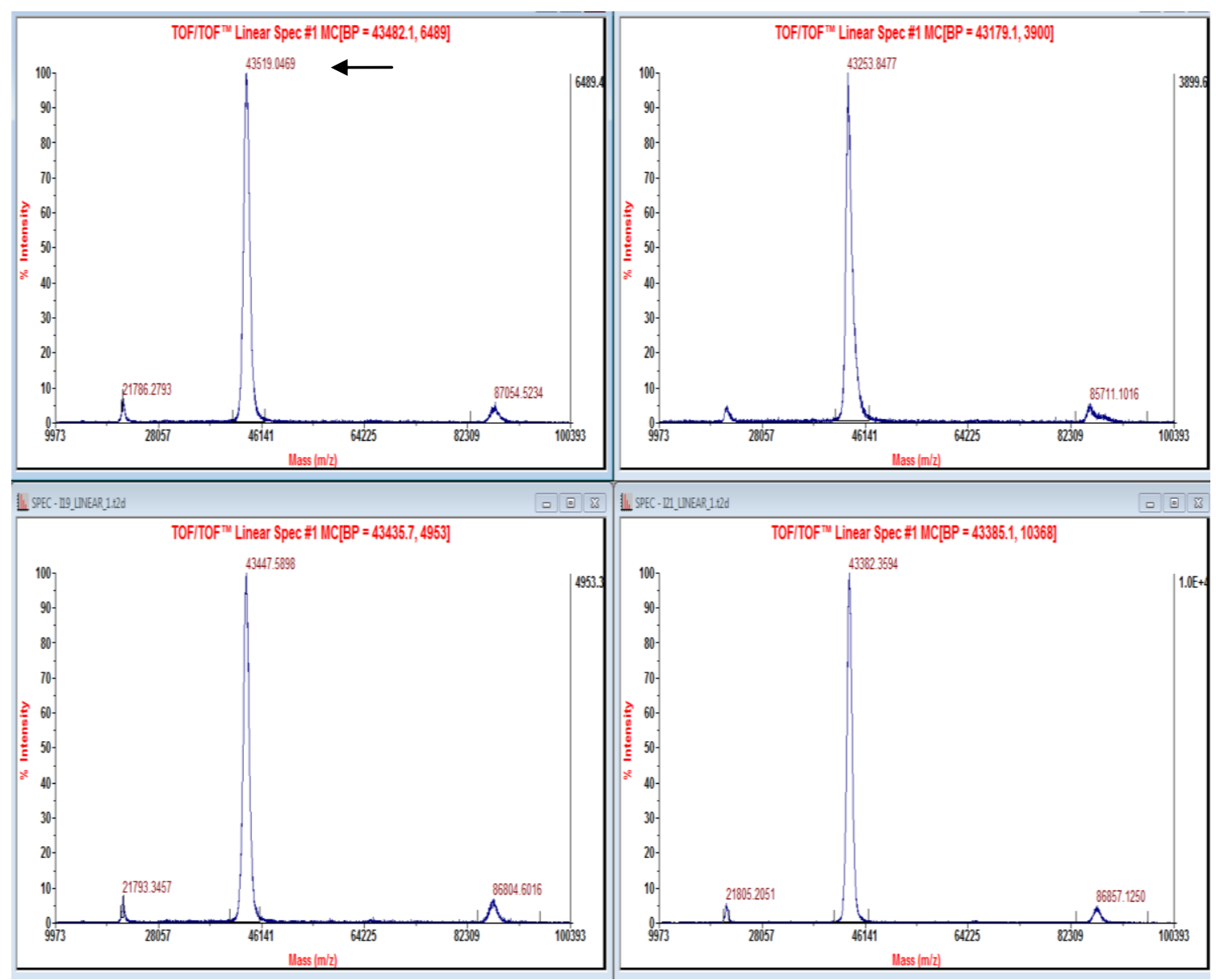

Figure 19: MALDI-TOF mass spectrometry of GTX-treated CK

These spectra show the reaction products of CK that was reacted with GTX for $24 \mathrm{~h}$ and then prepared in sinapinic acid matrix. The obtained masses show a mean of $43,400 \pm 97$. 


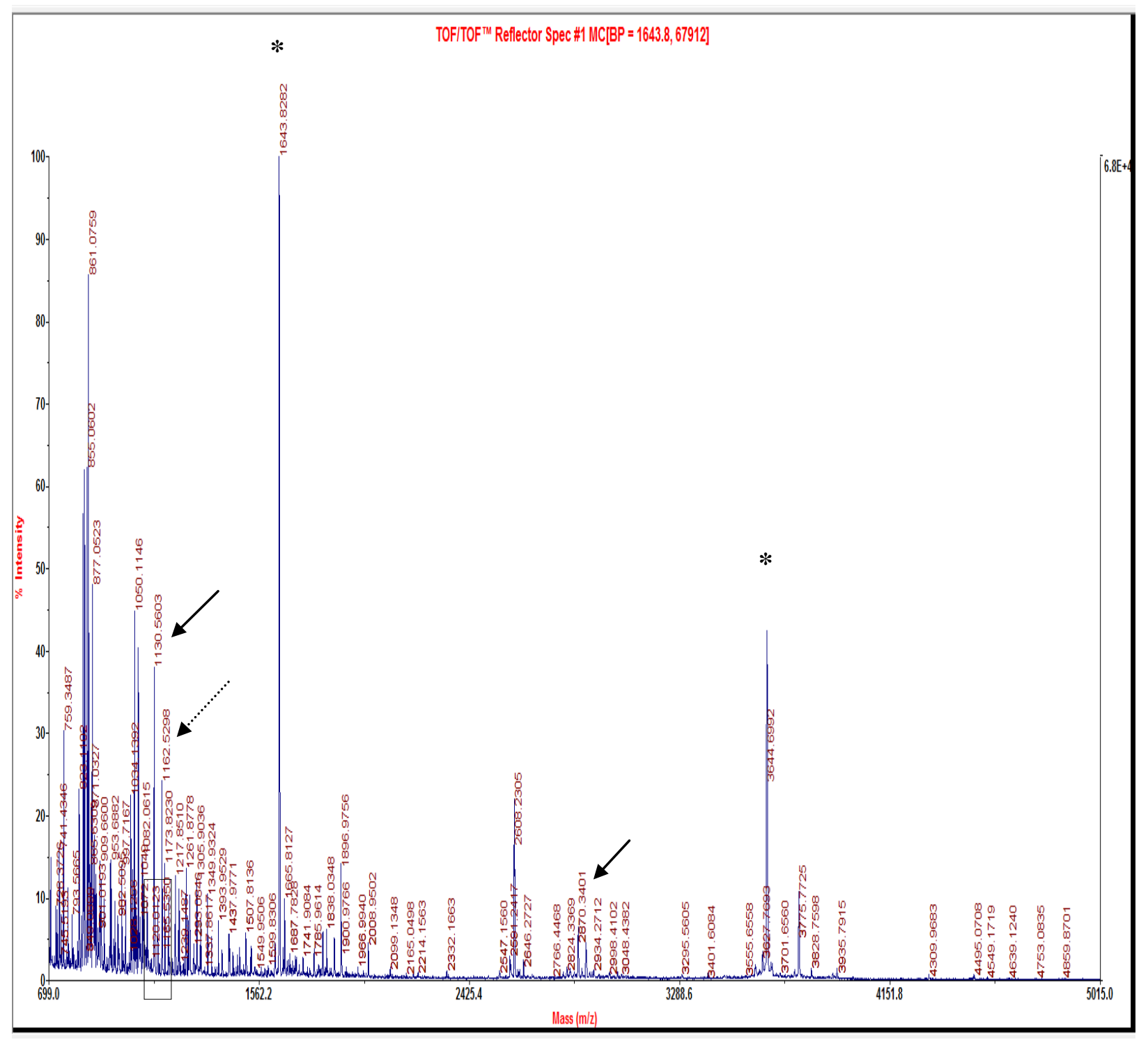

Figure 20: MALDI-TOF MS of tryptic digest of GTX-treated CK

The spectrum above shows CK reacted with GTX for $14 \mathrm{~h}$, then digested with trypsin and prepared in CHCA matrix. Arrows indicate the cys-containing peptides. A minor ion at $\mathrm{m} / \mathrm{z}$ 1120 is consistent with the Cys-254 that has a $326 \mathrm{Da}$ adduct. The detail of this spectrum in the mass range of 794 to $1124 \mathrm{Da}$ is shown in Fig. 21. The asterisks indicate non-cys containing peptides which are characteristic of a tryptic digest of CK. The dotted arrow shows an ion at $\mathrm{m} / \mathrm{z} 1162.5$, which is consistent with oxidized Cys-146 $\left(\mathrm{SO}_{2}\right)$. 


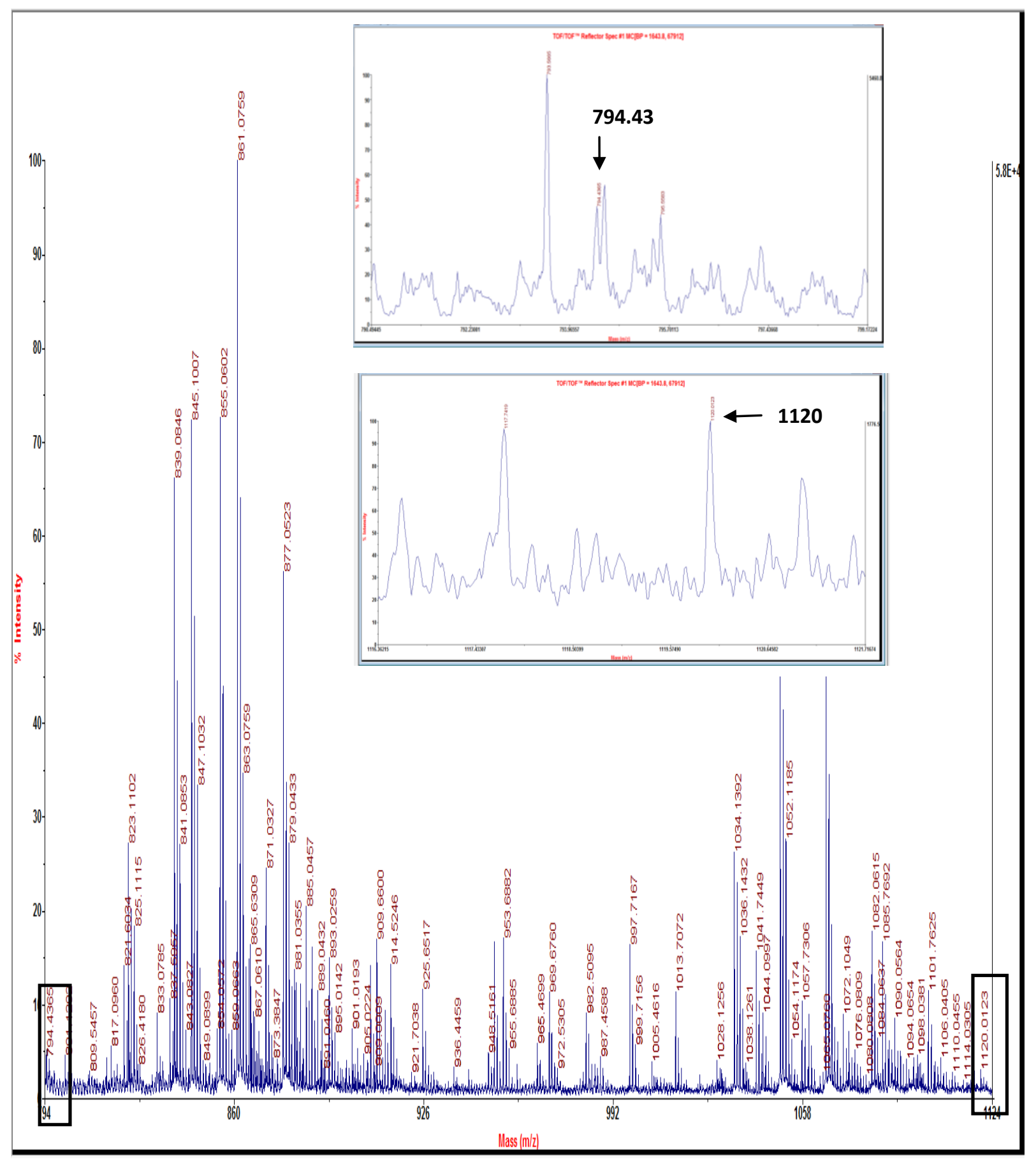

Figure 21: MALDI-TOF spectrum of tryptic digest of GTX-treated CK

Detail of the spectrum from GTX-treated CK after digestion with trypsin. The boxed ions indicate $\mathrm{m} / \mathrm{z} 794$ corresponding to the Cys-254 peptide and $\mathrm{m} / \mathrm{z} 1120$ which is consistent with the Cys-254 peptide with an adduct of $326 \mathrm{Da}$. 


\subsubsection{Comparing the tryptic peptides of CK and GTX-treated CK}

Fig. 22 compares the tryptic spectra of CK and GTX-treated CK (14 h reacted). Table 4 summarizes the tryptic digest of GTX-treated CK that exhibits the peptide fragments present in trypsinized CK.

\begin{tabular}{|c|c|c|c|c|}
\hline Mass & position & sequence & Trypsinized CK & $\begin{array}{l}\text { Trypsinized } \\
\text { GTX-treated CK }\end{array}$ \\
\hline 759 & $210-215$ & DWPDAR & $\checkmark$ & $\checkmark$ \\
\hline 794 & $253-259$ & FCVGLQK & $\checkmark$ & $\sqrt{ }$ \\
\hline 907 & Trypsin autolysis & & $\checkmark$ & $\checkmark$ \\
\hline 1130 & $139-148$ & GYTLPPHCSR & $\checkmark$ & $\checkmark$ \\
\hline 1231 & $87-96$ & DLFDPIIQDR & $\checkmark$ & $\sqrt{ }$ \\
\hline 1530 & $117-130$ & GGDDLDPHYVLSSR & $\checkmark$ & $\checkmark$ \\
\hline 1643 & $224-236$ & SFLVWVNEEDHLR & $\checkmark$ & $\checkmark$ \\
\hline 1785 & $342-358$ & LGSSEVEQVQLVVDGVK & $\checkmark$ & $\sqrt{ }$ \\
\hline 2008 & $321-341$ & GTGGVDTAAVGSVFDISNAD R & $\sqrt{ }$ & $\checkmark$ \\
\hline 2164 & Trypsin autolysis & & $\checkmark$ & $\checkmark$ \\
\hline 2870 & $267-292$ & AGHPFMWNEHLGYVLTCPSN LGTGLR & $\checkmark$ & $\checkmark$ \\
\hline 3644 & $178-209$ & SMTEQEQQQLIDDHFLFDKPVSPLLLASGMAR & $\checkmark$ & $\checkmark$ \\
\hline 4373 & $46-86$ & $\begin{array}{l}\text { ETPSGFTLDDVIQTGVDNPG } \\
\text { HPFIMTVGCVAGDEESYTVF K }\end{array}$ & $\checkmark$ & $\checkmark$ \\
\hline
\end{tabular}

Table 4: Theoretical and observed masses of trypsinized CK and GTX-treated CK. Ticked masses were present in acquired spectra. Masses at 907 and 2164 due to self-autolysis of trypsin were predicted from UniProtKB/Swiss-Prot. 


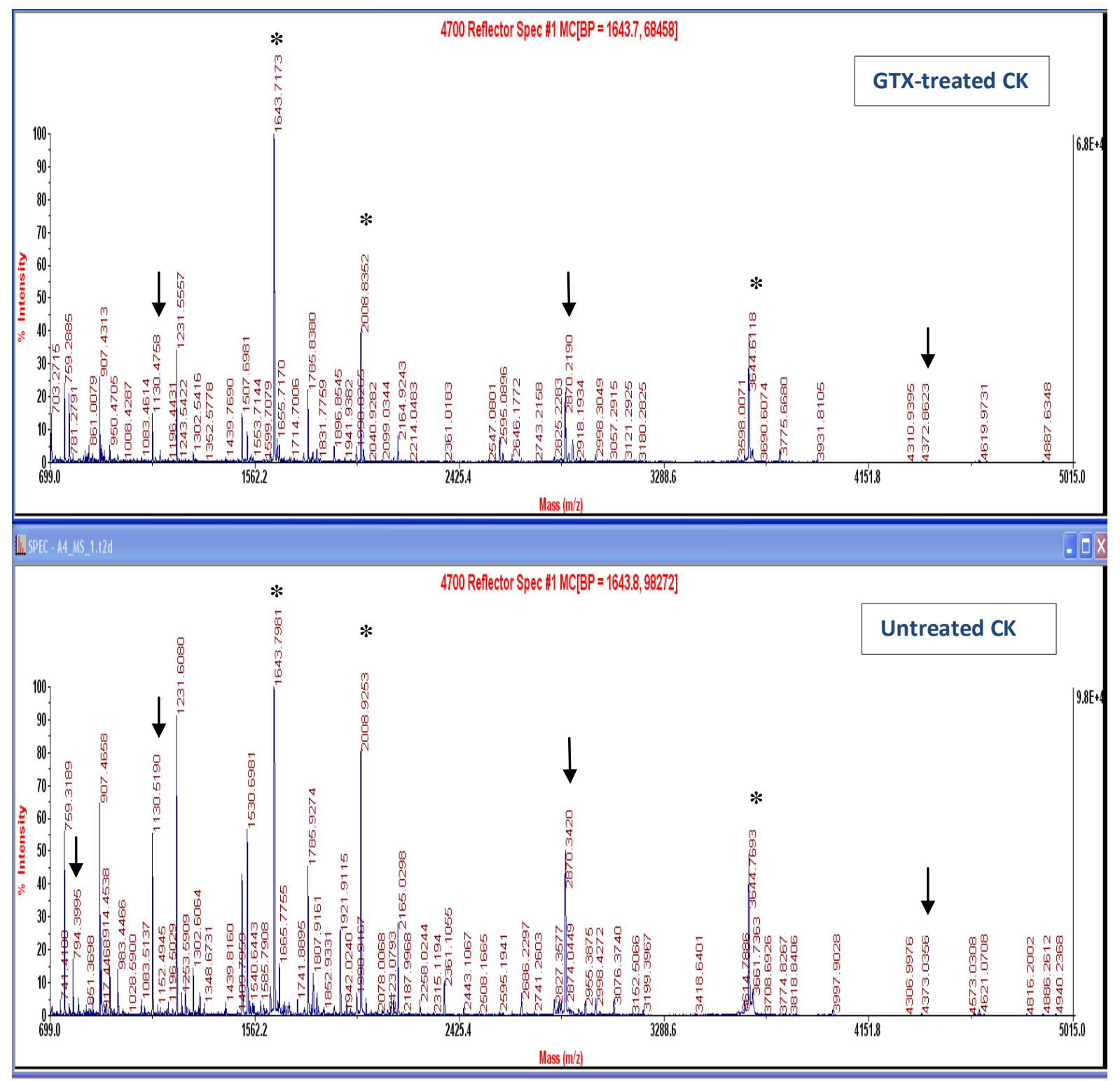

Figure 22: MALDI-TOF MS of tryptic digests of CK and GTX-treated CK

The spectra show untreated CK and GTX-treated CK after digestion with trypsin. The upper spectrum illustrates the GTX-treated CK and the lower spectrum illustrates the untreated CK. Arrows show cys-containing peptides and the asterisked masses show other peptide fragments of CK (Table 4). 


\subsection{Reduction of GTX-treated CK with DTT}

It has been reported that DTT prevents inactivation of CK by GTX either by direct reduction of GTX and/or by cleavage of the disulfide bond formed between CK and GTX (Hurne et al., 2000). Therefore, in this experiment CK was reacted with GTX for $14 \mathrm{~h}$ and then treated with DTT. According to expectation the MALDI spectrum below shows an ion at $\mathrm{m} / \mathrm{z} 42,946$, illustrating the release of CK from the GTX adduct. The tryptic digest of this sample is shown in Fig. 24. The spectrum shows the $\mathrm{m} / \mathrm{z} 1130$ ion corresponding to the Cys-146 peptide but ions corresponding to the unreacted Cys-254 or 283 peptides were not detected. The $\mathrm{m} / \mathrm{z}$ 1162.5 ion corresponding to oxidized Cys-146 peptide $\left(\mathrm{cysSO}_{2}\right)$ which was present in the spectrum of GTX-treated CK was not detected after reduction with DTT. The minor $\mathrm{m} / \mathrm{z} 1120$ ion corresponding to a GTX adduct of Cys-254 peptide was also not detected.

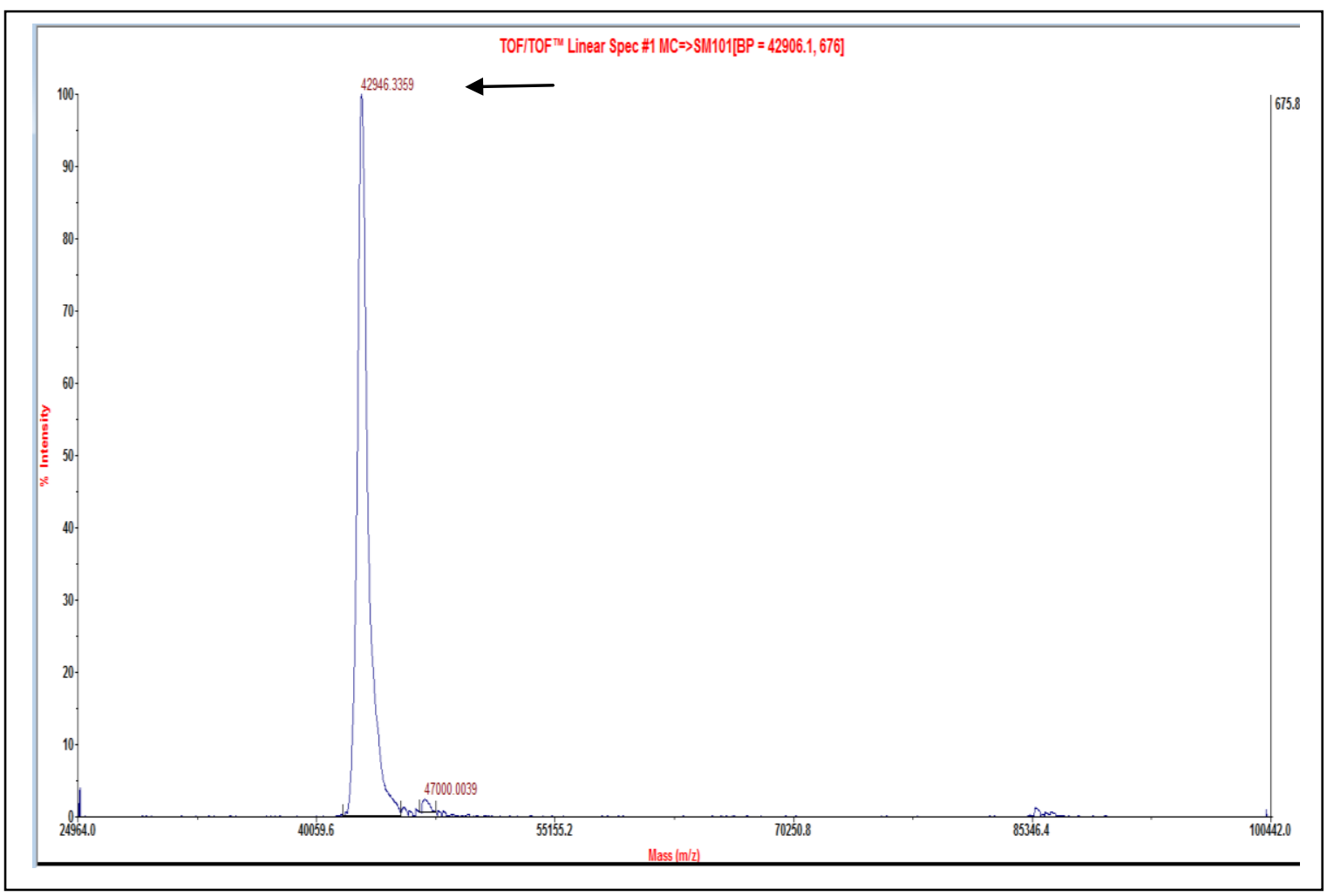

Figure 23: MALDI-TOF MS of GTX-treated CK reacted with DTT

MALDI spectrum of GTX-treated CK reacted with DTT. This spectrum shows the mass 42,946 . 


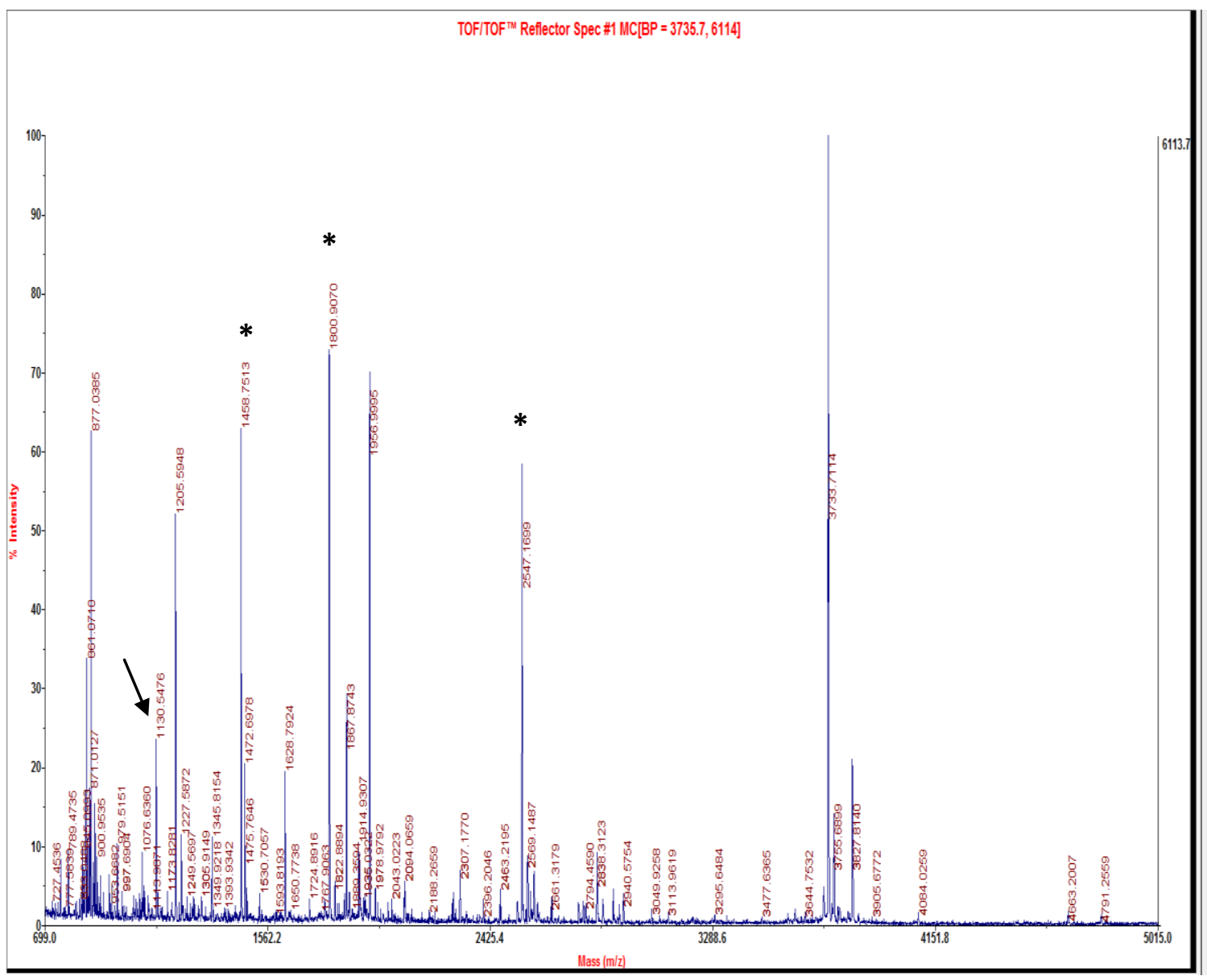

Figure 24: MALDI-TOF MS of tryptic digest of GTX-treated CK reacted with DTT

The spectrum shows GTX-treated CK reacted with DTT and digested with trypsin. The arrow indicates the Cys-146 tryptic peptide. Ions corresponding to the Cys-283 (2870.4) or Cys-254 (794.4) peptides or the GTX adducts were not detected. Expected non-cys peptides with 1 or 2 missed cleavages are marked with asterisks. 


\subsection{Alkylation of GTX-treated CK with IAA}

Figs. 12 and 13 showed the alkylation of cysteine residues of CK. To ascertain the involvement of sulfhydryls of cysteines in the reaction of CK with GTX, CK was reacted with GTX for $14 \mathrm{~h}$ and then with IAA for $1 \mathrm{~h}$. The prediction was that cysteines modified by reaction with GTX would not be accessible to reaction with IAA although there may be alkylation of the free thiol group of GTX in adducted peptides (Fig. 2). Fig. 25 shows the MALDI spectra of the protein. The spectra show the mean mass of $43,057 \pm 3.6 \mathrm{~m} / \mathrm{z}$, which is consistent with alkylation of two cysteines of GTX-free CK. This was an unexpected result as the predicted product was CK with addition of GTX plus alkylation. The tryptic digest of this sample in Fig. 26 shows ions at m/z 1187 and 2927 that are consistent with Cys-146 and 283 peptides with a mass addition of 57 , indicating that these cysteines were not adducted by GTX. The ion at $\mathrm{m} / \mathrm{z} 3055$ shown in this spectrum is consistent with the Cys-283 with one missed cleavage that has a $57 \mathrm{Da}$ adduct $(2998+57=3055 \mathrm{Da})$. Ions corresponding to the cys-containing peptides with a GTX adduct, or with GTX plus IAA were not detected. 

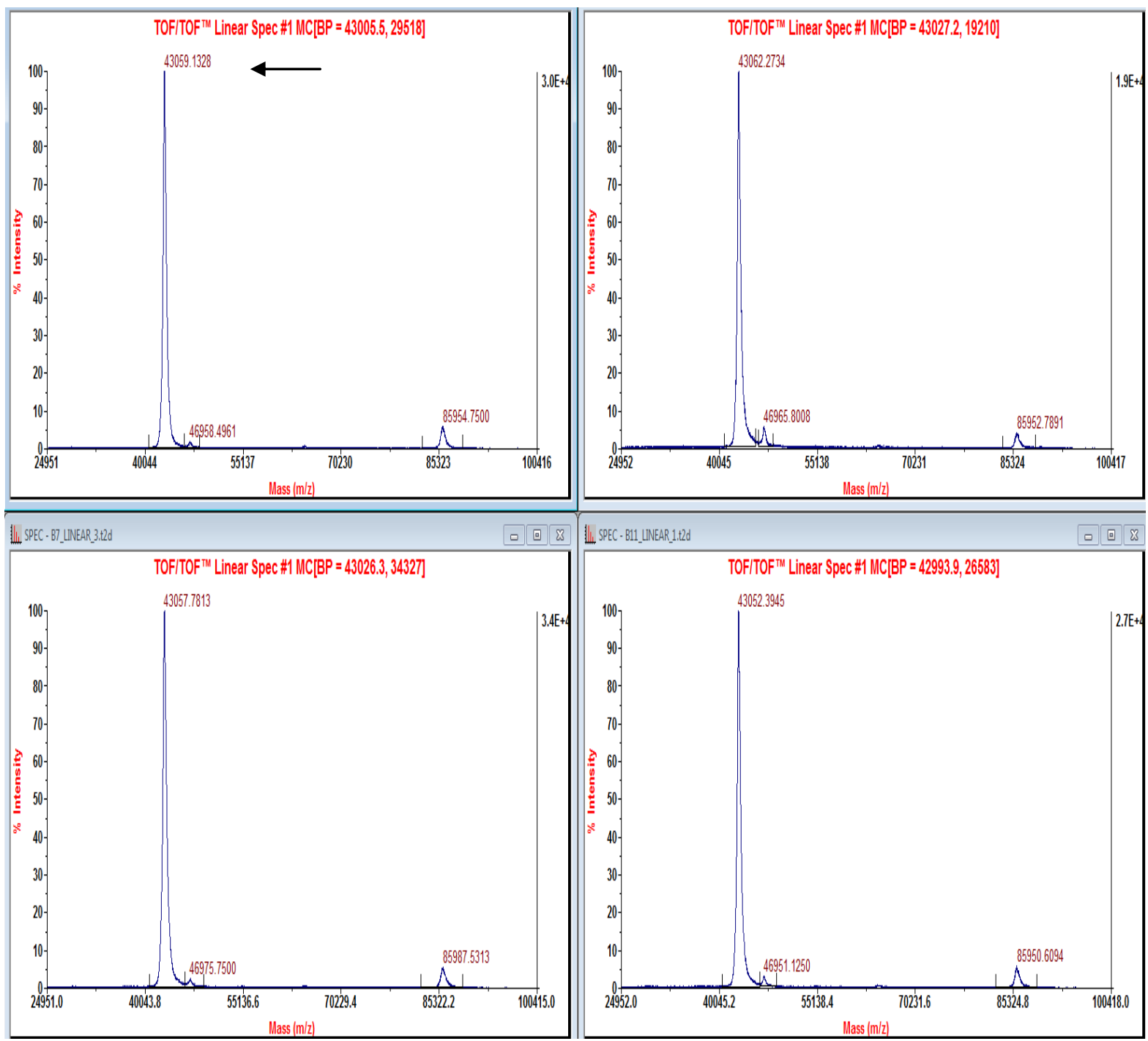

Figure 25: MALDI-TOF mass spectrometry of GTX-treated CK reacted with IAA

The MALDI spectra of alkylated GTX-treated CK in sinapinic acid matrix. The masses have a mean of $43,057 \pm 4$. 


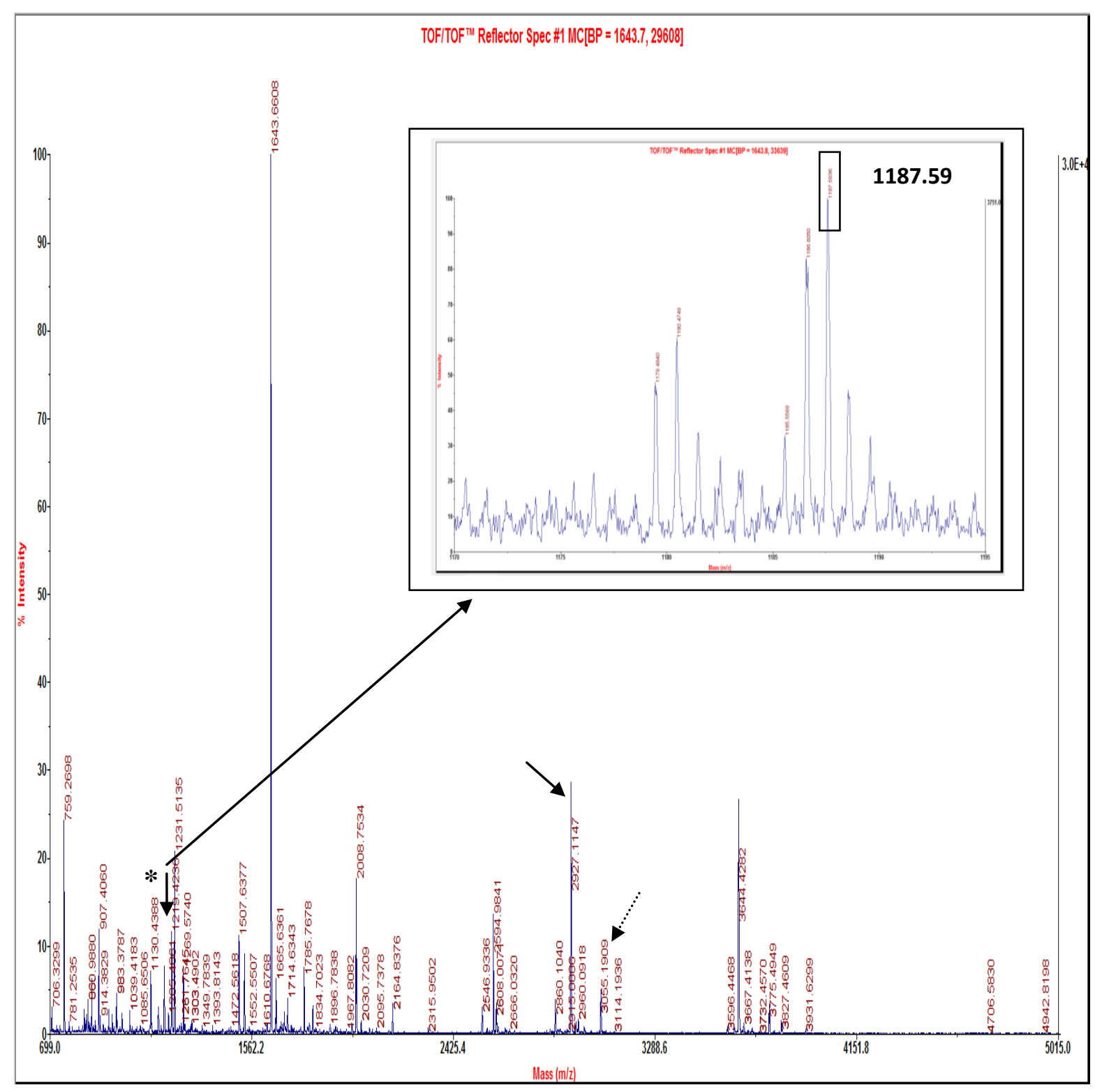

Figure 26: MALDI-TOF spectrum of tryptic digest of GTX-treated CK alkylated with IAA

The spectrum shows the GTX-treated CK reacted with IAA then digested with trypsin and prepared in CHCA matrix. Solid arrows indicate the Cys-146 and 283 containing peptides with a mass addition of 57 . Dotted arrow indicates the Cys-283 with one missed cleavage and a mass addition of 57. The asterisk corresponds to the unmodified Cys-146 peptide. 


\subsection{Oxidation of CK with $\mathrm{H}_{2} \mathrm{O}_{2}$}

To enable better understanding of the reaction of CK with GTX, CK was also reacted with $\mathrm{H}_{2} \mathrm{O}_{2}$ as a control. It was predicted that cysteine residues of $\mathrm{CK}$ would be oxidized after treatment with $\mathrm{H}_{2} \mathrm{O}_{2}$ to sulfenic $\left(\mathrm{CH}_{2} \mathrm{SO}\right)$, sulfinic $\left(\mathrm{CH}_{2} \mathrm{SO}_{2}\right)$ or sulfonic $\left(\mathrm{CH}_{2} \mathrm{SO}_{3}\right)$ acids (Table 5) and/or formation of an internal disulfide bond in CK. CK was subjected to reaction with $\mathrm{H}_{2} \mathrm{O}_{2}$ at room temperature for $10 \mathrm{~min}$ and the reaction was stopped by addition of catalase. The MALDI spectra in Fig. 27 show the reaction products with a mean mass of 43,020 \pm 9 $\mathrm{m} / \mathrm{z}$ which is consistent with the addition of two oxygen molecules to the cysteine residues of CK. The tryptic digest of this sample in Fig. 28 shows minor ions at m/z 1162.5 and 1178.5 corresponding to the Cys-146 peptide with two or three oxygen additions, but an abundant ion at 1130.5 was consistent with unmodified Cys-146 peptide. Although there was complete loss of the 2870.4 ion corresponding to the Cys-283 peptide (compare the spectrum in Fig. 10) products corresponding to cysteine oxidation were not detected. Possible explanations are that the oxidized peptides may not ionize well in the MALDI source, or that Cys-283 was oxidized to an intramolecular disulfide of CK. The mass of the oxidized protein corresponds to a single molecule of CK (Fig. 27), like CK (Fig. 9), suggesting that there was not substantial formation of disulfide bonded dimers of CK (expected mass approximately $86 \mathrm{kDa})$.

\begin{tabular}{||l|l|l|l|l||}
\hline \hline peptides & Mass (m/z) & SO & $\mathrm{SO}_{2}$ & $\mathrm{SO}_{3}$ \\
\hline $253-259$ & 794.4 & 810.4 & 826.4 & 842.4 \\
\hline $139-148$ & 1130.5 & 1146.5 & 1162.5 & 1178.5 \\
\hline $267-292$ & 2870.4 & 2886.4 & 2902.4 & 2918.4 \\
\hline $46-86$ & 4373 & 4389 & 4405 & 4421 \\
\hline \hline
\end{tabular}

Table 5: Predicted mass change of oxidized cys-containing tryptic peptides by addition of one, two, or three oxygen molecules. 

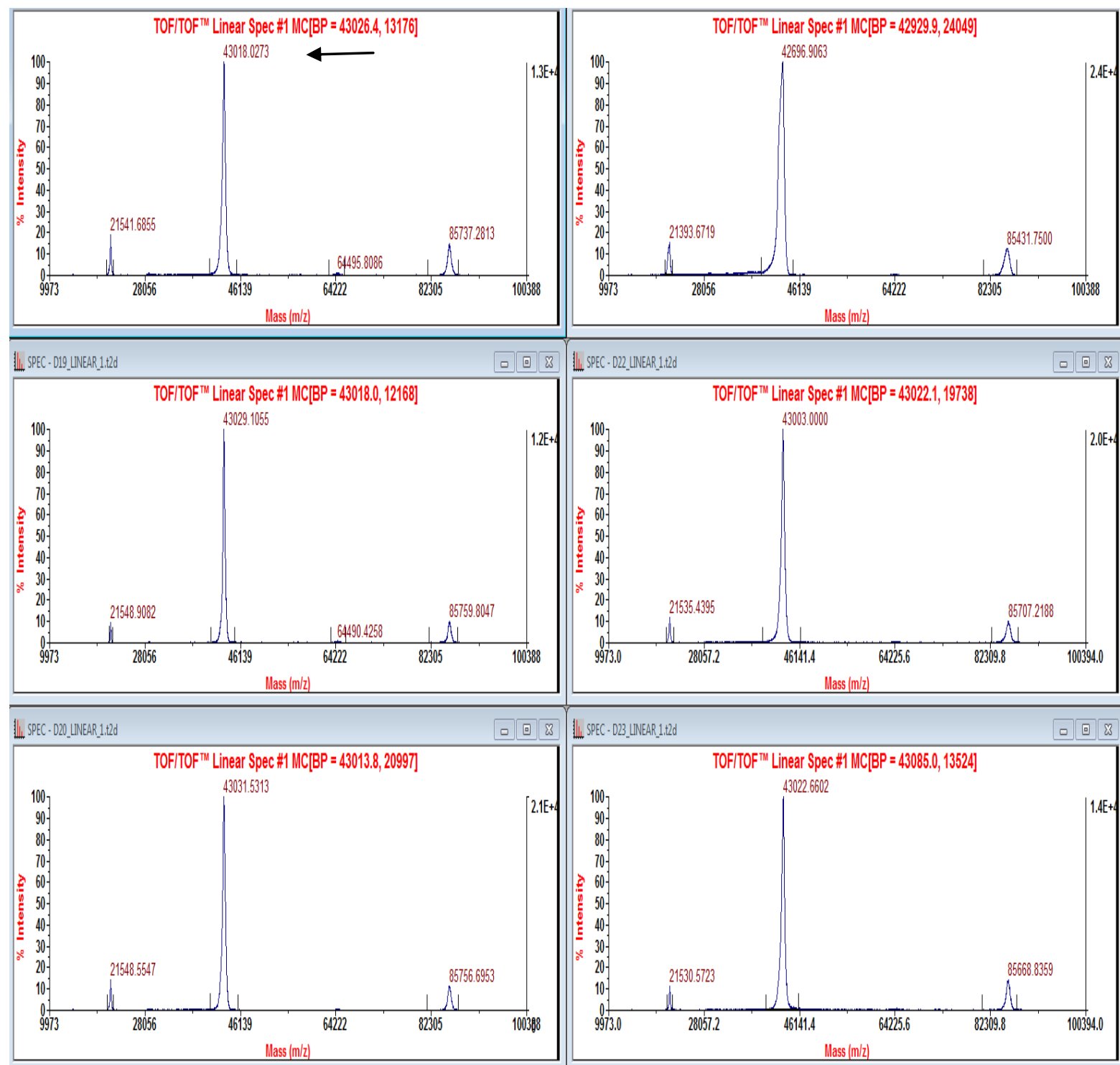

Figure 27: MALDI-TOF mass spectrometry of $\mathrm{H}_{2} \mathrm{O}_{2}$ treated CK

The spectra above show the reaction products of $\mathrm{H}_{2} \mathrm{O}_{2}$ treated $\mathrm{CK}$ in sinapinic acid matrix (arrowhead). These masses have a mean of $43,020 \pm 9 \mathrm{~m} / \mathrm{z}$. 


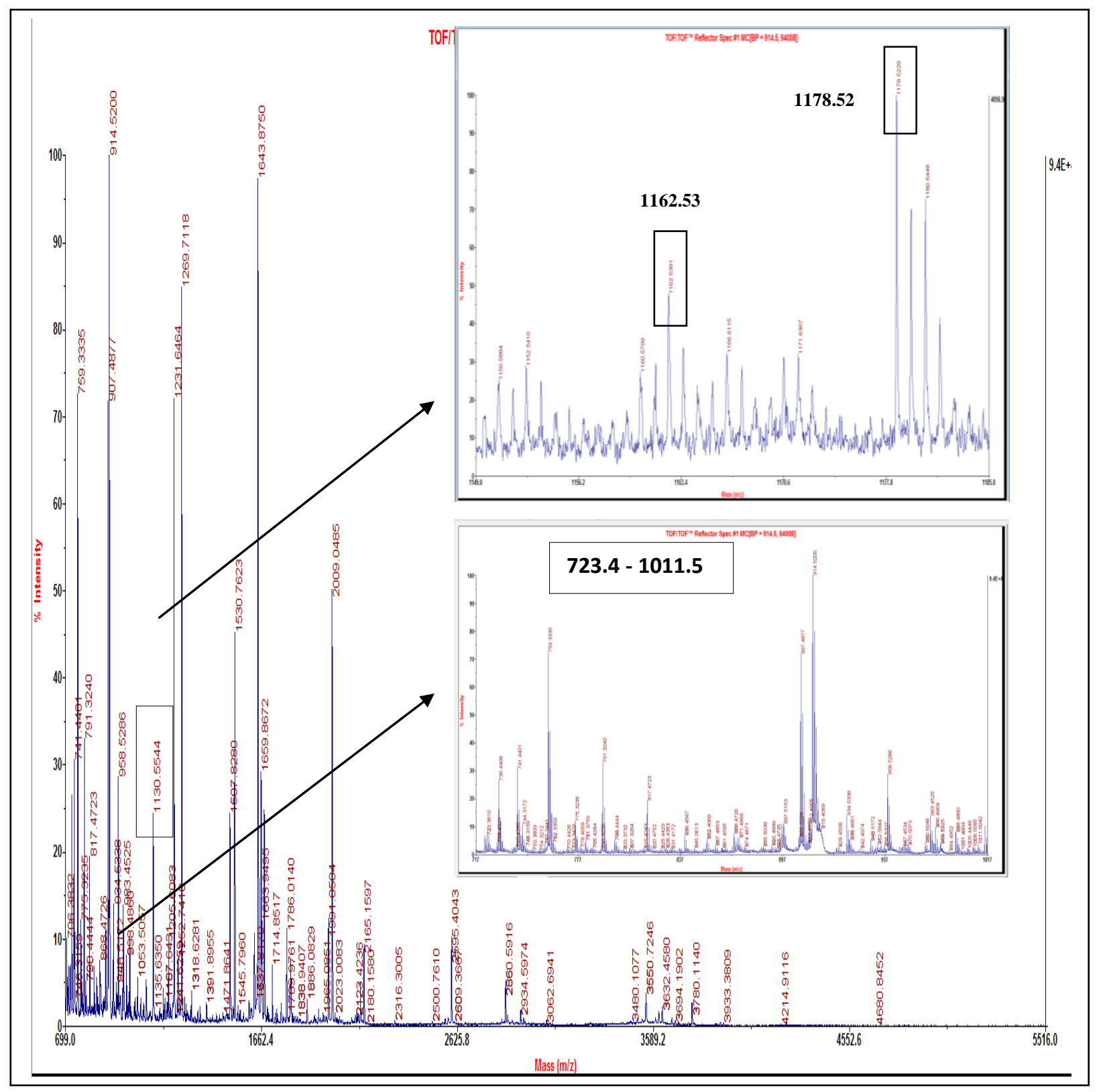

Figure 28: MALDI-TOF MS of tryptic digest of $\mathrm{H}_{2} \mathrm{O}_{2}$ treated CK

This MALDI spectrum shows the tryptic digest of $\mathrm{H}_{2} \mathrm{O}_{2}$ treated $\mathrm{CK}$ in CHCA matrix. The spectrum contains ions at $\mathrm{m} / \mathrm{z} 1162.5$ and 1178.5 corresponding to oxidized Cys-146 peptide with two and three oxygen molecules respectively. The $\mathrm{m} / \mathrm{z} 1130$ ion corresponds to the unmodified Cys-146 containing peptide. The lower small box indicates the mass range of 723.4 to $1011.5 \mathrm{Da}$. 


\subsection{ICAT labeling of CK}

In order to ascertain which cysteines of CK are modified by GTX, the ICAT approach was used which labels free cysteines. Initially native CK was reacted with Light ICAT reagent as a control. The expected mass addition to cysteine residues was $907.5 \mathrm{Da}$. The MALDI spectrum in Fig. 29 shows the masses of the reaction products; a, addition of ICAT to one cysteine; b, addition of ICAT to two cysteines; $c$, addition of ICAT to three cysteines; $d$, addition of ICAT to all four cysteines. Mass additions corresponding to 1-4 added ICAT residues were detected unlike the more limited alkylation of CK by IAA.

A spectrum for a tryptic digest of this sample is shown in Figs. 30 and 31 and contains ions at m/z 1701 (low intensity), 2037, and 3777 consistent with the Cys-254, 146, and 283 peptides with 907.5 Da mass additions. 


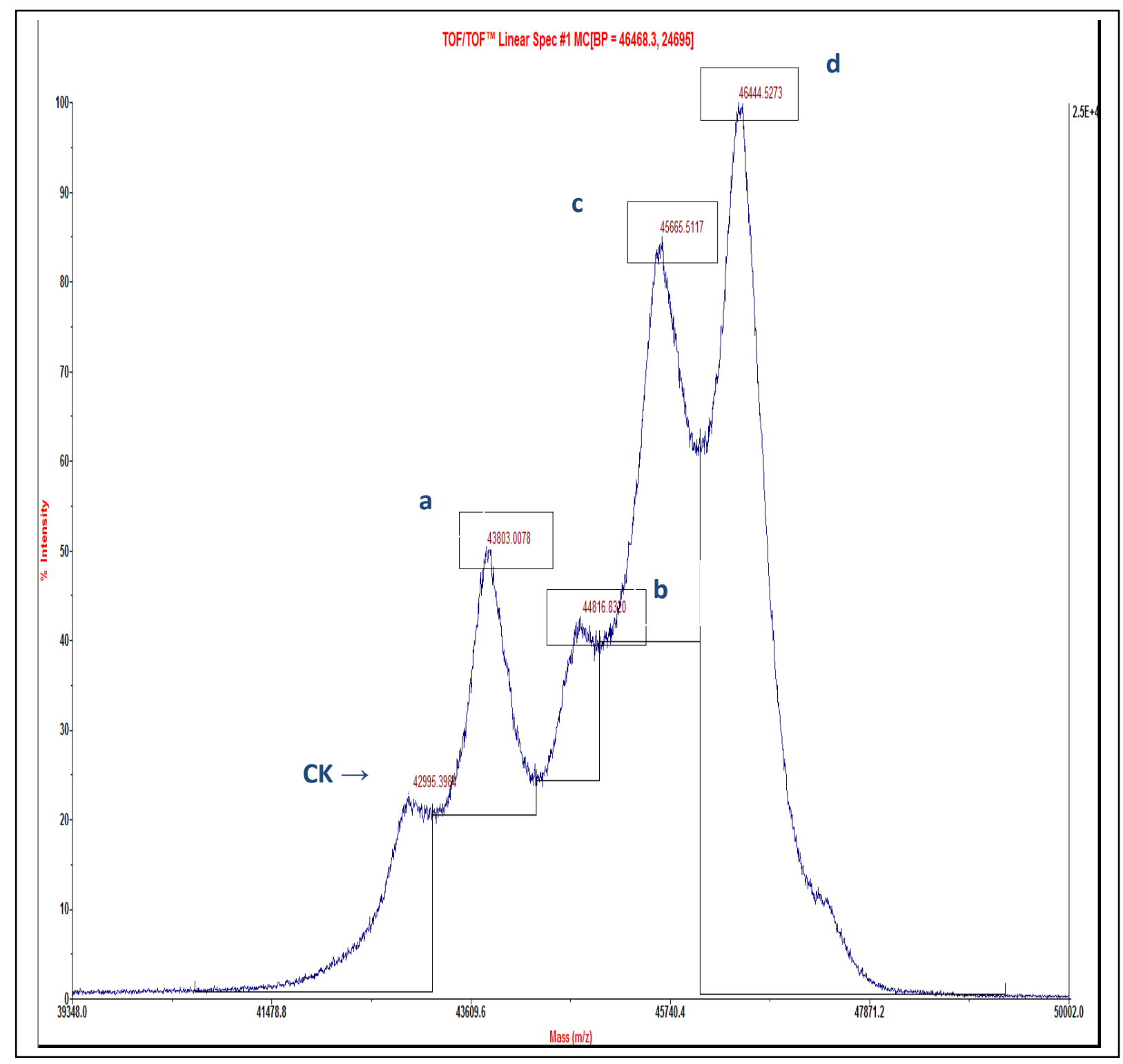

Figure 29: MALDI-TOF mass spectrum of CK labeled with Light ICAT

The spectrum shows Light ICAT-labeled CK in sinapinic acid matrix. The biotin tag was not cleaved after reaction. The spectrum indicates the presence of CK with 1-4 ICAT residues, with greatest abundance of the maximally labeled species. The labels $a, b, c, d$ indicate labeling of 1-4 cysteine residues. Detected masses show 42995 (CK), 43803 (+ 808 Da), 44816 (+ $1821 \mathrm{Da}), 45665$ (+2670 Da), 46444(+3449 Da). 


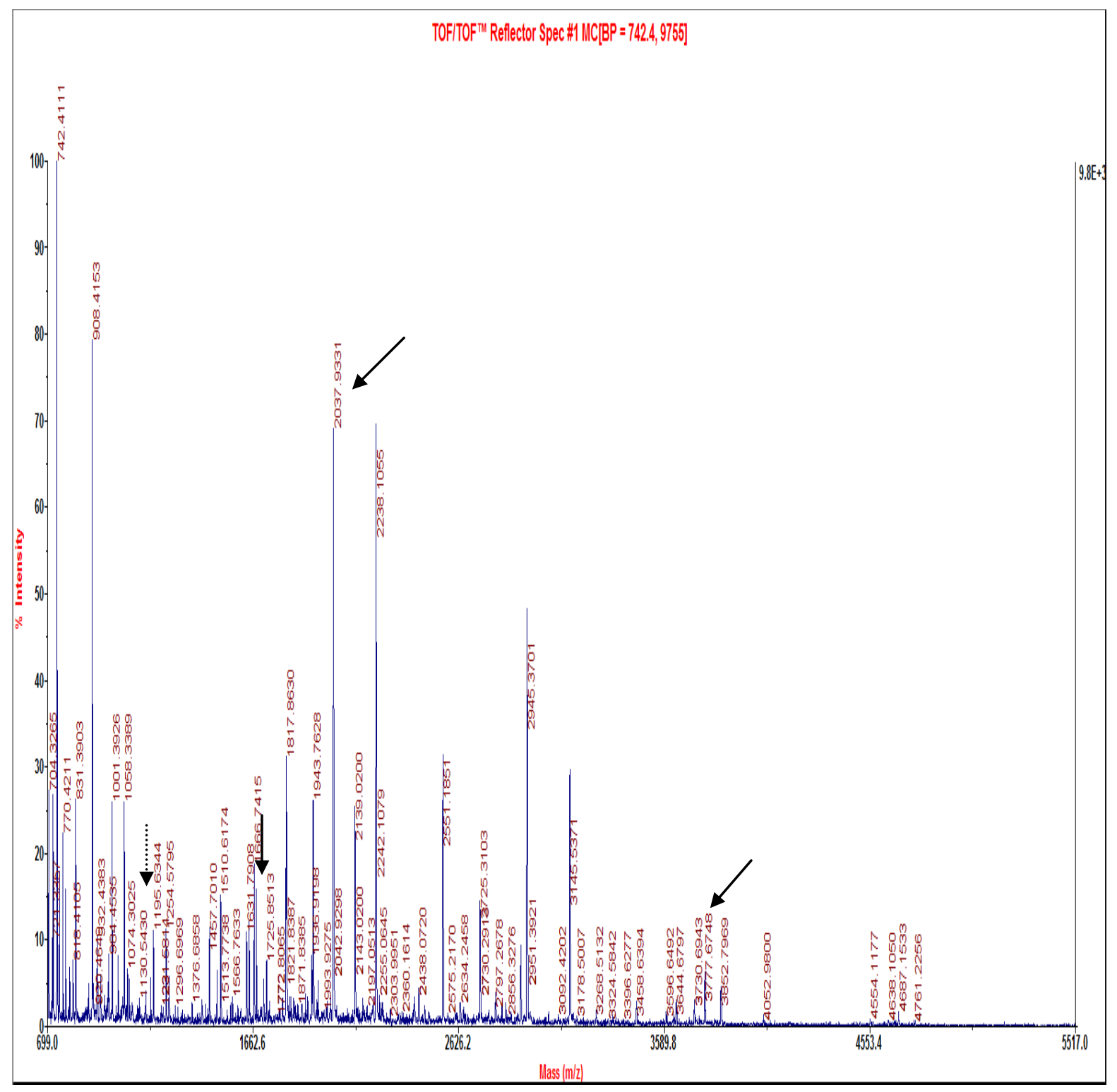

Figure 30: MALDI-TOF MS of tryptic digest of Light ICAT-labeled CK

The spectrum shows the Light ICAT-labeled CK digested with trypsin. The biotin tag was not cleaved from the ICAT product. Solid arrows indicate potential cys-containing peptides with a 907.5 Da mass addition. The dotted arrow indicates unreacted Cys-146. 

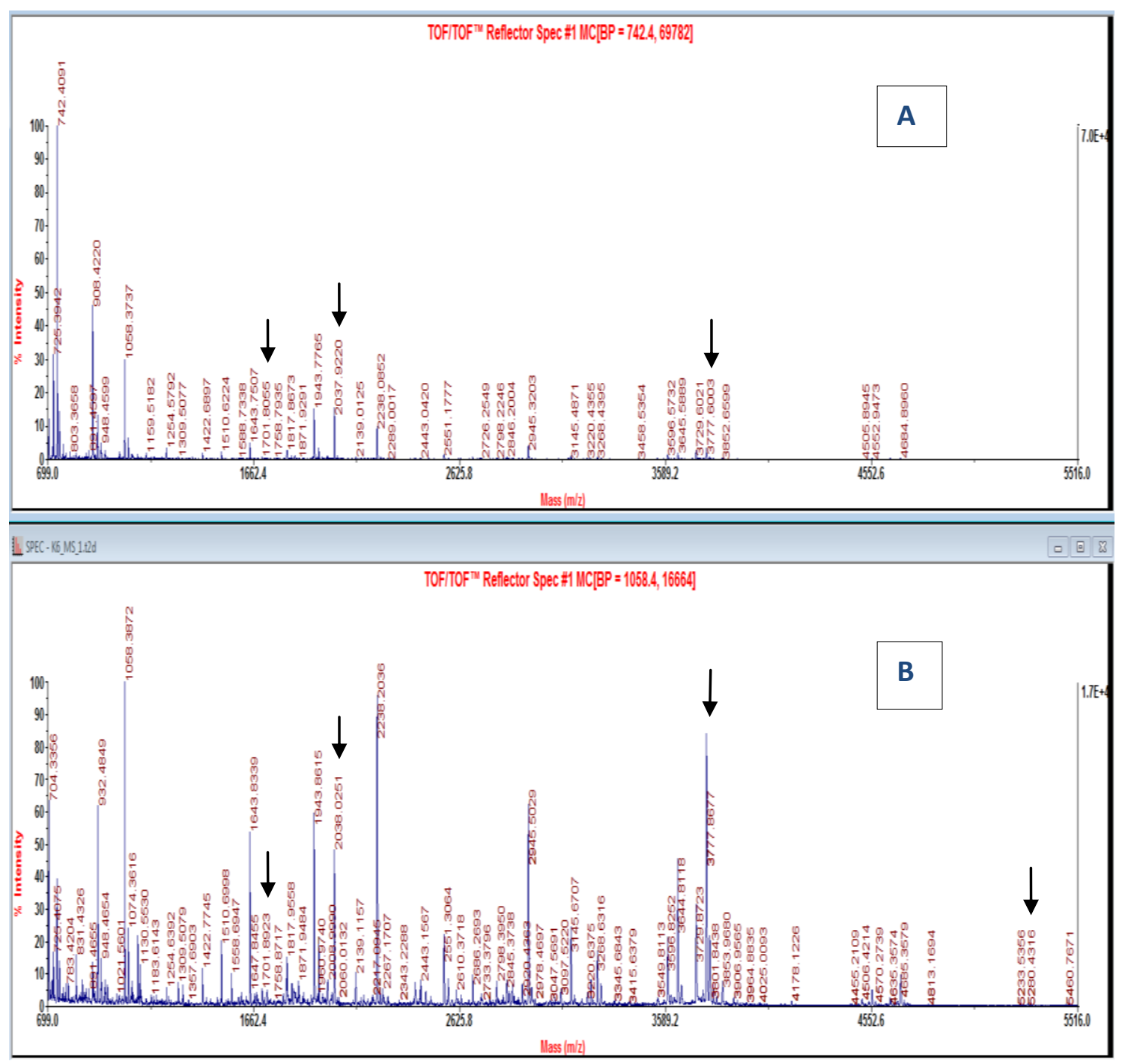

Figure 31: MALDI-TOF MS of Light ICAT-labeled CK before and after desalting and concentration

The MALDI spectra of the tryptic peptides of Light ICAT-labeled CK. Spectrum A shows the sample prepared by the dried droplet method (without desalting) and spectrum B shows the sample after desalting and concentration using Eppendorf PerfectPure ${ }^{\circledR}$ C-18 Tips. The arrows indicate potential masses of cys-containing peptides with a possible Light ICAT product. 


\subsection{ICAT labeling of GTX-treated CK}

To further examine which cysteines of CK were modified, CK was reacted with GTX for $14 \mathrm{~h}$ and then with Light ICAT reagent for $2 \mathrm{~h}$ at $37{ }^{\circ} \mathrm{C}$. Fig. 32 shows the MALDI spectra of this sample. The spectra have a mean mass of $43,145 \pm 23 \mathrm{~m} / \mathrm{z}$, implying that ICAT did not label the cysteine residues, but there was apparently some unexpected mass loss as the mean was less than that of GTX-treated CK prior to ICAT labelling Fig 18; 43,268 \pm 44 .

In order to compare the ICAT labeling of the cys-containing peptides of untreated CK and GTX-treated CK, these samples were labeled with Light and Heavy ICAT reagents respectively and were then mixed and digested with trypsin followed by cleavage of the biotin tag from the ICAT-labeled peptides (see Section 2.2.5). The mass of Light and Heavy ICAT after biotin cleavage is 227.13 and $326.16 \mathrm{Da}$ (9 Da difference). Fig. 33 shows a MALDI spectrum from this experiment. An ion at $\mathrm{m} / \mathrm{z} 1021$ is consistent with the Cys-254 with a Light ICAT added. Lack of Heavy ICAT labeling indicates the possible modification of this cysteine by GTX. The spectrum contained ions consistent with Light (1357.5767) and Heavy (1366.6021) ICAT tags on Cys-146. The $\mathrm{m} / \mathrm{z} 3097$ ion in this spectrum is consistent with the Cys-283 with a Light ICAT only. Absence of the Heavy ICAT labeling indicates the possible modification of this cysteine by GTX. The unlabeled fraction that was washed from the avidin cartridge was also analyzed by MALDI (Fig. 37) to detect other possible modified peptides. This spectrum contains a very low abundance ion with a low signal to noise at $\mathrm{m} / \mathrm{z}$ 1120.66 possibly corresponding to the Cys-254 peptide with a GTX adduct.

To further examine the peptides modified by GTX, MS/MS was carried out. MS/MS of the $\mathrm{m} / \mathrm{z} 1357$ predicted Cys-146 peptide ion was consistent with the expected sequence (GYTLPPHC(+227.13)SR) (Fig. 38) with a Light ICAT on the cysteine residue. The other primary ions had weaker MS/MS signals that were more difficult to interpret.

Overall, the results of ICAT analysis indicated that Cys-254 and 283, and possibly Cys-146 appeared to be modified and less susceptible to ICAT labeling. 

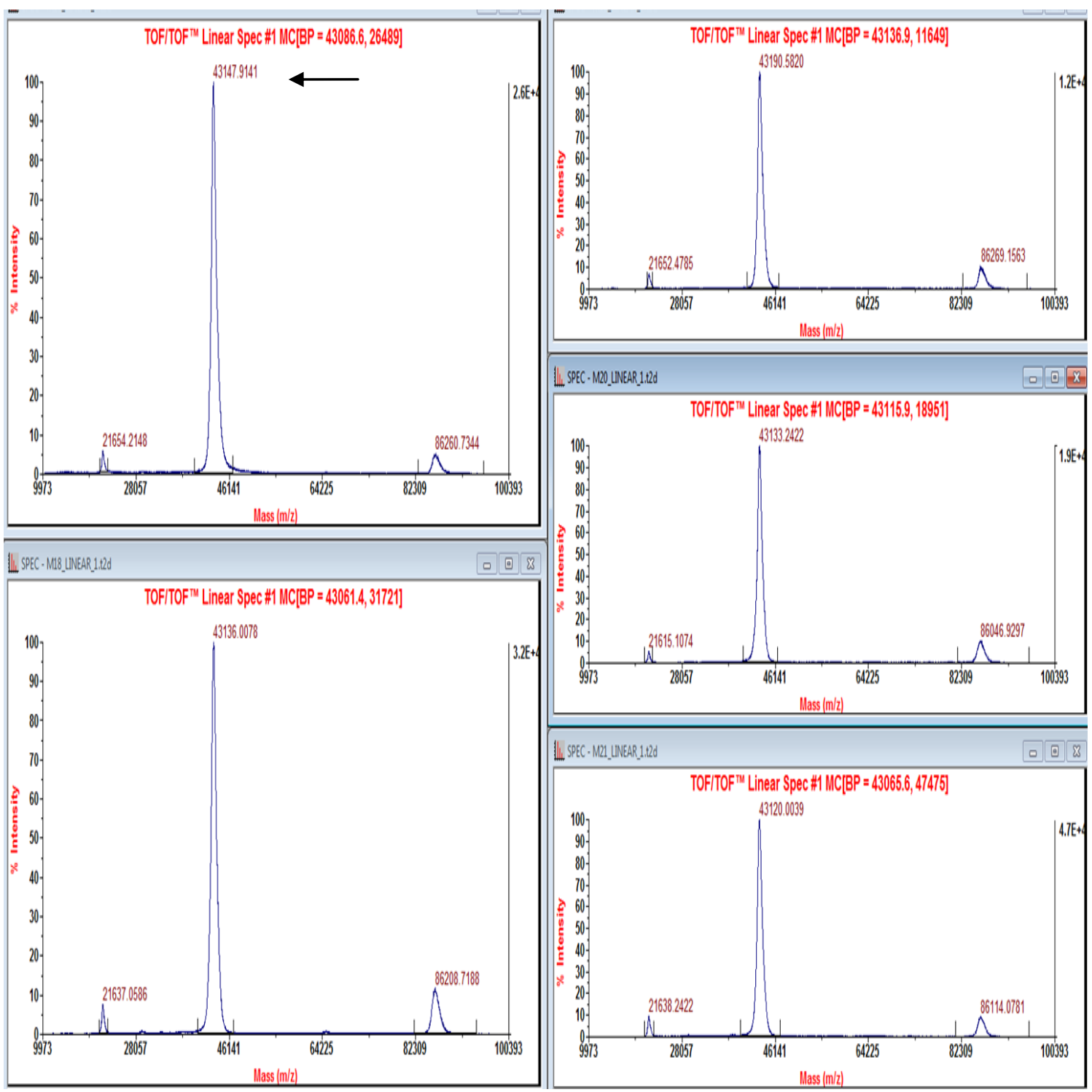

Figure 32: MALDI-TOF mass spectrometry of Light ICAT-labeled GTX-treated CK

The spectra above show the products of reaction of Light ICAT reagent with GTX-treated CK.

The biotin tag was not cleaved from the ICAT product. The mean mass was 43,145 \pm 23 . 


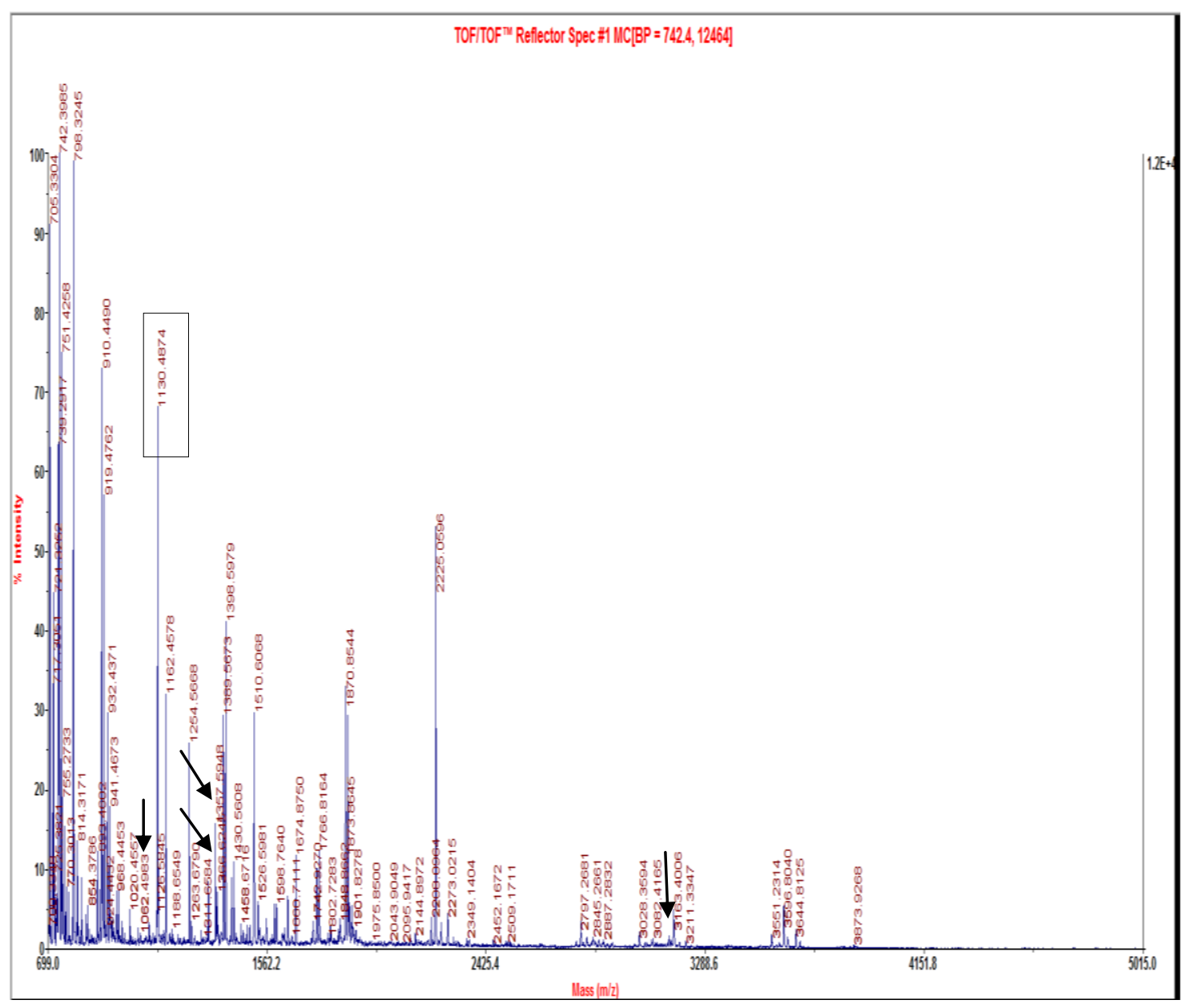

Figure 33: ICAT spectra of a trypsin digest of a mixture of Light ICAT-labeled CK plus Heavy ICAT-labeled GTX-treated CK

The MALDI-TOF MS spectrum above shows the Heavy ICAT-labeled GTX-treated CK and the Light ICAT-labeled untreated CK that were mixed and digested with trypsin. The $\mathrm{m} / \mathrm{z} 1130$ ion corresponds to the unmodified Cys-146 peptide and the arrows indicate cys-containing peptides with the possible ICAT label. Detail of the masses is shown in Figs. 34, 35, and 36. 


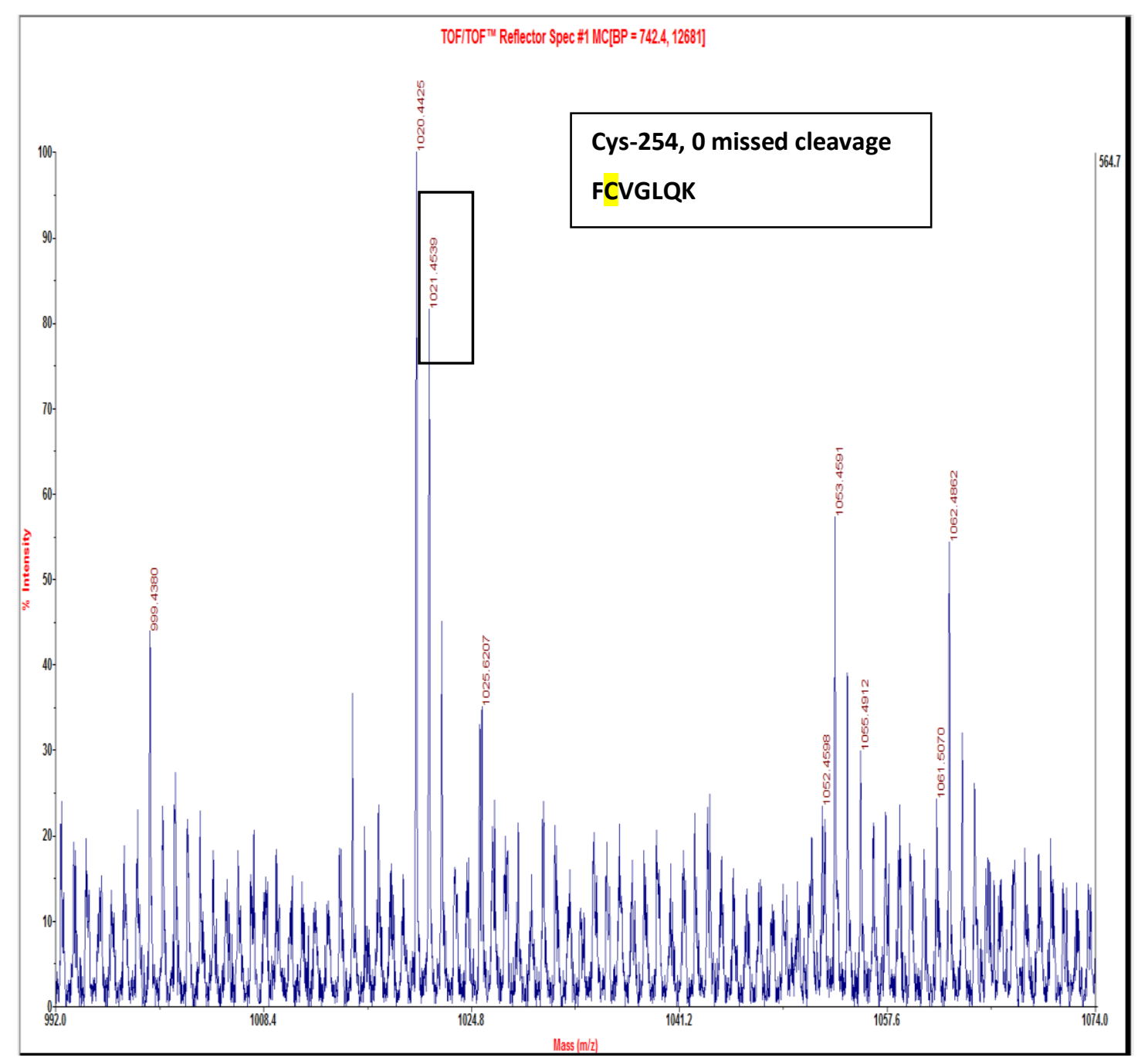

Figure 34: MALDI-TOF MS of ICAT labeling of Cys-254 peptide

The spectrum shows a region of the spectrum from Fig. 33. The m/z 1021 ion is consistent with Cys-254 peptide with a Light ICAT tag $(794+227.13=1021 \mathrm{Da})$. 


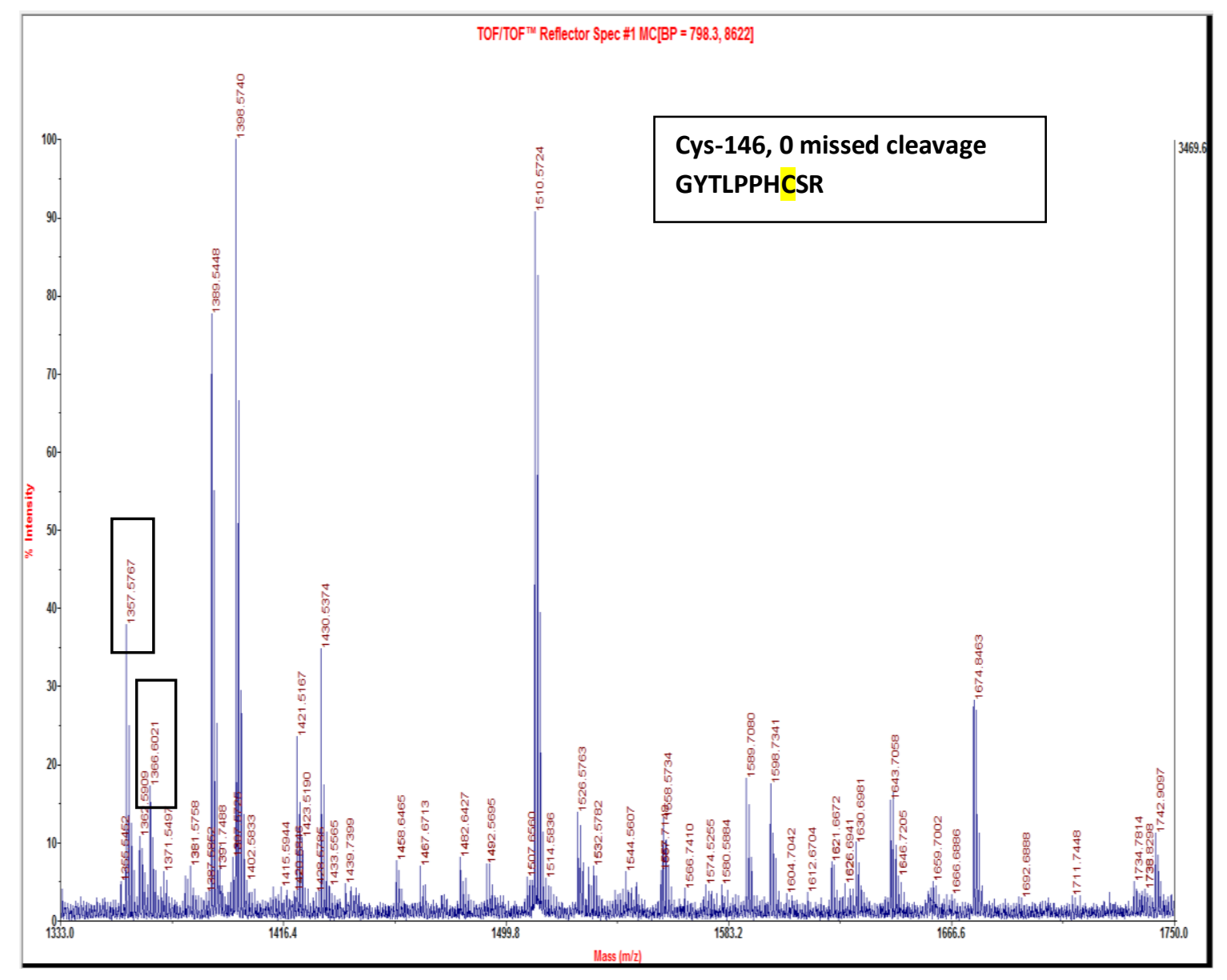

Figure 35: MALDI-TOF MS of ICAT labeling of Cys-146 peptide

The spectrum illustrates a region of the spectrum from Fig. 33 that contains ions consistent with a Light (1357.5767) and Heavy (1366.6021) ICAT on Cys-146, with apparent lower intensity of the Heavy label. 


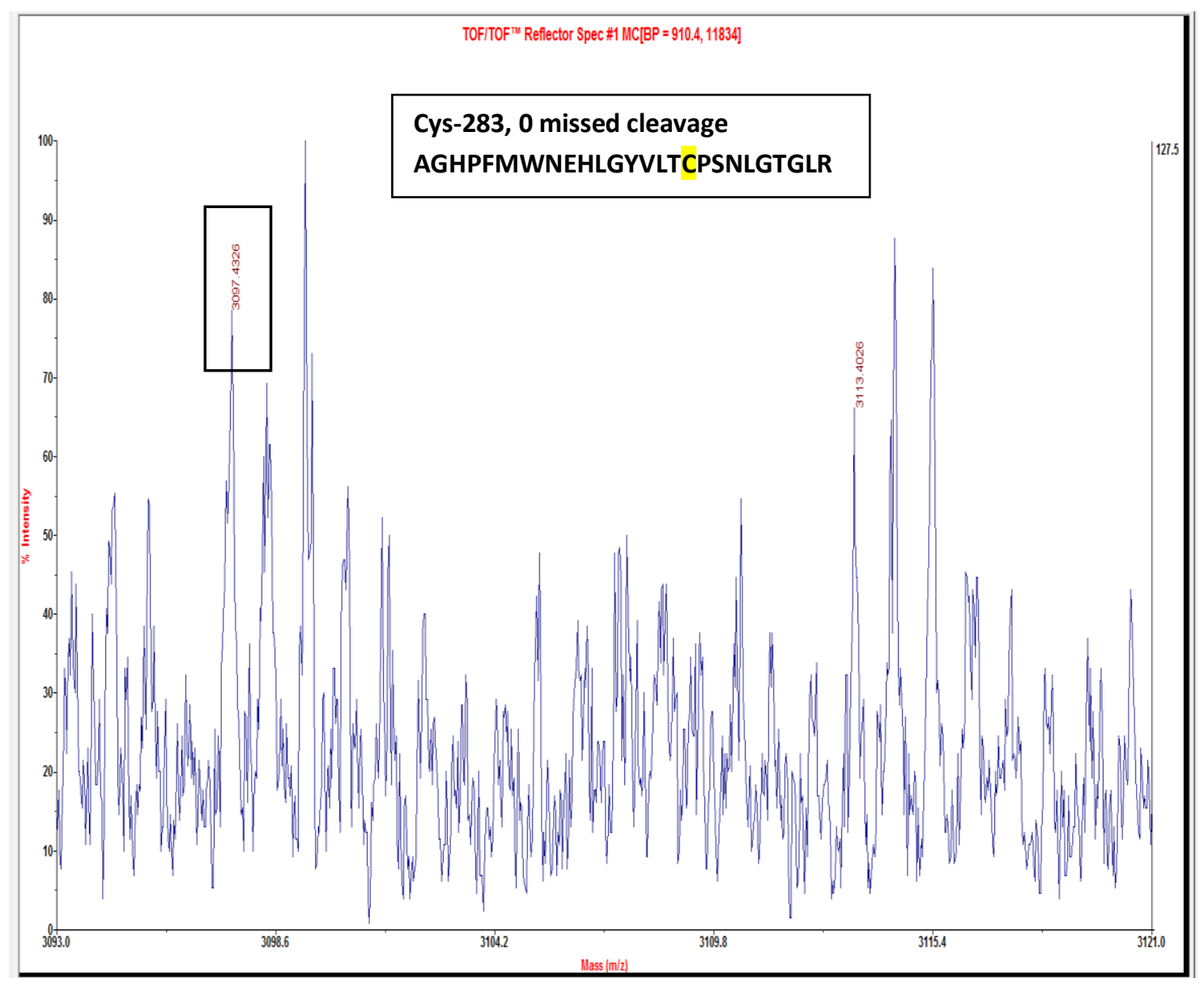

Figure 36: MALDI-TOF MS of ICAT labeling of Cys-283 peptide

The spectrum illustrates a region of the spectrum from Fig. 33 , which shows a minor $\mathrm{m} / \mathrm{z}$ 3097 ion that is consistent with the Cys-283 with a 227.13 Da adduct corresponding to Light ICAT. 


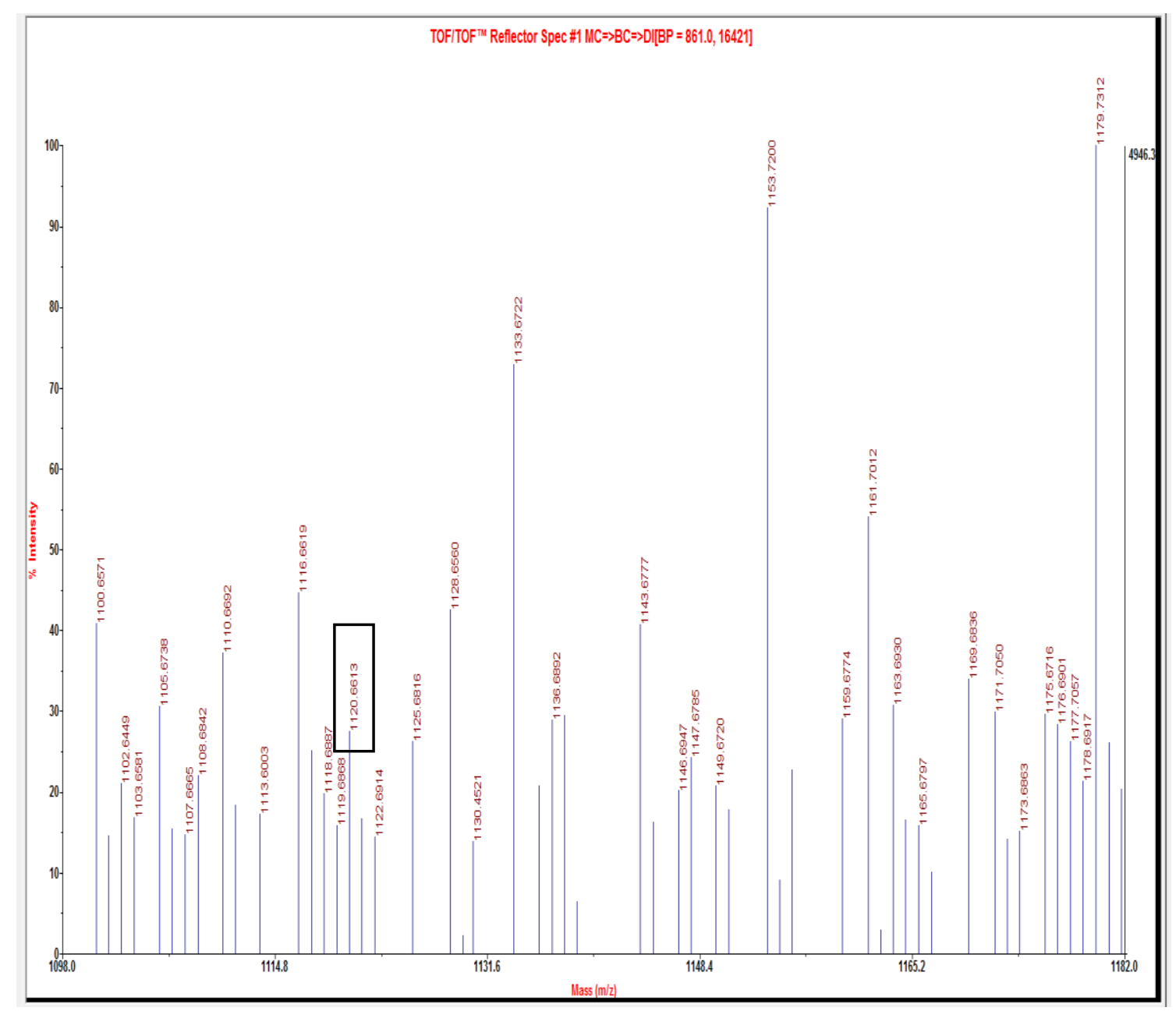

Figure 37: MALDI-TOF MS of GTX adduct on Cys-254 peptide

Figure shows the spectrum corresponding to the unlabeled fraction of ICAT experiment that was washed from the avidin cartridge, as explained in Section 2.2.5. This spectrum contains a low intensity ion at $\mathrm{m} / \mathrm{z} 1120$, which is consistent with the Cys-254 peptide with a possible GTX adduct. The peaks were deisotoped using Data Explorer software. 


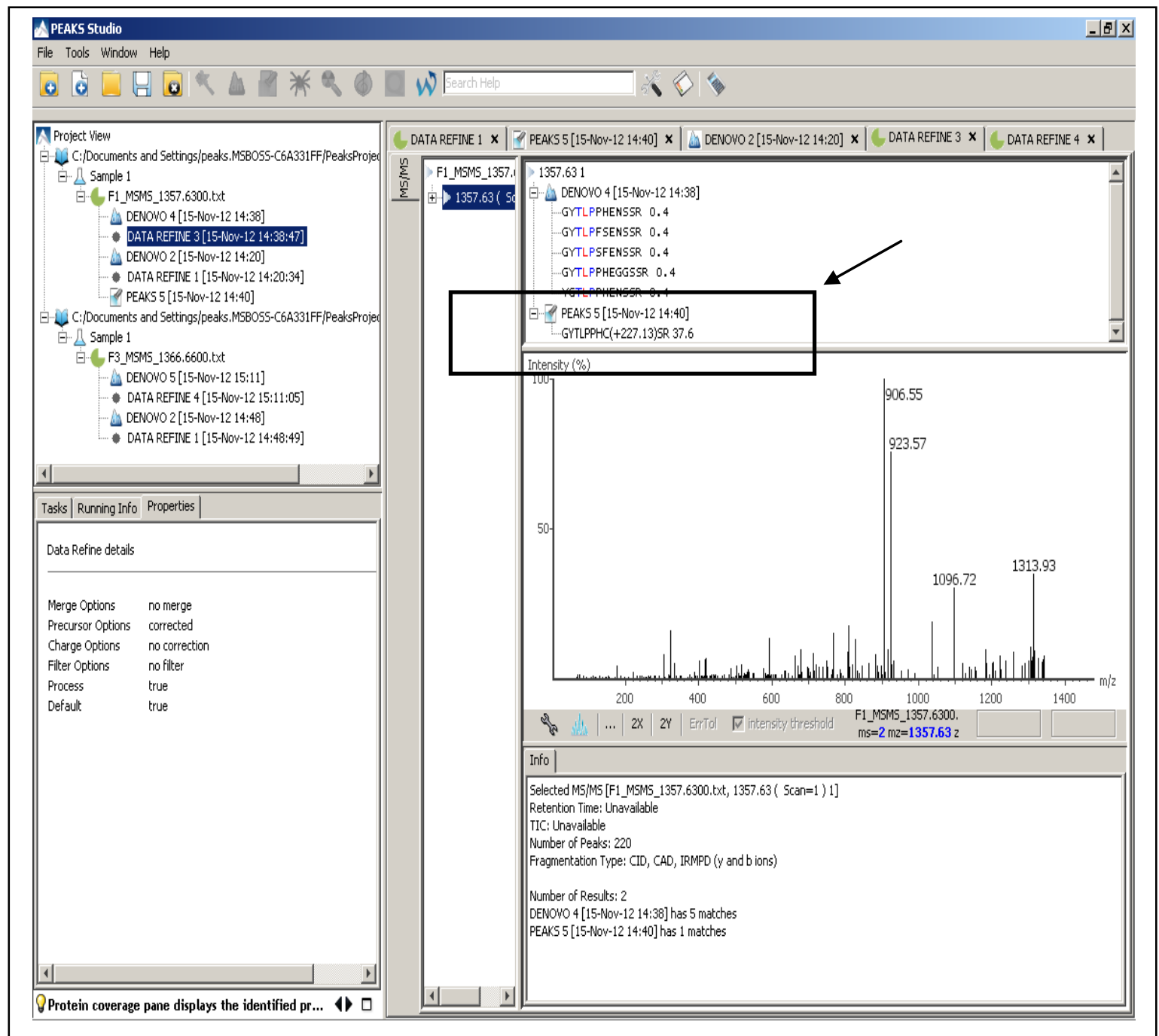

Figure 38: The peptide sequence corresponding to the $\mathrm{m} / \mathrm{z} 1357.6$ ion

The arrow indicates the cys-containing peptide sequence of the Cys-146 peptide that has a 227.13 Da adduct on cys residue corresponding to the Light ICAT reagent. 


\subsection{Alkylation of $\mathrm{H}_{2} \mathrm{O}_{2}$ treated CK with IAA}

As previously shown in Section 3.8, exposure of $\mathrm{CK}$ to $\mathrm{H}_{2} \mathrm{O}_{2}$ was consistent with oxidation of Cys-146. It was therefore decided to examine alkylation of $\mathrm{CK}$ treated with $\mathrm{H}_{2} \mathrm{O}_{2} \cdot \mathrm{H}_{2} \mathrm{O}_{2}$ treated CK was reacted with IAA for $1 \mathrm{~h}$. Fig. 39 shows the reaction products of this experiment that have a mean mass of $43,032 \pm 17$. The mass of $\mathrm{H}_{2} \mathrm{O}_{2}$ treated $\mathrm{CK}$ prior to the reaction with IAA was $43,020 \pm 9$, therefore it seems that the mass addition was less than the mass of one IAA, subject to the standard errors in mass accuracy. However, the spectrum for the tryptic digest of this sample (Fig. 40) contains an m/z 1187 ion corresponding to Cys-146 peptide with a $57 \mathrm{Da}$ addition. The $\mathrm{m} / \mathrm{z} 1130$ ion corresponding to the unmodified Cys-146 was also present in the spectrum suggesting only partial alkylation. Ions at 851.4 or 2927.4 (Table 3) corresponding to alkylation of the Cys-254 or 283 peptides were not detected suggesting that these cysteines had been modified by reaction with $\mathrm{H}_{2} \mathrm{O}_{2}$.

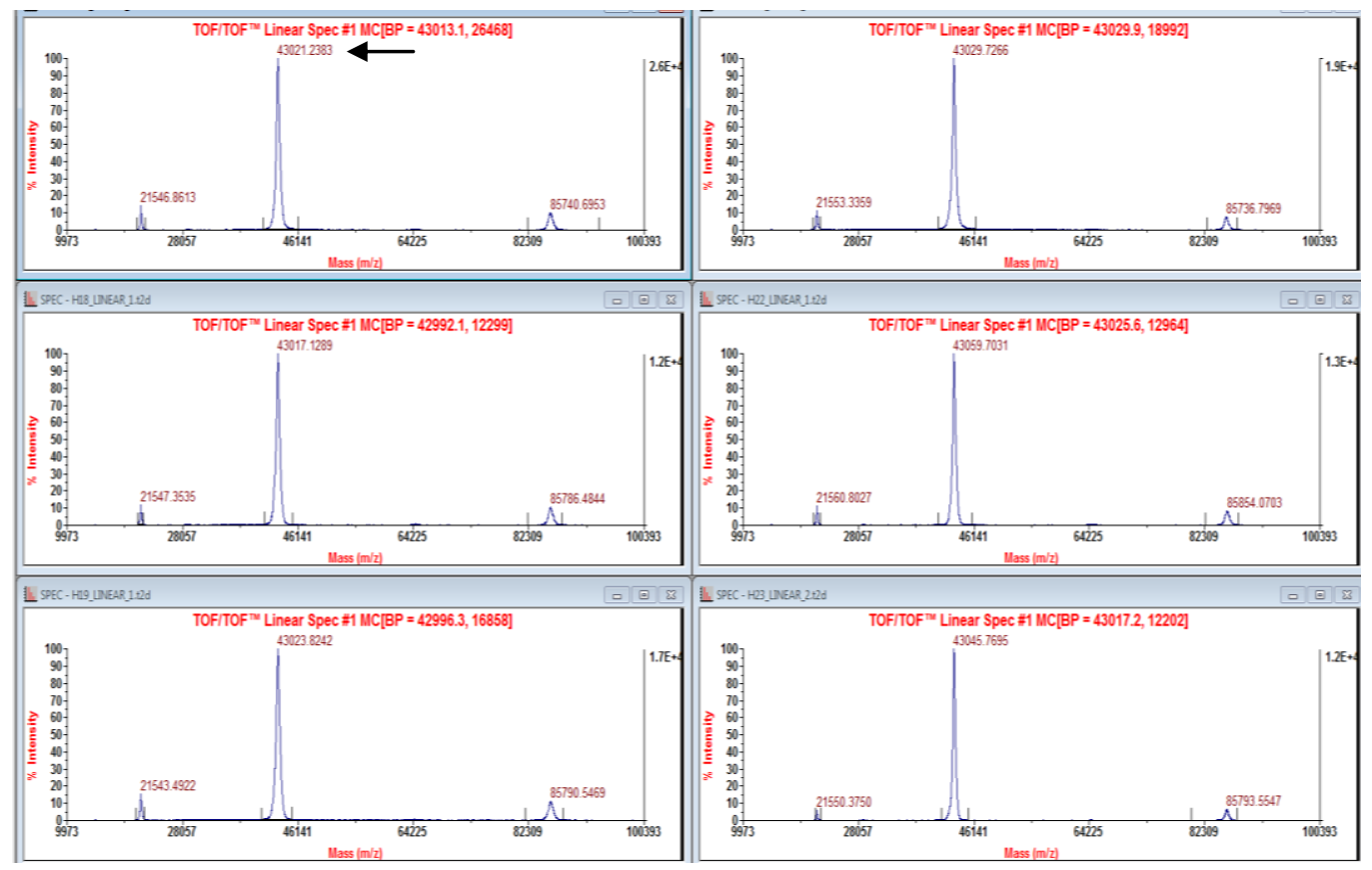

Figure 39: MALDI-TOF mass spectrometry of alkylated $\mathrm{H}_{2} \mathrm{O}_{2}$ treated CK with IAA

The spectra above show the $\mathrm{H}_{2} \mathrm{O}_{2}$ treated CK reacted with IAA and have the mean of 43,032 $\pm 17 \mathrm{~m} / \mathrm{z}$. 


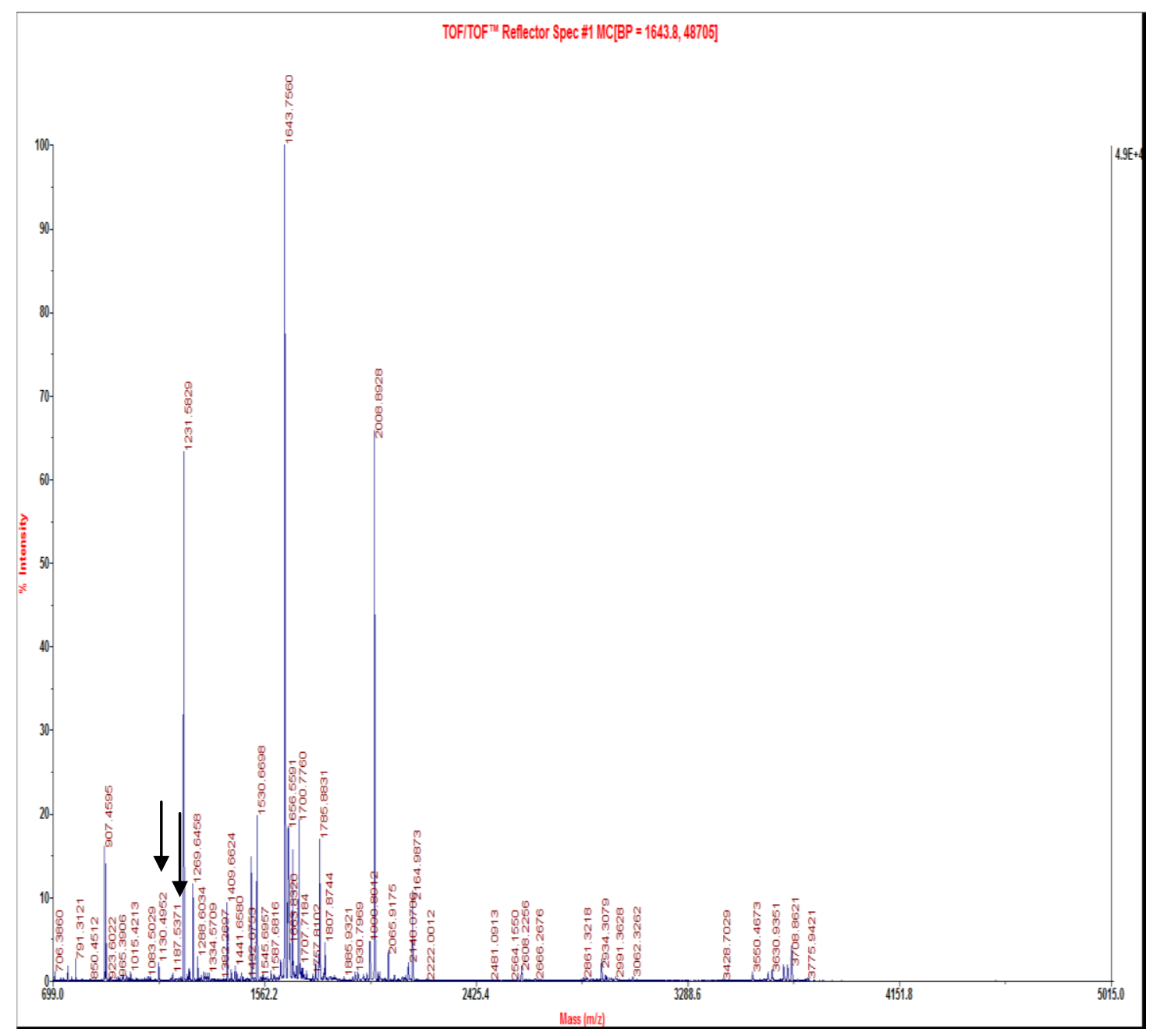

Figure 40: MALDI-TOF MS of tryptic digest of $\mathrm{H}_{2} \mathrm{O}_{2}$ treated CK reacted with IAA

The spectrum shows the $\mathrm{H}_{2} \mathrm{O}_{2}$ treated $\mathrm{CK}$ after alkylation and digesting with trypsin. Arrows indicate an $\mathrm{m} / \mathrm{z} 1130$ ion corresponding to the Cys-146 peptide and a m/z 1187 ion which is consistent with Cys-146 peptide with a mass addition of 57. 


\subsection{Summary of MS of CK}

The results showed that the reaction of CK with GTX was time dependent and after $14 \mathrm{~h}$ the mass of CK was consistent with addition of one GTX. However, the tryptic digest of GTXtreated CK showed only a minor m/z 1120 ion consistent with the Cys-254 peptide with a GTX adduct. Treatment with DTT resulted in release of protein with the mass of CK.

The results of ICAT labeling indicated that Cys- 254 was modified by exposure to GTX as it lost reactivity to ICAT labelling. The minor $\mathrm{m} / \mathrm{z} 1120$ ion that was detected in the fraction of unlabeled peptides again suggested binding of GTX to this cysteine. Additionally Cys-283 lost reactivity to ICAT but an ion corresponding to this cysteine with a possible GTX adduct was not detected. Cys-146 was accessible to reaction with ICAT both before and after exposure of CK to GTX, but the ratio of Light/Heavy was approximately 0.5 .

Reaction of $\mathrm{CK}$ with $\mathrm{H}_{2} \mathrm{O}_{2}$ was consistent with addition of two oxygen molecules to $\mathrm{CK}$. A tryptic digest of this sample indicated oxidized Cys-146 $\left(\mathrm{SO}_{2}\right.$ and $\left.\mathrm{SO}_{3}\right)$. Table 6 summarizes the masses of tryptic peptides of CK after reaction of the cys-containing peptides with GTX and $\mathrm{H}_{2} \mathrm{O}_{2}$.

\begin{tabular}{|c|c|c|c|c|c|c|c|c|c|c|}
\hline \multirow{2}{*}{\multicolumn{3}{|c|}{ Samples }} & \multicolumn{4}{|c|}{ Predicted mass } & \multicolumn{4}{|c|}{ Observed mass } \\
\hline & & & $\begin{array}{l}\text { Cys- } \\
254\end{array}$ & $\begin{array}{l}\text { Cys- } \\
146\end{array}$ & $\begin{array}{l}\text { Cys- } \\
283\end{array}$ & $\begin{array}{l}\text { Cys- } \\
74 \\
\end{array}$ & $\begin{array}{l}\text { Cys- } \\
254\end{array}$ & $\begin{array}{c}\text { Cys- } \\
146\end{array}$ & $\begin{array}{l}\text { Cys- } \\
283\end{array}$ & $\begin{array}{l}\text { Cys- } \\
74\end{array}$ \\
\hline \multicolumn{3}{|l|}{ CK } & 794 & 1130 & 2870 & 4373 & 794 & 1130 & 2870 & $4373^{*}$ \\
\hline \multicolumn{3}{|l|}{ CK + GTX } & 1120 & 1456 & 3196 & 4699 & $1120^{*}$ & - & - & - \\
\hline \multicolumn{3}{|l|}{ CK + Light ICAT } & 1021 & 1357 & 3097 & 46000 & 1021 & 1357 & $3097^{*}$ & - \\
\hline \multirow{2}{*}{$\begin{array}{l}\text { CK + GTX + } \\
\text { Heavy ICAT }\end{array}$} & \multicolumn{2}{|l|}{ Cys + GTX } & 1120 & 1456 & 3196 & 4699 & $1120 *$ & - & - & - \\
\hline & \multicolumn{2}{|c|}{ Cys + Heavy ICAT } & 1030 & 1366 & 3106 & 4609 & - & 1366 & - & - \\
\hline \multirow{3}{*}{$\mathrm{CK}+\mathrm{H}_{2} \mathrm{O}_{2}$} & \multirow{3}{*}{$\begin{array}{l}\text { Oxidized } \\
\text { Cys }\end{array}$} & SO & 810 & 1146 & 2886 & 4389 & - & - & - & - \\
\hline & & $\mathrm{SO}_{2}$ & 826 & 1162 & 2902 & 4405 & - & $1162^{*}$ & - & - \\
\hline & & $\mathrm{SO}_{3}$ & 842 & 1178 & 2918 & 4421 & - & 1178 & - & - \\
\hline
\end{tabular}

Table 6: Predicted and observed masses of cys-containing tryptic peptides. Asterisks indicate ions that have minor intensity. 


\subsection{Morphological effects of GTX on HL-60 cells}

\subsubsection{Treatment of HL-60 cells with GTX}

To examine the effects of GTX on HL-60 cells, flasks containing $9 \times 10^{6}$ cells in $10 \mathrm{~mL}$ of medium were treated with 2,10 or $50 \mu \mathrm{g}$ GTX. Control flasks contained $10 \mu \mathrm{L}$ added DMSO. Morphological changes were examined at $24 \mathrm{~h}$ after GTX treatment. Images were captured using phase contrast microscopy. Morphological changes were present in 10 and $50 \mu \mathrm{g}$ GTXtreated flasks (Fig.41). Some cells showed blebbing. The images at 10x objective (Fig. 42 A) show debris around the cells. Trypan blue exclusion (images not shown) showed cell viability after $24 \mathrm{~h}$ was $89.7 \%$ for untreated controls, $91.2 \%$ for DMSO control, $59.8 \%$ for $2 \mu \mathrm{g}$ GTXtreated, $14.5 \%$ for $10 \mu \mathrm{g}$ GTX-treated and $11.3 \%$ for $50 \mu \mathrm{g}$ GTX-treated cells respectively.

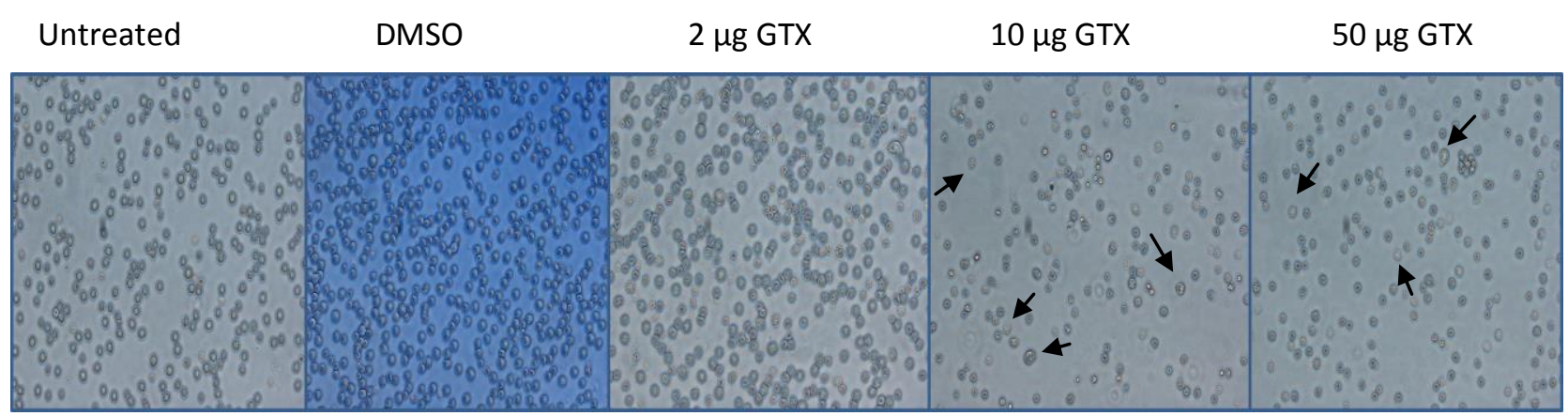

Figure 41: Cultured HL-60 cells at $24 \mathrm{~h}$ after GTX treatment

HL-60 cells $24 \mathrm{~h}$ after treatment with 2, 10 and $50 \mu \mathrm{g} \mathrm{GTX}$ at 20x magnification. Untreated and DMSO treated samples are controls. The arrows indicate cells with blebs. 
A

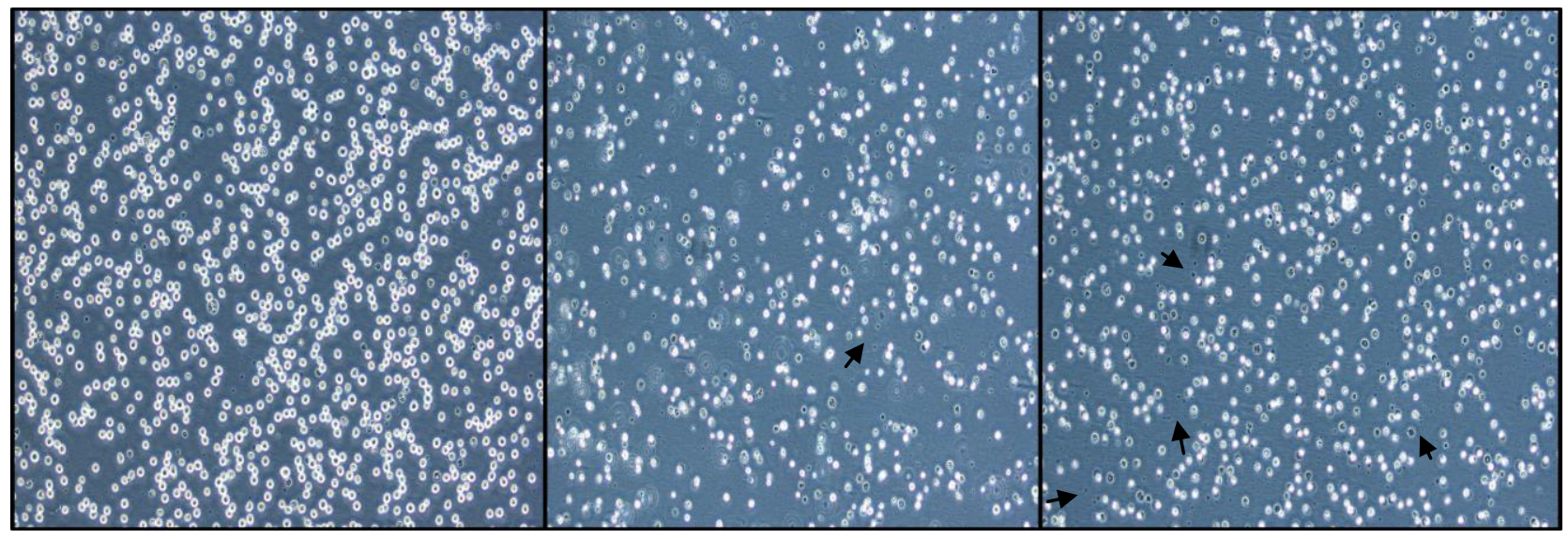

B

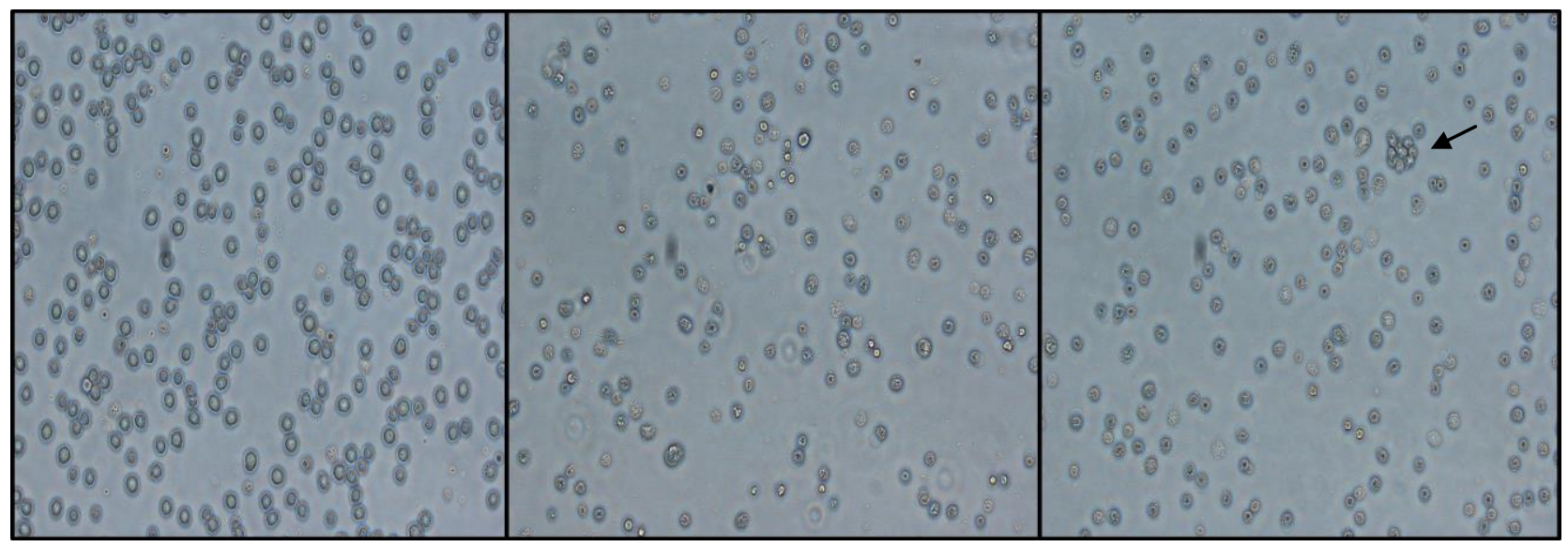

Figure 42: Cultured HL-60 cells at $24 \mathrm{~h}$ after GTX treatment

(A) HL-60 cells $24 \mathrm{~h}$ after GTX treatment, 10x magnification. The arrows show debris formed around the GTX-treated cells. (B) HL-60 cells at 20x magnification. The GTX-treated cells show changes in their shapes compared with the untreated cells. $50 \mu \mathrm{g}$ GTX sample show a clump of cells (arrow) which the results of the trypan blue test identified were dead cells. 


\subsubsection{ICAT analysis of HL-60 cells exposed to GTX}

\subsubsection{MALDI MS}

A preliminary examination of ICAT labeling of HL-60 cells was carried out to investigate the potential for detection of protein modification by GTX. The proteins of $10 \mu \mathrm{g}$ GTX-treated and untreated HL-60 cells were extracted and labeled with Heavy and Light ICAT reagents respectively using the methods described in Section 2.2.5. Although there were major change in cell viability at this concentration of GTX it was expected that changes in protein modification would be great enough for detection.

Fig. 43 shows MALDI mass spectrometry of the ICAT labeled samples. The spectrum contains potential ICAT pairs of peptides with 9 Da differences. From this preliminary data it is not possible to estimate the differences in ion intensity that reflect significant differences in Light and Heavy ICAT labeling but Light/Heavy ratio $>2$ may reflect modification of cysteine after exposure of CK to GTX. Potential ICAT pairs were 704.3/713.3, 725.4/734.4, 742.4/751.4, 881.4/890.4, 932.5/941.5, 964.4/973.4, 984.4/993.4, 1006.4/1015.4. Additionally other major ions may be cys peptides labeled only with Light ICAT. If Heavy ICAT is greater abundance, it is possible that reduced GTX in cells has reacted with protein disulfides resulting in adducted proteins with the second cysteine of the disulfide being exposed to reaction with ICAT reagent. The MS/MS spectra of ICAT pairs were searched using de novo Sequencing Assisted Database Search (Zhang et al., 2011) in PEAKS software to find the sequences of the potential ICAT-labeled peptides. The derived sequences for most of the potential ICAT pairs contained cys residues (Appendix C) but without ICAT mass tags. Further analysis of the MS/MS ions would be necessary to confirm the identity of these peptides. 


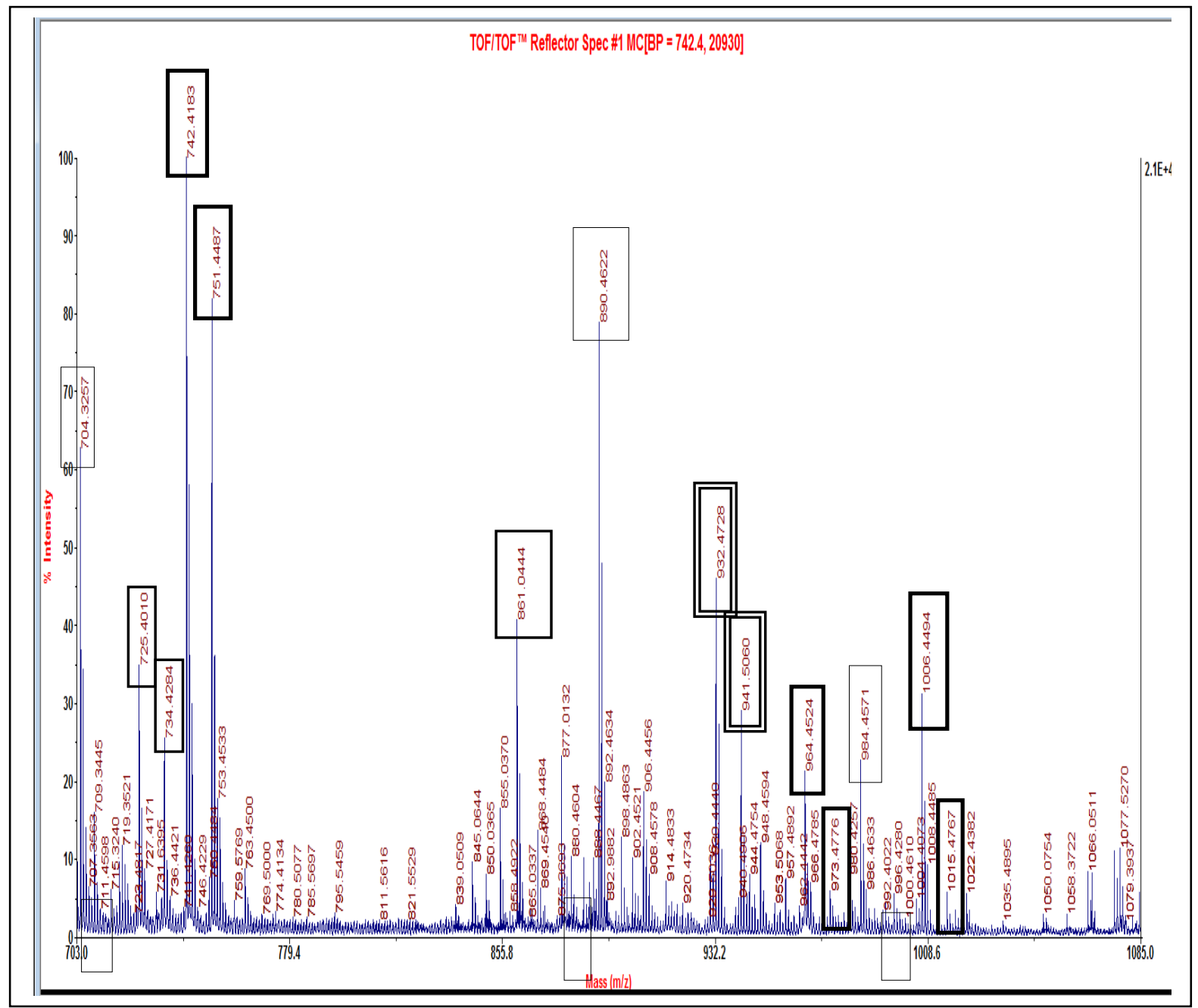

Figure 43: MALDI-TOF MS of tryptic digest of a mixture of Light ICAT-labeled untreated HL60 cells plus Heavy ICAT-labeled GTX-treated HL-60 cells

The spectra show the Light and Heavy ICAT-labeled peptides of HL-60 cells. The boxed masses correspond to potential ICAT pairs with 9 Da differences. Each ICAT pair has been shown with different shaped boxes. 


\section{Discussion}

GTX is an ETP toxin and redox active molecule that can form mixed disulfides with accessible thiol groups on target proteins and/or oxidize thiol groups of proteins (Waring et al., 1995). In this project, CK from rabbit muscle was used as an experimental model, followed by preliminary examination of the effects of GTX on HL-60 cells. The first experimental strategy was use of MS to investigate modification of CK after exposure to GTX. This was done by analysis of changes in the mass of $\mathrm{CK}$, and by examination of the masses of tryptic digests of CK to determine which cysteines were modified and whether mass changes were consistent with formation of GTX adducts or oxidation of cysteines. One complicating factor was that Srinivasan et al. (2006) found that although ETPs including GTX formed mixed disulfide adducts with the protein glutaredoxin, the adducts could not be detected after tryptic digestion of the peptides. They suggested that stability of the mixed disulfides was dependent on the conformation of the intact protein.

CK is a non-covalently bound dimer which contains two identical monomers which separate as monomers in the mass spectrometer. CK contains four cysteine residues (Cys-283, Cys254, Cys-146, and Cys-74) for each of its monomers. Hurne et al. (2000) proposed that GTX interaction with CK includes mixed disulfide formation between GTX and Cys-283 residue of CK and/or that reaction leads to oxidation of CK. Schematics for these reactions are shown in Figs. 2 and 5.

The spectra of native CK (Fig. 9) showed the expected $1^{+}(\mathrm{M}+1)$ ion with a mean of $42,944 \pm$ $24 \mathrm{Da}$ which was consistent with the theoretical mass of CK when the $\mathrm{N}$-terminal methionine is removed. Fig. 10 shows a tryptic digest of CK that contains ions at $\mathrm{m} / \mathrm{z} 794.43$, 1130.55, 2870.37, and $\mathrm{m} / \mathrm{z} 4372.92$ that are consistent with the four cys-containing peptides (Cys-254, 146, 283, and 74). This spectrum also contains ions (asterisked) that are consistent with the non-cys tryptic peptides of CK. Table 1 summarizes the cys-containing tryptic peptides that match the predicted masses.

Mass spectrometry was also used to examine the reactions of CK. IAA is an alkylating agent that reacts with accessible cysteine residues to form carbamidomethyl-cysteine with consequent mass addition of 57 for each alkylated cysteine (Tables 2 and 3). Cys-containing 
peptides are usually detected more efficiently by MALDI MS after alkylation. ICAT reagents also contain an IAA moiety that can bind to reactive cysteine residues in proteins. Although the increase in mass of CK after reaction with IAA (Fig. 12) indicted reaction equivalent to one cysteine for each CK molecule, analysis of the tryptic digests indicated reaction with Cys-254, 146, and 283. An ion at m/z 1130 corresponding to unmodified Cys-146 was also detected, suggesting partial reaction of this cysteine. Alkylation of the multiple cyscontaining peptides may have been due to continuation of alkylation during the tryptic digestion. The initial conclusions were that Cys-254 and 283 were more reactive to alkylation than Cys-146.

In a subsequent experiment CK was reduced with DTT and then reacted with IAA. DTT reduces disulfide bonds and facilitates reaction of IAA to thiol groups of cysteine residues. After reduction, reaction with IAA was consistent with the alkylation of three to four cysteines of CK (Fig. 14). A tryptic digest of this sample (Fig. 15) contained Cys-254, 146, and 283 peptides with a mass addition of $57 \mathrm{Da}$. An ion at $\mathrm{m} / \mathrm{z} 1130$ corresponding to the unmodified Cys-146 peptide indicated the partial reaction of this cysteine with IAA.

ETP fungal toxins such as GTX disrupt cellular functions through reaction with cysteine residues of target proteins (Waring et al., 1995). The toxicity of GTX is dependent on its disulfide bond (Fig. 1) that is highly reactive and essential for its activity (Srinivasan et al., 2006). The possibility of formation of a mixed disulfide between GTX and cysteine residues of CK was therefore examined. Formation of a single mixed disulfide adduct of GTX with CK was predicted to result in a mass addition of 326.4 (Table 2).

As shown in Fig. 17 CK did not show modification by GTX after $2 \mathrm{~h}$ reaction, but after $14 \mathrm{~h}$ reaction (Fig. 18) there was a mass increase consistent with addition of GTX. Hurne et al. (2000) previously showed time-dependent reaction and that $6 \mathrm{~h}$ incubation of CK with 0.1 mM GTX resulted in $80 \%$ inactivation of $\mathrm{CK}$.

However, analysis of the tryptic peptides after reaction of CK with GTX showed only a minor ion at $\mathrm{m} / \mathrm{z} 1120$ consistent with formation of a mixed disulfide with the Cys-254 peptide (Figs. 20, 21). An ion at $\mathrm{m} / \mathrm{z} 1162.5$ was consistent with an oxidized Cys-146 $\left(\mathrm{SO}_{2}\right)$ peptide. lons corresponding to unmodified Cys-146 and 283 peptides were also present in the spectrum. One explanation for lack of detection of major GTX-peptide products might be 
due to poor ionization of such peptides in the MALDI. Alternatively as suggested by Srinivasan et al. (2006) the GTX adducts may be unstable in the tryptic digests. Srinivasan et al. (2006) showed that at least four of the five cysteines of glutaredoxin were involved in inactivation of this enzyme by sporidesmin or GTX and although an adduct was formed it could not be detected in the tryptic digests.

Hurne et al. (2000) reported that treatment of CK that was inactivated by GTX with reducing agents such as DTT or glutathione resulted in the restoration of CK activity. The spectrum in Fig. 23 indicates that the modification of CK by GTX was reversible after addition of DTT and shows the expected $43 \mathrm{kDa}$ mass of CK. In the tryptic digests (Fig. 24) there was no evidence of the $\mathrm{m} / \mathrm{z} 1120$ ion corresponding to the possible GTX-modified Cys-254 peptide. However, although the Cys-146 peptide was detected, other cys-containing peptides were not present. The typtic digest of this sample differed from the digest of CK indicating that there may have been other modifications. Apparent addition of two oxygens (+ 32) to the Cys-146 peptide ( $\mathrm{m} / \mathrm{z} 1162.5)$ was detected with GTX. This mass addition was lost after reduction of modified CK with DTT. DTT typically reduces cysteine sulfenic but not sulfinic acids, and as there is only a single cysteine in the sequence (GYTLPPHCSR) oxidation of other amino acids, possibly including histidine (Ji, Zhang, Cheng \& Wang, 2009), should be considered.

To ascertain the involvement of thiol groups in the reaction of CK with GTX, the GTX-treated CK was alkylated with IAA. It was expected that cysteines modified by GTX would no longer be accessible to alkylation with IAA. The spectra in Fig. 25 show a mean mass of $43,057 \pm 4$ $\mathrm{Da}$, which is less than the mass of GTX-treated CK prior to reaction with IAA. It appears that $\mathrm{m} / \mathrm{z} 43,057$ is consistent with the presence of GTX-free CK with alkylation of two cysteines. Srinivasan et al. (2006) have suggested that the loss of cysteine reactivity might be due to elimination of sulfur from cysteine adducts, conformational inaccessibility or sulfur oxygenation. The tryptic digest of alkylated GTX- treated CK contained ions consistent with Cys-146 and 283 peptides with a mass addition of 57 suggesting that these cysteines were not extensively modified by reaction with GTX (Fig. 26).

Modification of $\mathrm{CK}$ thiols was also examined using $\mathrm{H}_{2} \mathrm{O}_{2}$ that may oxidize cysteines to form sulfenic $\left(\mathrm{CH}_{2} \mathrm{SO}\right)$, sulfinic $\left(\mathrm{CH}_{2} \mathrm{SO}_{2}\right)$, or sulfonic $\left(\mathrm{CH}_{2} \mathrm{SO}_{3}\right)$ acids or promote formation of disulfide bonds. Sethuraman et al. (2004) using an ICAT application reported that Cys-283, 
but not Cys-146 was sensitive to oxidation by $1 \mathrm{mM} \mathrm{H}_{2} \mathrm{O}_{2}$. The MALDI spectra of CK reacted with $\mathrm{H}_{2} \mathrm{O}_{2}$ (Fig. 27) indicate a mean mass of $43,020 \pm 9$ suggesting addition of two oxygen molecules. The tryptic digest (Fig. 28) indicated complete loss of the Cys-283 peptide (loss of 2870.4) without evidence of the expected products of cys oxidation. There was possible evidence of the oxidation of Cys-146 from the presence of $\mathrm{m} / \mathrm{z} 1178.5\left(\mathrm{SO}_{3}\right)$ and $\mathrm{m} / \mathrm{z} 1162.5$ $\left(\mathrm{SO}_{2}\right)$ ions, although the ion corresponding to unmodified Cys-146 peptide was also present indicating the partial reaction of this cysteine.

To further investigate the reactions of CK, ICAT was used to measure the relative abundance of cysteines. The ICAT strategy is based on reaction with cysteine thiol groups in proteins, followed by mixing the tagged proteins and enzymatic digestion, and subsequent quantitative analysis of the ICAT-labeled peptides using mass spectrometry (Turecek, 2002). Native CK labeled with Light ICAT reagent (Fig. 29) showed modification of all four cysteines. The spectra indicate the presence of CK and additional 1-4 ICAT residues with greatest abundance of the maximally labeled species. The tryptic digest (Figs. 30, 31) confirmed ICAT labeling of cys-containing peptides, although labeling of Cys-74 was not seen as the mass was beyond the range of detection using CHCA matrix. The presence of the unlabeled Cys146 in the spectrum suggests only partial labeling of this cysteine. The Cys-74 peptide also has a C-terminal lysine which generally gives a weaker MALDI signal than arginine containing peptides. The ICAT reagent showed more reactivity with cysteine residues than had been detected with IAA.

In order to examine which cysteines of CK were modified by GTX, the GTX-treated CK was also labeled with Light ICAT reagent. As ICAT labels free cysteines, it was predicted that cysteines modified by GTX would lose labeling. The spectra shown in Fig. 32 show a mean mass of $43,145 \pm 23$ which indicates that ICAT had not labeled the cysteine residues. However, this mass was less than the mass of GTX-treated CK before reacting with ICAT, indicating an unexpected mass loss.

The next experiment was performed to quantify free cysteines in CK and GTX-treated CK in the same spectrum. CK exposed to GTX was labeled with Heavy ICAT $\left(9 \times{ }^{13} \mathrm{C}\right)$ and the control CK was labeled with Light ICAT $\left(9 \times{ }^{12} \mathrm{C}\right)$. After digestion with trypsin, the trypsinized unlabeled peptides were washed from the avidin cartridge and the ICAT-labeled peptides 
eluted and analyzed in the MALDI mass spectrometer (Figs. 33-36). Hurne et al. (2000) suggested that Cys-74, 146 and 254 require denaturation of CK to be accessible for labeling by radiolabeled GTX but Cys-283 is reactive without denaturation. Cysteines that were unmodified after reaction with GTX should give similar intensity Light and Heavy ICAT ions separated by 9 mass units in the spectrum. Loss of Heavy ICAT labeling is expected for cysteines that had been modified in the prior reaction of CK with GTX.

The ICAT analysis (Fig. 33) showed that Cys-254 only had Light ICAT label (Fig. 34) indicating modification of this cysteine after reaction with GTX.

The Cys-146 peptide had both Light (1357.5) and Heavy (1366.6) labels with the predicted mass difference of $9 \mathrm{Da}$ (Fig. 35), although the ratio of Light/Heavy was approximately 0.5. In addition, an $\mathrm{m} / \mathrm{z} 1130$ ion corresponding to unmodified Cys-146 peptide was present in the spectrum (Fig. 33) suggesting that Cys-146 peptide remained unmodified by GTX and was less reactive with ICAT. The ICAT-labeled peptides corresponding to Cys-146 gave relatively intense signals possibly because arginine-terminated peptides ionize well during MALDI MS.

The Cys-283 peptide ion showed only Light label indicating that this cysteine had been modified during reaction with GTX. However, ions corresponding to the Cys-283 with a possible GTX adduct, or with a GTX plus Heavy ICAT label, were not detected. In addition to possible modifications already discussed, formation of an internal disulfide between Cys-283 and 74 as proposed by Hurne et al. (2000) would result in loss of reactivity with ICAT reagents.

No peptides corresponding to the Cys-74 peptide with Light or Heavy ICAT were detected. The larger mass of this peptide is not compatible with analysis using CHCA matrix. Hurne et al. (2000) suggested that the intramolecular disulfide bond is formed between Cys-283 and Cys-74 in CK, which are in close proximity (Fig. 4) therefore, it is important to know the status of Cys-74 peptide.

These results are reasonably consistent with those obtained by Hurne et al. (2000) using CK treated with radiolabeled $\left[{ }^{35} \mathrm{~S}\right] \mathrm{GTX}$. The obtained peptide fragments showed that $\left[{ }^{35} \mathrm{~S}\right] \mathrm{GTX}$ reacted with Cys-254 and in lesser amounts with Cys-283, possibly due to rapid conversion 
of Cys-283 adduct to a CK intramolecular disulfide (Fig. 5). There was no evidence of labeled Cys-74 or Cys-146.

My result that Cys-146 was apparently most susceptible to oxidation was not consistent with results obtained by Sethuraman et al. (2004) who used ICAT to identify CK thiols sensitive to oxidation by $\mathrm{H}_{2} \mathrm{O}_{2}$ and showed that Cys-283 but not Cys-146 was oxidant sensitive. One difference was that Sethuraman et al. (2004) used capillary high-performance liquid chromatography for peptide separation prior to electrospray MS/MS of the tryptic ICAT mixtures. A comparison of CK peptides using MALDI and electrospray ionization might be useful as same peptides are better suited to detection using one or the other technique.

A preliminary examination of the use of ICAT to analyze the effects of GTX on HL-60 cells in culture was also carried out. HL-60 cells proliferate continuously in liquid suspension culture with a doubling time of about 36 to 48 hours. Light ICAT labeling of control cells, and Heavy ICAT labeling of GTX-treated cells was done after $24 \mathrm{~h}$ incubation with $10 \mu \mathrm{g} / \mathrm{mL}$ GTX. Then was substantial cell injury at this time.

Fig. 43 shows the spectrum of ICAT-labeled HL-60 cell proteins. The MS/MS spectra of potential ICAT pairs were analyzed with PEAKS de novo sequencing software to find the sequences of the ICAT-labeled peptides. Although potential pairs of ICAT peptides were detected in the MALDI MS/MS spectra ICAT tagged sequences were not predicted using PEAKS. The results therefore indicate both the potential of ICAT labeling and the need for chromatographic separation of peptides before MS/MS. This could be done using either the TEMPO MALDI spotter for high performance liquid chromatographic separation of peptides prior to MS/MS or by using on-line chromatography of the tryptic peptides into an electrospray ionization mass spectrometric. Chromatographic separation of peptides is the commonly used strategy for ICAT as many more peptides are detected in sufficient abundance for MS/MS based sequence analysis.

In summary the results of analysis of CK showed that the ICAT strategy was effective for detection of cysteine modification, although it was not possible to completely characterize of mechanisms of cysteine modification from the MALDI spectra. The potential ICAT pairs identified in HL-60 cell spectra can be further studied including quantitative analysis that 
would provide information about the relative abundance of free thiols and detection of the proteins modified by GTX. 


\subsection{Conclusions and future prospects}

In conclusion, the purpose of this project was to develop mass spectrometry methods to examine the reactions of GTX with protein cysteines. Reaction of CK with GTX suggested mass addition consistent with formation of an adduct although the expected products could not be detected in the tryptic digests. Srinivasan et al. (2006) previously suggested that the stability of ETP-protein mixed disulfides was dependent on the conformation of the intact protein. ICAT appeared to be more effective than IAA for reaction with CK cysteines, and was useful for detection of modified cysteines through the loss of reactivity with ICAT reagents. Although modification of CK by GTX appeared to be complex change was detected using ICAT, and potential ICAT pairs were detected in HL-60 cells exposed to the toxin. There is therefore good potential to apply ICAT for detection of proteins whose cysteine residues are modified by GTX or other ETPs. Such studies should be useful in probing the cellular toxicity of these compounds. 


\section{References}

Applied Biosystems handbook for methods of ICAT reagents.

Aebersold, R., \& Mann, M. (2003). Mass spectrometry-based proteomics. Nature, 422, 198207.

Ashcroft, A. E. (2003). Protein and peptide identification: the role of mass spectrometry in proteomics. Natural Product Reports, 20, 202-2015.

Balibar, C. J., \& Walsh, C. T. (2006). Glip, a multimodular nonribosomal peptide synthetase in Aspergillus fumigatus, makes the diketopiperazine scaffold of gliotoxin. Biochemistry, 45, 15029-15038.

Baust, H., Schoke, A., Brey, A., Gern, U., Los, M., Schmid, R. M., Rottinger, E. M., \& Seufferlein, T. (2003). Evidence for radiosensitizing by gliotoxin in HL-60 cells: implications for a role of NF-KB independent mechanisms. Oncogene, 22, 8786-8796.

Bernardo, P. H., Brasch, N., Chai, C. L. L., \& Waring, P. (2003). A novel redox mechanism for the glutathione-dependent reversible uptake of a fungal toxin in cells. The Journal of Biological Chemistry, 47, 46549-46555.

Biswas, S., Chida, A. S., \& Rahman, I. (2006). Redox modifications of protein-thiols: Emerging rols in cell signaling. Biochemical Pharmocology, 71, 551-564.

Bok, J. W., Chung, D., Balajee, S. A., Marr, K. A., Andes, D., Nielsen, K. F., Frisvad, J. C., Kirby, K.A., \& Keller, N. P. (2006). Gliz, a transcriptional regulator of gliotoxin biosynthesis, contributes to Aspergillus fumigates virulence. Infection and Immunity, 74, 6761-6768.

Cantwell, J. S., Novak, W. R., Wang, P. F., McLeish, M. J., Kenyon, G. L., \& Babiitt, P. C. (2001). Mutagenesis of two acidic site residues in human muscle creatine kinase: implications for the catalytic mechanism. Biochemistry, 40, 3056-3061.

Chai, C. L., Waring, P. (2000). Redox sensitive epidithiodioxopiperazines in biological mechanisms of toxicity. Redox Report, 5, 257-264.

Choi, H. S., Shim, J. S. Kim, J. A., Kang, S. W., \& Kwon, H. J. (2007). Discovery of gliotoxin as a new small molecule targeting thioredoxin redox system. Biochemical and Biophysical Research Communications, 359, 523-528.

Cramer, R. A., Gamcsik, M. P., Brooking, R. M., Najvar, L. K., Kirkpatrick, W. R., Patterson, T. F., Balibar, C. J., Graybill, J. R., Perfect, J. R., Abraham, S. N., \& Steinbach, W.J. (2006). Disruption of a nonribosomal peptide synthetase in Aspergillus fumigatus eliminates gliotoxin production. Eukaryotic Cell, 5, 972-980. 
Fox, E. M., \& Howlett, B. J. (2008). Biosynthetic gene clusters for epipolythiodioxopiperazines in filamentous fungi. Mycological Research, 112, 162-169.

Fridrichsons, J., \& Mathieson, A. M. (1967). The crystal structure of gliotoxin. Acta Cryst. 23, 439- 448.

Fu, C., Hu, J., Liu, T., Ago, T., Sadoshima, J., \& Li, H. (2008). Quantitative analysis of redoxsensitive proteome with DIGE and ICAT. Journal of Proteome Research, 7, 3789-3802.

Fukuyama, T., Nakatsuka, S. H., Kishi, Y. (1981). Total synthesis of gliotoxin dehydrogliotoxin and hyalodendrin. Tetrahedron (2045-2078). Cambridge, MA., US: Pergamon Press Ltd.

Gardiner, D. M., Waring, P., \& Howlett, B. J. (2005). The epipolythiodioxopiperaz ine (ETP) class of fugal toxins: distribution, mode of action, functions and biosynthesis. Microbiology, 151, 1021-1032.

Grovel, O., Kerzaon, I., Petit, K., Pont, T. R. D., \& Pouchus, Y. F. (2006). A new and rapid bioassay for the detection of gliotoxin and related epipolythiodioxopiperazines produced by fungi. Journal of Microbiological Methods, 66, 286-293.

Hood, B. L., Veenstra.T.D., Conrads.T.P. (2004). Mass spectrometry-based proteomics. International Congress Series 1266 (pp. 375-380). Frederick, MD., USA: Elsevier B.V.

Hou, L. X., \& Zhou, J. X. (1996). Creatine Kinase: The characteristics of the enzyme regenerated from the thio-methylated creatine kinase reflect a differentiation in function between the two reactive thiols. Biochimie, 78, 219-226.

Hsu, J. L., \& Chen, S. H. (2005). Recent progress in quantitative proteomics using stable isotope labeling, multidimensional liquid chromatography and mass spectrometry. Current Proteomics, 2, 287-302.

Hur, J. M., Yun, H. J., Yang, S. H., Lee, W. Y., Joe, M. H., \& Kim, D. (2008). Gliotoxin enhances radiotherapy via Inhibition of radiation-induced GADD45a, P38, NFkB activation. Journal of Cellular Biochemistry, 104, 2174-2184.

Hurne, A. M., Chais, C.L.L., \& Waring, P. (2000). Inactivation of rabbit muscle creatine kinase by reversible formation of an internal disulfide bond by the fungal toxin gliotoxin. The Journal of Biological Chemistry. 275, 25202-25206.

Ji, J. A., Zhang, B., Cheng, W., Wang, Y. J., (2009). Methionine, tryptophan, and histidine oxidation in a model protein, PTH: mechanisms and stabilization. Journal of Pharmaceutical Sciences, 98, 4485-4500.

Jones, R. W, \& Hancock, J. G. (1988). Mechanism of gliotoxin action and factors mediating gliotoxin sensitivity. Journal of General Microbiology, 134, 2067-2075.

Jordan, T. W., \& Cordiner, S. J. (1987). Fungal epipolythiodioxopiperazine toxins have therapeutic potentioal and roles in disease. Trends in Pharmacological Sciences, 8, 144-149. 
Jordan, T. W., \& Pedersen, J. S. (1986). Sporidesmin and Gliotoxin Induce Cell Detachment and Perturb Microfilament Structure in Cultured Liver Cells. J. Cell Sci, 85, 33-46.

Lin, K. T., Xue, J. Y., Lin, M. C., Spokas, E. G., Sun, F. F., \& Wong, P. Y. k. (1988). Peroxynitrite induces apoptosis of HL-60 cells byactivation of a caspase-3 family protease. Am J Physiol Cell Physiol 274, C855-C860.

Mann, M., \& Kelleher, N. L. (2008). Precision proteomics: The case for high resolution and high mass accuracy. Proc Natl Acad Sci U S A, 1-7.

Miller, P.A., Milstrey, K.P., \&Trown, P.W. (1968). Specific inhibition of viral ribonucleic acid replication by Gliotoxin. Science, 159, 431-432.

Mullbacher, A., \& Eichner, R. D. (1984). Immunosuppression in vitro by a metabolite of a human pathogenic fungus. Proc Natl Acad Sci U S A, 81, 3835-3837.

Munday, R. (1989). Toxicity of thiols and disulphides: involvement of free-radical species. Free Radical Biology and Medicine, 7, 659-673.

Orr, J.G., Leel, V., Cameron, G.A., Marek, C.J., Haughton, E.L., Elrick, L.J., Trim, J.E., Hawksworth, G.M., Halestrap, A.P., \& Wright, M.C. (2004). Mechanism of action of the antifibrogenic compound gliotoxin in rat liver cells. Hepatology, 40, 232-242.

Page, M. J., Griffiths, T. A.M., Bleackley, M.R., \& MacGillivray, R. T. A. (2006) Proteomics: applications relevant to transfusion medicine. Transfusion Medicine Reviews, 20, 63-74.

Pahl, H. L., Krau, B. B., Schulze-Osthoff, K., Decker, T., Traenckner, E. B. M., Vogt, M., Myers, C., Parks. T., Warring. P., Mühlbacher. A., Czernilofsky, A. P., \& Baeuerle, P. A. (1996). The immunosuppressive fungal metabolite gliotoxin specifically inhibits transcription factor NFkB. J Exp Med. 183, 1829-1840.

Pan, S., Aebersold, R., Chen, R., Rush, J., Goodlett, D.R., Mcintosh, M. W., Zhang, J., \& Brentnall, T. A. (2009). Mass spectrometry based targeted protein quantification: methods and applications. Journal of Proteome Research, 8, 787-797.

Price, N.C., Hunter, M.G. (1976). Non-identical behaviour of the subunits of rabbit muscle creatine kinas. Biochimica et Biophysica Acta (BBA)-Enzymology, 445, 364-376.

Rao. J. K. M., Bujacz, G., \& Wlodawer, A. (1998). Crystal structure of rabbit muscle creatine kinase. FEBS Letters, 439, 133-137.

Reeves, E. P., Murphy, T., Daly, P., \& Kavanagh, K. (2004). Amphotericin B enhances the synthesis and release of the immunosuppressive agent gliotoxin from the pulmonary pathogen Aspergiluus fumigates. Journal of Medical Microbiology, 53, 719-725. 
Rementeria, A., Molina, N. L., Ludwig, A., Vivanco, A. B., Bikandi, J., Poton, J., \& Garaizar, J. (2005). Genes and molecules involved in Aspergillus fumigates virulence. Rev Iberoam Micol, 22, 1-23.

Rezanka, T., Sobotka, M., Spizek. J., \& Sigler, K. (2006). Pharmacologically active sulfurcontaining compounds. Anti-Infective Agents Medicinal Chemistry, 5, 187-224.

Schrettl, M., Carberry, S., Kavanagh, K., Haas, H., Jones, G.W., O'Brien, J., Nolan, A., Stephens, J., Fenelon, O., \& Doyle, S. (2010). Self-protection against gliotoxin--a component of the gliotoxin biosynthetic cluster, GliT, completely protects Aspergillus fumigates against exogenous gliotoxin. PLoS Pathog. 6, 1-15.

Sethuraman, M., McCombs, M. E., Heibeck, T., Costellos, C. E., \& Cohen, R. A. (2004). Isotope-coded affinity tag approach to indentify and quantify oxidant-sensitive protein thiols. Molecular and Cellular Proteomics, 3, 273-278.

Siepen, J. A., Keevil, E. J., Knight, D., \& Hubbard, S. J. (2007). Prediction of missed cleavage sited in tryptic peptides aids protein identification in proteomics. Journal of Proteome Research, 6, 399-408.

Srinivasan, U., Bala, S., Jao, S. C., Starke, D. W., Jordan, T. W., \& Mieyal, J.J. (2006). Selective inactivation of glutaredoxin by sporidesmin and other epidithiopiperazinediones. Biochemistry, 45, 8978-8987.

Stack, D., Neville, C., \& Doyle, S. (2007).Nonribosomal peptide synthesis in Aspergillus fumigatus. Microbiology, 153, 1297-1306.

Stanzani, M., Orciuolo, E., Lewis, R., Kontoyannis, D. P., Martins, S. L. R., John, L. S. S., \& Komanduri, K. V. (2005). Aspergillus fumigauts suppresses the human cellular immune response via gliotoxin-mediated apoptosis of monocytes. Blood, 105, 2258-2265.

Turecek, F. (2002). Mass spectrometry in coupling with affinity capture-release and isotopecoded affinity tags for quantitative protein analysis. Journal of Mass Spectrometry. 37, 1-14.

Vanlaere, E., Segeant, K., Dawyndt, P., Kallow, W., Erhard, M., Sutton, H., Dare, D.,Devreese, B., Samyn, B., \& Vandamme, P. (2008). Matrix-assisted laser desorption-time-of-flight mass spectrometry of intact cells allows rapid identification of Burkholdera cepacia complex. Journal of Microbiological Methods, 75, 279-286.

Waring, P., Eichner, R. D., Mullbacher, A., \& Sjaarda, A. (1988). Gliotoxin induces apoptosis in macrophages unrelated to its antiphagocytic properties. The Journal of Biological Chemistry, 263, 18493-18499.

Waring, P., Eichner, R. D., \&Mullbacher, A. (1988). The chemistry and biology of the immunomodulating agent gliotoxin and related epipolythiodioxopiperazines. Medical Research Review, 8, 499-524. 
Waring, P., Sjaarda, A., \& Lin, Q. H. (1995). Gliotoxin inactivates alcohol dehydrogenase by either covalent modification or free radical damage mediated by redox cycling. Biochemical Pharmacology, 47, 1195-1201.

Wu, C.L., Li, Y. H., Lin, H. C., Yeh, Y. H., Yan, H. Y., Hsiao, C. D., Hui, C. F. \& Wu, J. L. (2011). Activity and function of rabbit muscle-specific creatine kinase at low temperature by mutation at gly $\mathrm{y}^{268}$ to asn ${ }^{268}$. Comparative Biochemistry and Physiology, 158. 189-198.

Yamada, A., Kataoka, T., \& Nagai, K. (2000). The Fungal metabolite gliotoxin: immunosuppressive activity on CTL-mediated cytotoxicity. Immunology Letters, 71, 27-32.

Zhang, J., Xin, L., Shan, B., Chen, W., Xie, M., Yuen, D., Zhang, W., Zhang, Z., Lajoie, G., \& Ma, B. (2011). PEAKS DB: de novo sequencing assisted database search for sensitive and accurate peptide itdentification. Molecular \& Cellular Proteomics 10.1074/mcp.M111.010587.

Zhao, T. J., Yan, Y. B., Liu, Y., \& Zhou, H. M. (2007). The generation of the oxidized form of cratine kinase is a negative regulation on muscle creatine kinase. Journal of Biological Chemistry, 283, 12022-12029. 


\section{Appendix A. Exclusion list for MALDI TOF/TOF MS/MS}

\begin{tabular}{|l|l|}
\hline Mass (Da) & Tolerance \\
\hline 2465.19 & 0.03 \\
\hline 861.60 & 0.10 \\
\hline 877.000 & 0.10 \\
\hline 906.505 & 0.03 \\
\hline 1020.503 & 0.03 \\
\hline 1153.574 & 0.03 \\
\hline 1175.523 & 0.03 \\
\hline 1433.721 & 0.03 \\
\hline 1493.599 & 0.03 \\
\hline 1676.777 & 0.03 \\
\hline 1774.851 & 0.03 \\
\hline 2163.057 & 0.03 \\
\hline 2193.003 & 0.03 \\
\hline 2193.995 & 0.03 \\
\hline 2273.160 & 0.03 \\
\hline 2289.155 & 0.03 \\
\hline 2305.150 & 0.03 \\
\hline 2514.339 & 0.03 \\
\hline 2550.233 & 0.03 \\
\hline 2552.249 & 0.03 \\
\hline 2612.181 & 0.03 \\
\hline 2613.350 & 0.03 \\
\hline 3211.475 & 0.03 \\
\hline 3227.470 & 0.03 \\
\hline 805.417 & 0.03 \\
\hline 659.384 & 0.03 \\
\hline & \\
\hline & \\
\hline & \\
\hline
\end{tabular}

These ions which are ubiquitously present in all spectra include matrix ions and autodigestion products of trypsin. 


\section{Appendix B. Predicted tryptic peptides of creatine kinase.}

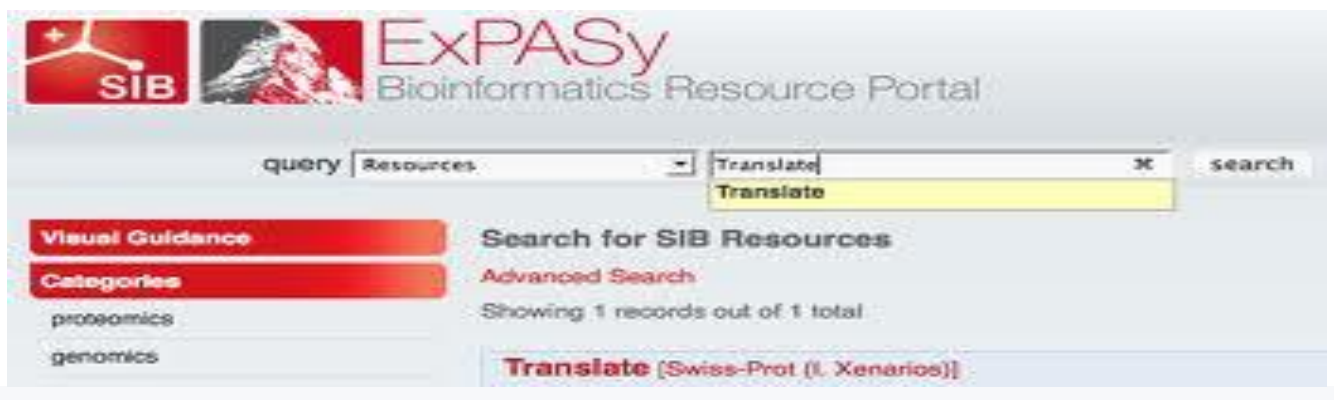

\section{PeptideMass}

The entered protein is: P00563

The selected enzyme is: Trypsin

Maximum number of missed cleavages (MC): 1

All cysteines in reduced form.

Methionines have been oxidized to form methionine sulfoxide (MSO).

Using monoisotopic masses of the occurring amino acid residues and giving peptide masses as $[\mathrm{M}+\mathrm{H}]^{+}$.

You have selected KCRM_RABIT ( $\underline{P 00563}$ ) from UniProtKB/Swiss-Prot:

Creatine kinase M-type (EC 2.7.3.2) (Creatine kinase M chain) (M-CK)

Chain Creatine kinase M-type at positions 1 - 381 [Theoretical pl: 6.63 / Mw (average mass): 43112.06 / Mw (monoisotopic mass): 43084.84]

\begin{tabular}{|c|c|c|c|c|c|c|}
\hline mass & position & \#MC & artif.modific & cation(s) & $\underline{\text { modifications }}$ & peptide sequence \\
\hline 5585.6402 & 46-96 & 1 & MSO: 70 & 5601.6351 & & $\begin{array}{l}\text { ETPSGFTLDDVIQTGVDNPG } \\
\text { KDLFDPIIQDR }\end{array}$ \\
\hline 4616.1483 & 44-86 & 1 & MSO: 70 & 4632.1432 & & DKETPSGFTLDDVIQTGVDN PGHPFIMTVGCVAGDEESYT VFK \\
\hline 4385.1328 & $\begin{array}{l}178- \\
215\end{array}$ & 1 & $\begin{array}{l}\text { MSO: } 17 \\
207\end{array}$ & 79, 4417.1227 & & SMTEQEQQQLIDDHFLFDKP VSPLLLASGMARDWPDAR \\
\hline 4373.0264 & $46-86$ & 0 & MSO: 70 & 4389.0213 & & ETPSGFTLDDVIQTGVDNPG HPFIMTVGCVAGDEESYTVF K \\
\hline 4309.1671 & $\begin{array}{l}173- \\
209\end{array}$ & 1 & $\begin{array}{l}\text { MSO: } \quad 17 \\
207\end{array}$ & 79, 4341.1569 & & YYPLKSMTEQEQQQLIDDHF LFDKPVSPLLLASGMAR \\
\hline 3775.8984 & $321-$ & 1 & & & & GTGGVDTAAVGSVFDISNAD RLGSSEVEQVQLVVDGVK \\
\hline 3644.8087 & $\begin{array}{l}178- \\
209\end{array}$ & 0 & $\begin{array}{l}\text { MSO: } \\
207\end{array}$ & 79, 3676.7985 & & SMTEQEQQQLIDDHFLFDKP VSPLLLASGMAR \\
\hline 3447.7201 & $\begin{array}{l}267- \\
298\end{array}$ & 1 & MSO: 272 & 3463.7150 & & AGHPFMWNEHLGYVLTCPSN LGTGLRGGVHVK \\
\hline 2998.4814 & $\begin{array}{l}266- \\
292\end{array}$ & 1 & MSO: 272 & 3014.4763 & & KAGHPFMWNEHLGYVLTCPS NLGTGLR \\
\hline 2870.3864 & 267- & 0 & MSO: 272 & 2886.3814 & & AGHPFMWNEHLGYVLTCPSN LGTGLR \\
\hline
\end{tabular}




\begin{tabular}{|c|c|c|c|c|c|}
\hline & 292 & & & & \\
\hline 2646.3728 & $\begin{array}{l}342- \\
365\end{array}$ & 1 & $\begin{array}{l}\text { MSO: } \quad 36 \\
363\end{array}$ & 60, 2678.3626 & LGSSEVEQVQLVVDGVKLMV EMEK \\
\hline 2608.2691 & $\begin{array}{l}216- \\
236\end{array}$ & 1 & & & GIWHNDNKSFLVWVNEEDHL R \\
\hline 2595.2433 & $\begin{array}{l}108- \\
130\end{array}$ & 1 & & & TDLNHENLKGGDDLDPHYVL SSR \\
\hline 2331.1801 & $\begin{array}{l}224- \\
242\end{array}$ & 1 & MSO: 240 & 2347.1750 & SFLVWVNEEDHLRVISMEK \\
\hline 2199.1192 & 87-105 & 1 & & & DLFDPIIQDRHGGFKPTDK \\
\hline 2165.0581 & $\begin{array}{l}320- \\
341\end{array}$ & 1 & & & RGTGGVDTAAVGSVFDISNA DR \\
\hline 2028.9079 & $16-32$ & 1 & MSO: 30 & 2044.9029 & SEEEYPDLSKHNNHMAK \\
\hline 2008.9570 & $\begin{array}{l}321- \\
341\end{array}$ & 0 & & & GTGGVDTAAVGSVFDISNAD R \\
\hline 1935.0433 & $\begin{array}{l}153- \\
170\end{array}$ & 1 & & & AVEKLSVEALNSLTGEFK \\
\hline 1785.9592 & $\begin{array}{l}342- \\
358\end{array}$ & 0 & & & LGSSEVEQVQLVVDGVK \\
\hline 1785.8878 & $\begin{array}{l}117- \\
132\end{array}$ & 1 & & & GGDDLDPHYVLSSRVR \\
\hline 1780.9163 & $26-40$ & 1 & MSO: 30 & 1796.9112 & HNNHMAKVLTPDLYK \\
\hline 1723.7935 & $\begin{array}{l}210- \\
223\end{array}$ & 1 & & & DWPDARGIWHNDNK \\
\hline 1714.8170 & $12-25$ & 1 & & & LNYKSEEEYPDLSK \\
\hline 1692.9166 & $\begin{array}{l}157- \\
172\end{array}$ & 1 & & & LSVEALNSLTGEFKGK \\
\hline 1672.8574 & $\begin{array}{l}367- \\
381\end{array}$ & 1 & MSO: 376 & 1688.8523 & LEKGQSIDDMIPAQK \\
\hline 1643.8176 & $\begin{array}{l}224- \\
236\end{array}$ & 0 & & & SFLVWVNEEDHLR \\
\hline 1553.8396 & $\begin{array}{l}253- \\
265\end{array}$ & 1 & & & FCVGLQKIEEIFK \\
\hline 1530.7183 & $\begin{array}{l}117- \\
130\end{array}$ & 0 & & & GGDDLDPHYVLSSR \\
\hline 1507.8002 & $\begin{array}{l}157- \\
170\end{array}$ & 0 & & & LSVEALNSLTGEFK \\
\hline 1472.7063 & $\begin{array}{l}139- \\
151\end{array}$ & 1 & & & GYTLPPHCSRGER \\
\hline 1458.7522 & $\begin{array}{l}136- \\
148\end{array}$ & 1 & & & SIKGYTLPPHCSR \\
\hline 1348.6968 & $\begin{array}{l}106- \\
116\end{array}$ & 1 & & & HKTDLNHENLK \\
\hline 1336.6466 & $1-11$ & 1 & MSO: 1 & 1352.6416 & MPFGNTHNKYK \\
\hline 1302.6358 & $\begin{array}{l}370- \\
381\end{array}$ & $\mathbf{0}$ & MSO: 376 & 1318.6307 & GQSIDDMIPAQK \\
\hline
\end{tabular}




\begin{tabular}{|c|c|c|c|c|}
\hline 1269.6950 & $305-$ & 1 & & HPKFEEILTR \\
\hline 1251.6592 & 97-107 & 1 & & HGGFKPTDKHK \\
\hline 1245.7426 & $\begin{array}{l}293- \\
304\end{array}$ & 1 & & GGVHVKLAHLSK \\
\hline 1231.6317 & $87-96$ & 0 & & DLFDPIIQDR \\
\hline 1196.5317 & $16-25$ & 0 & & SEEEYPDLSK \\
\hline 1193.6017 & $\begin{array}{l}237- \\
247\end{array}$ & 1 & $\begin{array}{l}\text { MSO: } 240, \\
246\end{array}$ & VISMEKGGNMK \\
\hline 1176.6735 & $\begin{array}{l}308- \\
316\end{array}$ & 1 & & FEEILTRLR \\
\hline 1130.5411 & $\begin{array}{l}139- \\
148\end{array}$ & 0 & & GYTLPPHCSR \\
\hline 1083.5429 & $\begin{array}{l}108- \\
116\end{array}$ & 0 & & TDLNHENLK \\
\hline 1076.6350 & $33-41$ & 1 & & VLTPDLYKK \\
\hline 1045.4884 & $1-9$ & 0 & MSO: $1 \quad 1061.4833$ & MPFGNTHNK \\
\hline 1037.5196 & $\begin{array}{l}243- \\
251\end{array}$ & 1 & MSO: $246 \quad 1053.5146$ & GGNMKEVFR \\
\hline 1030.6156 & $\begin{array}{l}299- \\
307\end{array}$ & 1 & & LAHLSKHPK \\
\hline 1007.5264 & $\begin{array}{l}359- \\
366\end{array}$ & 1 & $\begin{array}{l}\text { MSO: } \\
363\end{array}$ & LMVEMEKK \\
\hline 986.5054 & 97-105 & 0 & & HGGFKPTDK \\
\hline 983.4693 & $\begin{array}{l}216- \\
223\end{array}$ & 0 & & GIWHNDNK \\
\hline 950.5240 & $\begin{array}{l}252- \\
259\end{array}$ & 1 & & RFCVGLQK \\
\hline 948.5400 & $33-40$ & 0 & & VLTPDLYK \\
\hline 907.4883 & $\begin{array}{l}308- \\
314\end{array}$ & 0 & & FEEILTR \\
\hline 906.5295 & $\begin{array}{l}260- \\
266\end{array}$ & 1 & & IEEIFKK \\
\hline 879.4314 & $\begin{array}{l}359- \\
365\end{array}$ & 0 & $\begin{array}{l}\text { MSO: } \quad 360,911.4212 \\
363\end{array}$ & LMVEMEK \\
\hline 868.4927 & $\begin{array}{l}171- \\
177\end{array}$ & 1 & & GKYYPLK \\
\hline 851.3941 & 26-32 & 0 & 867.3890 & HNNHMAK \\
\hline 828.4614 & $10-15$ & 1 & & YKLNYK \\
\hline 794.4229 & $\begin{array}{l}253- \\
259\end{array}$ & 0 & & FCVGLQK \\
\hline 778.4345 & 260- & 0 & & IEEIFK \\
\hline
\end{tabular}




\begin{tabular}{|c|c|c|c|c|}
\hline 759.3420 & $\begin{array}{l}210- \\
215\end{array}$ & 0 & & DWPDAR \\
\hline 706.3995 & $\begin{array}{l}248- \\
252\end{array}$ & 1 & & EVFRR \\
\hline 706.3804 & $\begin{array}{l}237- \\
242\end{array}$ & MSO: 240 & 722.3753 & VISMEK \\
\hline 683.3763 & $\begin{array}{l}173- \\
177\end{array}$ & 0 & & YYPLK \\
\hline 668.4090 & $\begin{array}{l}299- \\
304\end{array}$ & 0 & & LAHLSK \\
\hline 661.3991 & $\begin{array}{l}133- \\
138\end{array}$ & 1 & & TGRSIK \\
\hline 657.4406 & $\begin{array}{l}315- \\
319\end{array}$ & 1 & & LRLQK \\
\hline 602.3620 & $\begin{array}{l}152- \\
156\end{array}$ & 1 & & RAVEK \\
\hline 596.3514 & $\begin{array}{l}293- \\
298\end{array}$ & 0 & & GGVHVK \\
\hline 588.3576 & $\begin{array}{l}131- \\
135\end{array}$ & 1 & & VRTGR \\
\hline 550.2983 & $\begin{array}{l}248- \\
251\end{array}$ & 0 & & EVFR \\
\hline 544.3565 & $\begin{array}{l}317- \\
320\end{array}$ & 1 & & LQKR \\
\hline 537.3031 & $12-15$ & 0 & & LNYK \\
\hline 531.3249 & $42-45$ & 1 & & LRDK \\
\hline 517.3344 & $\begin{array}{l}366- \\
369\end{array}$ & 1 & & KLEK \\
\hline 517.2841 & $\begin{array}{l}149- \\
152\end{array}$ & 1 & & GERR \\
\hline 506.2391 & $\begin{array}{l}243- \\
247\end{array}$ & MSO: 246 & 522.2340 & GGNMK \\
\hline 446.2609 & $\begin{array}{l}153- \\
156\end{array}$ & 0 & & AVEK \\
\hline 416.2980 & $41-43$ & 1 & & KLR \\
\hline 389.2394 & $\begin{array}{l}367- \\
369\end{array}$ & 0 & & LEK \\
\hline 388.2554 & $\begin{array}{l}317- \\
319\end{array}$ & 0 & & LQK \\
\hline 381.2245 & $\begin{array}{l}305- \\
307\end{array}$ & 0 & & HPK \\
\hline 361.1830 & $\begin{array}{l}149- \\
151\end{array}$ & 0 & & GER \\
\hline 347.2289 & $\begin{array}{l}136- \\
138\end{array}$ & 0 & & SIK \\
\hline 333.1881 & $\begin{array}{l}133- \\
135\end{array}$ & 0 & & TGR \\
\hline
\end{tabular}




\begin{tabular}{|c|c|c|c|}
\hline 310.1761 & $10-11$ & 0 & YK \\
\hline 288.2030 & $42-43$ & 0 & LR \\
\hline 288.2030 & $\begin{array}{l}315- \\
316\end{array}$ & 0 & LR \\
\hline 284.1717 & $\begin{array}{l}106- \\
107\end{array}$ & 0 & HK \\
\hline 274.1873 & $\begin{array}{l}131- \\
132\end{array}$ & 0 & VR \\
\hline 262.1397 & $44-45$ & 0 & DK \\
\hline 204.1342 & $\begin{array}{l}171- \\
172\end{array}$ & 0 & GK \\
\hline 175.1189 & $\begin{array}{l}152- \\
152\end{array}$ & 0 & $\mathbf{R}$ \\
\hline 175.1189 & $\begin{array}{l}252- \\
252\end{array}$ & 0 & $\mathbf{R}$ \\
\hline 175.1189 & $\begin{array}{l}320- \\
320\end{array}$ & 0 & $\mathbf{R}$ \\
\hline 147.1128 & 41-41 & 0 & K \\
\hline 147.1128 & $\begin{array}{l}266- \\
266\end{array}$ & 0 & K \\
\hline 147.1128 & $\begin{array}{l}366- \\
366\end{array}$ & 0 & K \\
\hline
\end{tabular}

$100.0 \%$ of sequence covered (you may modify the input parameters to display also peptides $<0$ Da or $>100000000000 \mathrm{Da}$ ):

\begin{tabular}{|c|c|c|c|c|c|}
\hline $1 \underline{0}$ & $2 \underline{0}$ & $3 \underline{0}$ & $4 \underline{0}$ & $5 \underline{0}$ & $6 \underline{0}$ \\
\hline MPFGNTHNKY & KLNYKSEEEY & PDLSKHNNHM & AKVLTPDLYK & KLRDKETPSG & FTLDDVIQTG \\
\hline $7 \underline{0}$ & $8 \underline{0}$ & $9 \underline{0}$ & $10 \underline{0}$ & $11 \underline{0}$ & $12 \underline{0}$ \\
\hline VDNPGHPFIM & TVGCVAGDEE & SYTVFKDLFD & PIIQDRHGGF & KPTDKHKTDL & NHENLKGGDD \\
\hline $13 \underline{0}$ & $14 \underline{0}$ & $15 \underline{0}$ & $16 \underline{0}$ & $17 \underline{0}$ & $18 \underline{0}$ \\
\hline LDPHYVILSSR & VRTGRSIKGY & TLPPHCSRGE & RRAVEKLSVE & ALNSLTGEFK & GKYYPLKSMT \\
\hline $19 \underline{0}$ & $20 \underline{0}$ & $21 \underline{0}$ & $22 \underline{0}$ & $23 \underline{0}$ & $24 \underline{0}$ \\
\hline EQEQQQLIDD & HFLFDKPVSP & LLLASGMARD & WPDARGIWHN & DNKSFLVWVNN & EEDHLRVISM $\bar{M}$ \\
\hline $25 \underline{0}$ & $26 \underline{0}$ & $27 \underline{0}$ & $28 \underline{0}$ & $29 \underline{0}$ & $30 \underline{0}$ \\
\hline EKGGNMKEVF & RRFCVGLQKI & EEIFKKAGHP & FMWNEHLGYYV & LTCPSNLGTG & LRGGVHVKLA \\
\hline 310 & $32 \underline{0}$ & $33 \underline{0}$ & $34 \underline{0}$ & $35 \underline{0}$ & $36 \underline{0}$ \\
\hline HLSKHPKFEE & ILTRLRLQKR & GTGGVDTAAV & GSVFDISNAD & RLGSSEVEQV & QLVVDGVKLM \\
\hline $37 \underline{0}$ & & & & & $38 \underline{0}$ \\
\hline
\end{tabular}




\section{Appendix C. PEAKS analysis of ICAT spectra.}

The peptide sequences for HL-60 ICAT pairs. These figures show the peptide sequences of $751.4,725.4,734.4,890.4$, and 1018.4 ions.

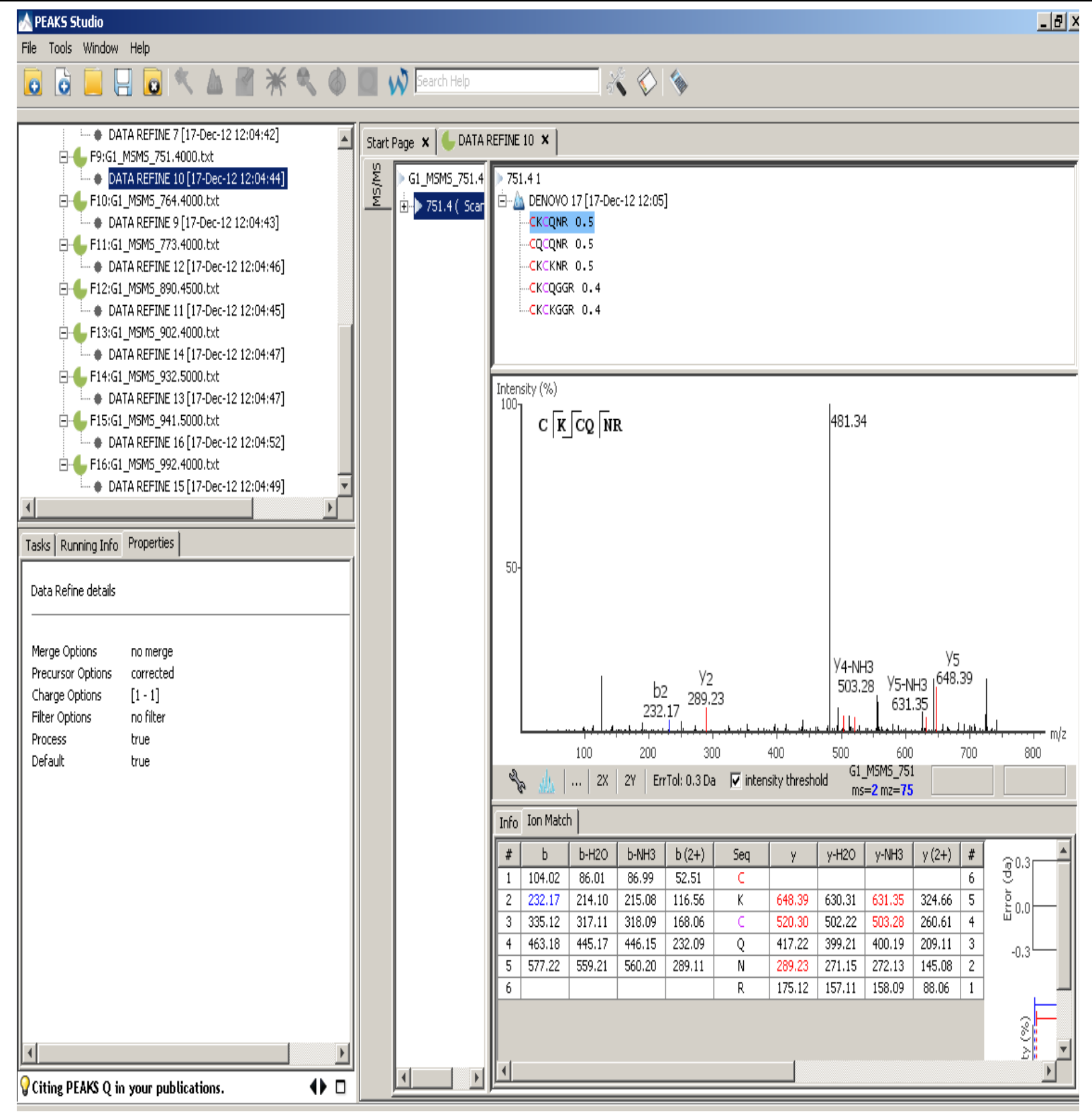




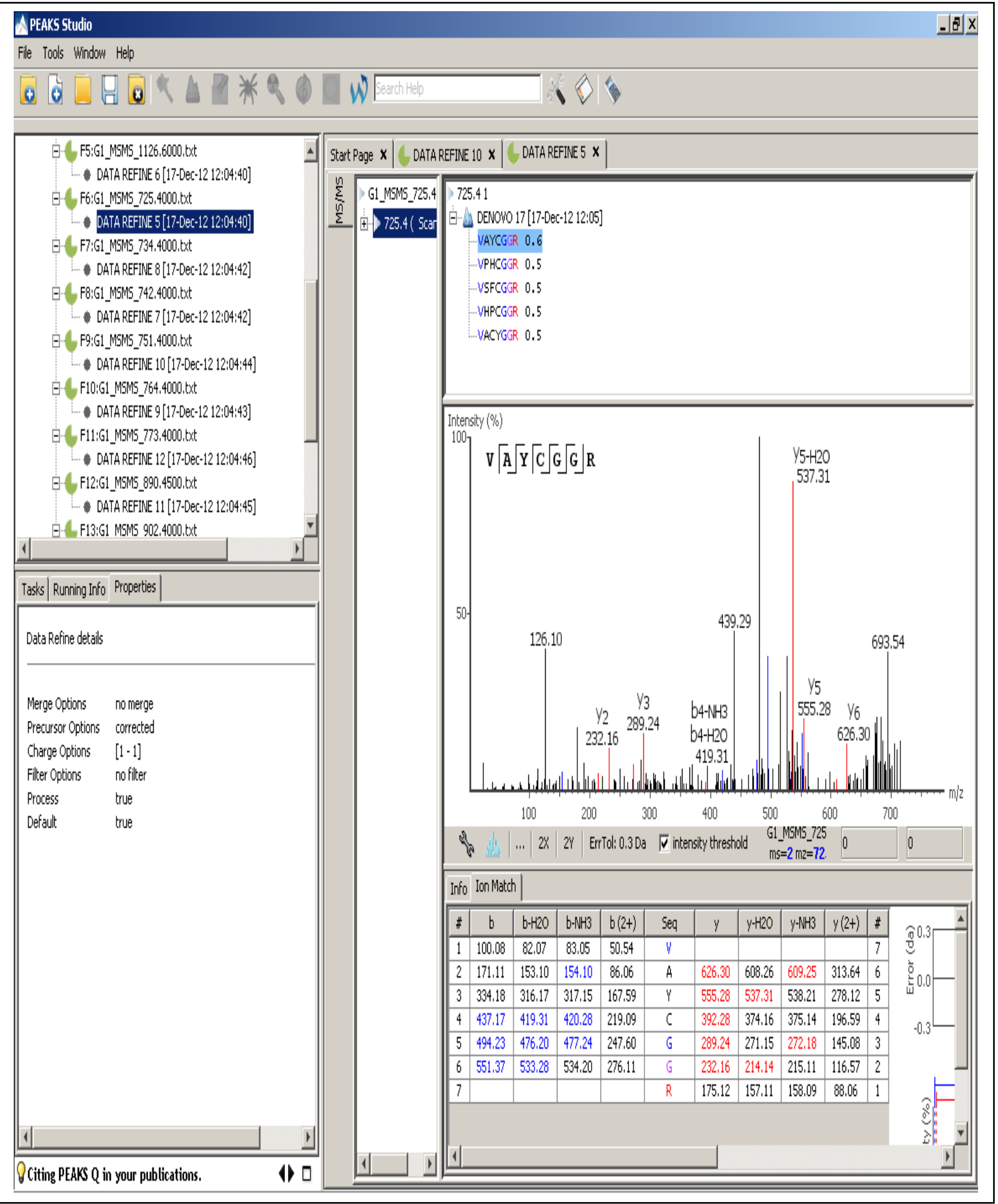




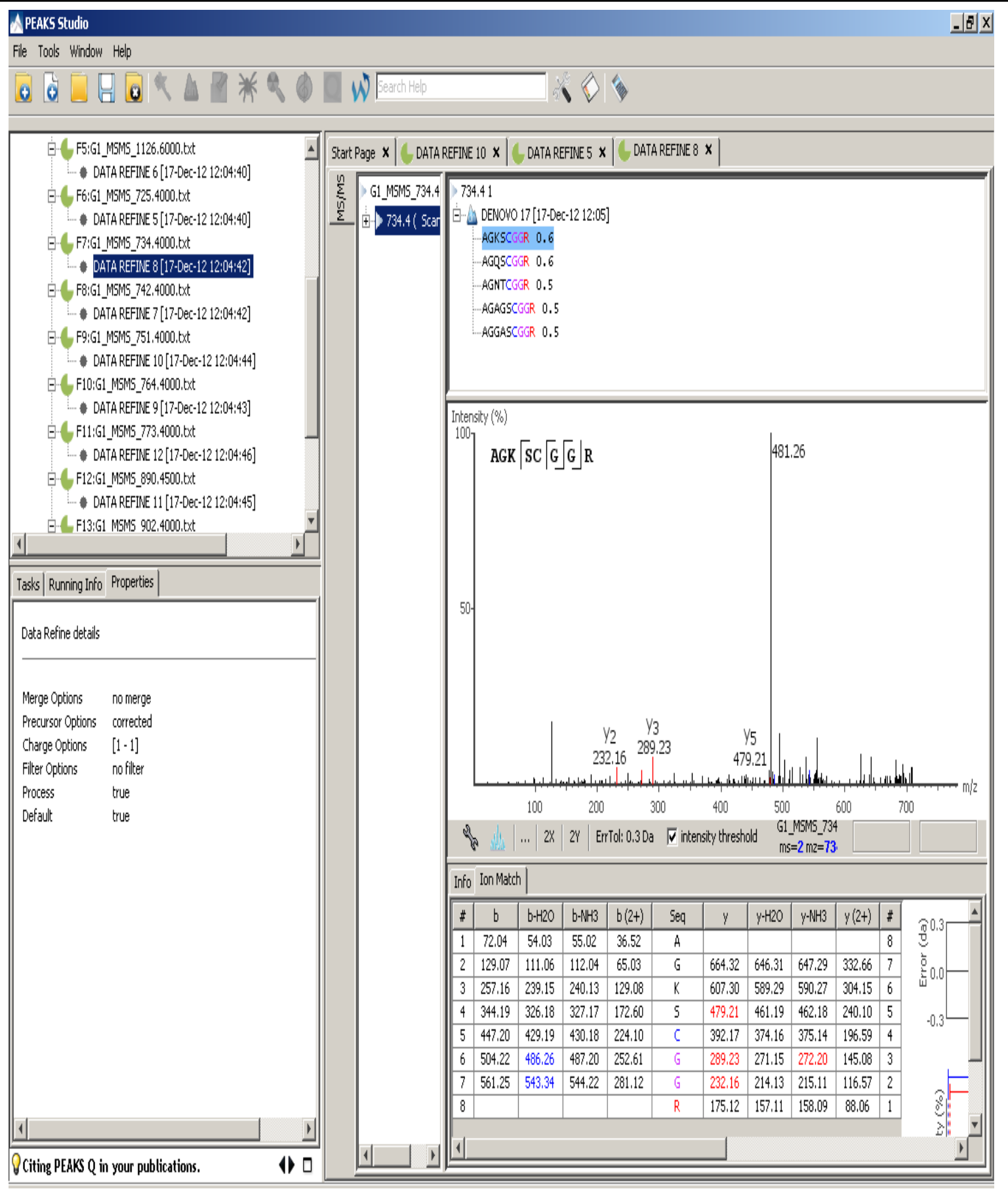




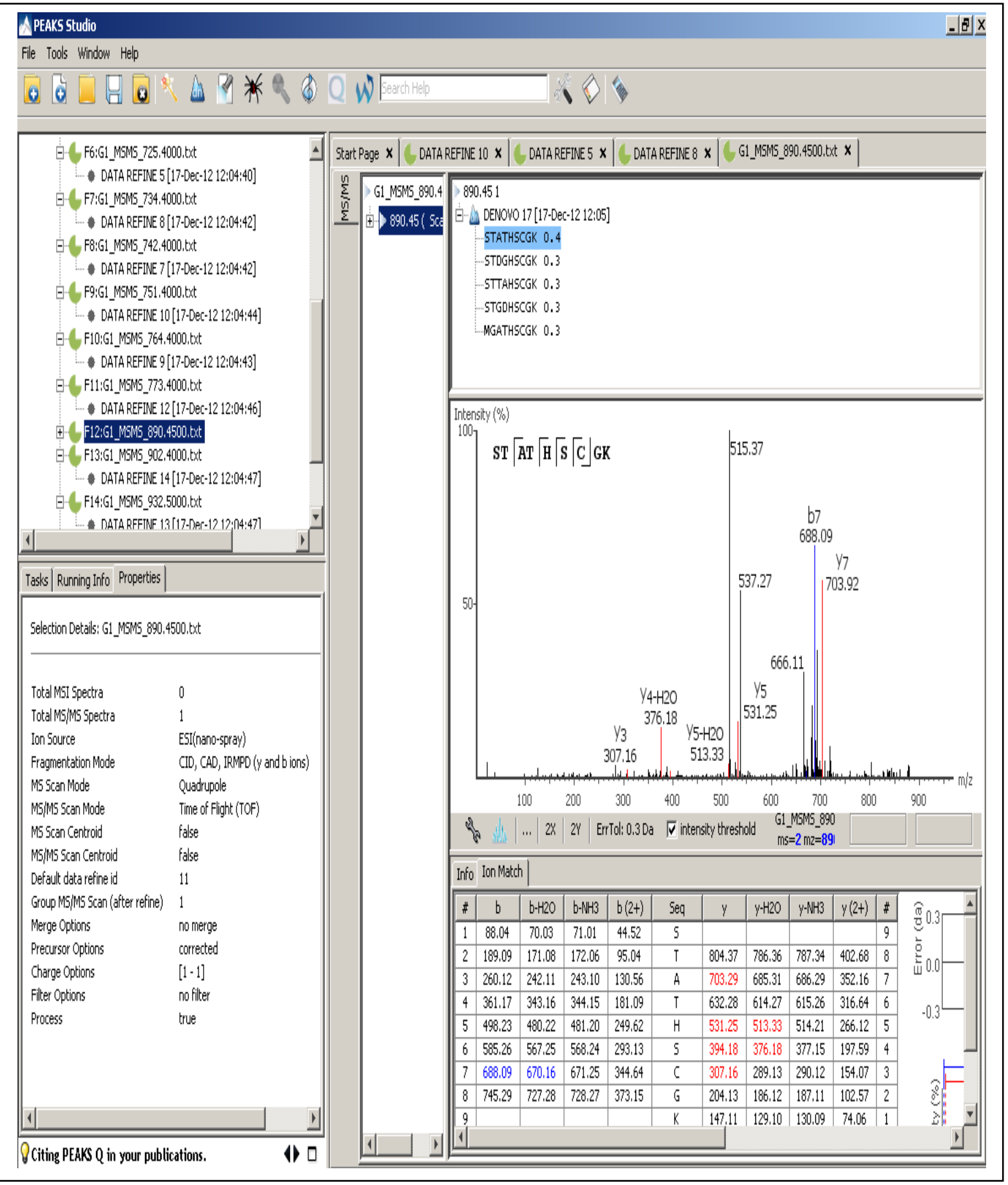




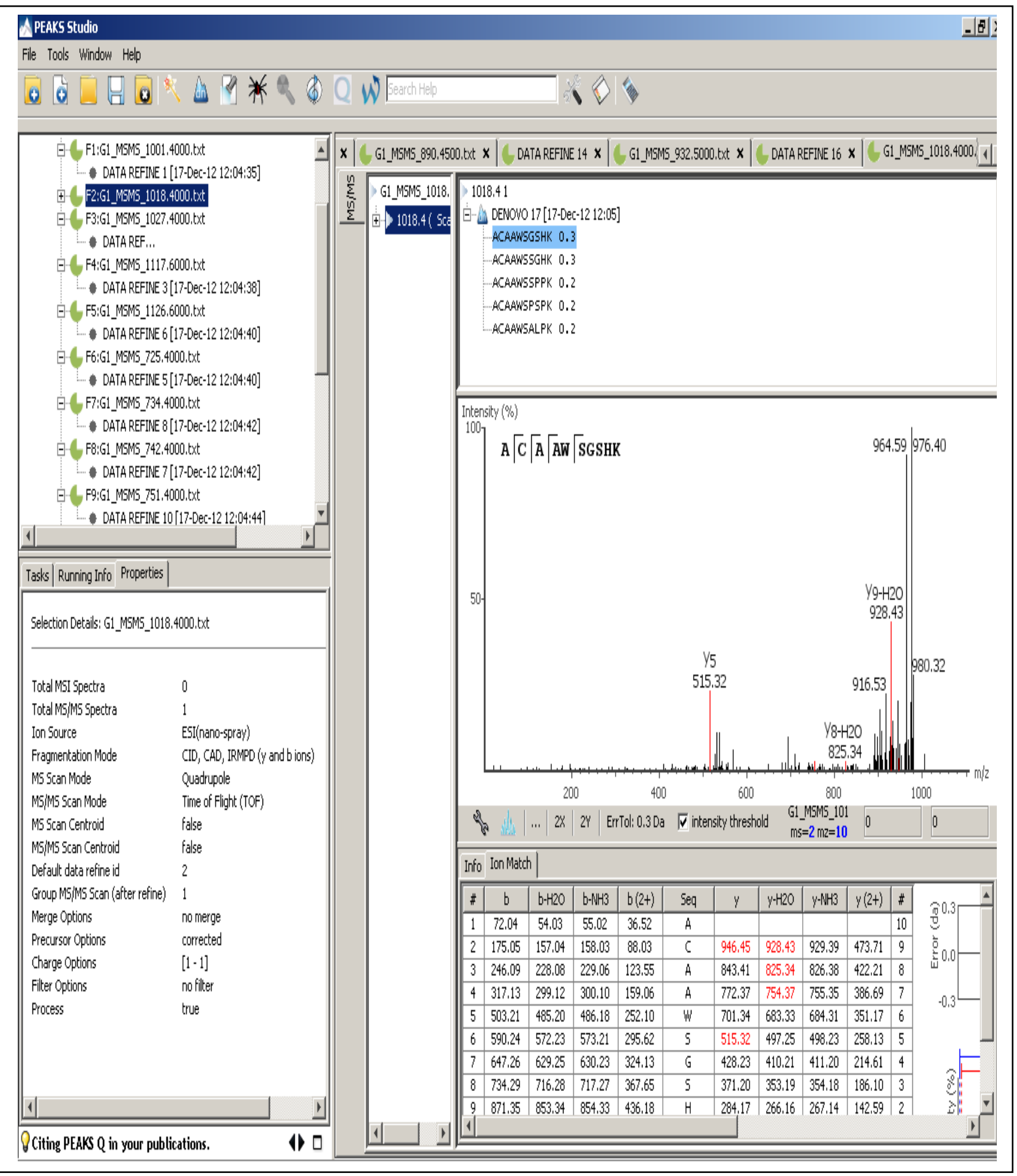


$=/$ SCRIPT $>$

\section{\{MATENCER\} Mascot Search Results}

User

Search tit1

Database
Taxonomy

Taxonomy
Timestamp

Enzyme

variable modifications

Mass values
Protein Mass

Peptide Mass Tolerance

Fragment Mass Toleran

Instrument type

Number of queries

Number of quer
Protein $=i$ its

\section{$=/ \mathrm{B}>$}

NCBInrEukaryote 23022011 (2385481 sequences; $=81413870$ residues)

ukaryota (eucaryotes) (1305516 =equences)

29 Jun 2012 at 04:06:04 GMT

Trypsin

Monoisotopic

$\pm 0.5 \mathrm{Da}$
$\pm 0.5 \mathrm{Da}$

MALDI-TOF-TOF

1180

gi|125307 RecName: Full=Creatine kinase =-type; AltName: Full=Creatine kinase M chain; AltName: =ull=M-CK

gi|125304 RecName: Full=Creatine kinase =-type; AltName: Full=Creatine kinase M chain; AltName: =ull=M-CK

gi 125310 ReCName: Full=Creatine Kinase $=$-ype; AltName: Full=Creatine Kinase M Chain; AltName: Full=M-CK; $=1$ tName: Full=NU-2 protein

gi|3183536 RecName: Full=Creatine kinase =-type, mitochondrial; AltName: Full=Basic-type mitochondrial creatine =inase; Short=Mib-CK; AltName: Full=Sarcomeric mitochondrial =reatine kinase; Sho

.$/$ data/20120629/F10720

Select Summary Report

Format As

Select Summary (protein hits)

Help

Significance threshold $\mathrm{p}<$

Max. number of hits AUTO

Standard scoring $\odot$ MudPIT scoring $\odot$ Ions score or expect cut-off

Show sub-sets 0

Show pop-ups $\odot$ Suppress pop-ups $\odot$ scoredown

Require bold red

$=$ INPUT value $=$ MIS type $=$ hidden name $=$ SEARCH $>$ Monoisotopic 0.5

value="Eukaryota (eucaryotes)" type=hidden name=TAXONOMY>

Re-Search

Below

\begin{tabular}{|c|c|c|c|c|c|c|c|}
\hline \multicolumn{2}{|c|}{ gi|125307 } & $43=85$ & Score: 1106 & \multicolumn{2}{|c|}{ Ma $=$ ches : } & $\begin{array}{l}263(101) \\
=C r e a t \text { ) }\end{array}$ & \multirow{2}{*}{$\begin{array}{l}\text { Sequences } \\
\text { e kinase M }\end{array}$} \\
\hline & & tine kinas & se M-type; $F$ & & & & \\
\hline Query & Observed & $\operatorname{Mr}(\operatorname{expt})$ & $\mathrm{Mr}(\mathrm{calc})$ & Delta & & Score & \\
\hline 113 & 759.3526 & 758.3453 & 758.3347 & 0.0106 & 0 & 36 & \\
\hline 149 & 778.4458 & 777.4385 & 777.4272 & 0.0113 & 0 & 25 & 4.4 \\
\hline 175 & 794.4398 & 793.4325 & 793.4156 & 0.0169 & 0 & 28 & 1.8 \\
\hline 450 & 879.4307 & 878.4235 & 878.4241 & -0.0007 & 0 & 20 & 12 \\
\hline 515 & 907.4846 & 906.4773 & 906.4811 & -0.0037 & 0 & 37 & 0.22 \\
\hline 557 & 914.4544 & 913.4471 & 913.4406 & 0.0065 & 0 & 27 & 2.4 \\
\hline 570 & 948.5413 & 947.5340 & 947.5328 & 0.0013 & 0 & 20 & 12 \\
\hline 607 & 983.4736 & 982.4663 & 982.4621 & 0.0042 & & 43 & 0.047 \\
\hline 612 & 986.5097 & 985.5024 & 985.4981 & 0.0043 & 0 & 72 & $6.1 \mathrm{e}-005$ \\
\hline 645 & 1083.5530 & 1082.5457 & 1082.5356 & 0.0101 & 0 & 30 & 0.86 \\
\hline 671 & 1130.5419 & 1129.5346 & 1129.5339 & 0.0007 & & & 0.2 \\
\hline 729 & 1196.5387 & 1195.5314 & 1195.5244 & 0.0070 & 0 & 51 & 0.0072 \\
\hline 749 & 1231.6428 & 1230.6355 & 1230.6245 & 0.0111 & 0 & 67 & 0.0002 \\
\hline 824 & 1302.6368 & 1301.6296 & 1301.6285 & 0.0010 & & 72 & $5.9 e-005$ \\
\hline 828 & 1318.6257 & 1317.6185 & 1317.6235 & -0.0050 & 0 & (21) & \\
\hline 886 & 1530.7216 & 1529.7143 & 1529.7110 & 0.0032 & 0 & 89 & $7.9 e-007$ \\
\hline 954 & 1643.8378 & 1642.8305 & 1642.8103 & 0.0201 & 0 & 74 & $2.1 \mathrm{e}-005$ \\
\hline 1027 & 1785.9600 & 1784.9527 & 1784.9520 & 0.0007 & 0 & 99 & \\
\hline 1097 & 2008.9678 & 2007.9605 & 2007.9498 & 0.0107 & 0 & 157 & $8.7 e-014$ \\
\hline 1180 & 3644.8718 & 3643.8646 & 3643.8014 & 0.0631 & 0 & 13 & 7.1 \\
\hline
\end{tabular}

0) $\delta \mathrm{n}=\mathrm{sp} ;$ empaI: 2,40

Mhain; AltName: =ull=M-

Peptide
R. DWPDAR.

K. IEEIFK.K 147148

R. FCVGLQK.I 163164

K.FEEILTR.I 516517519520521523525526530531532533536538540543545

M. PFGNTHNK.Y 561562

K.VLTPDLYK.K 571574

R. GIWHNDNK.S 608609610611

K. TDENPTDK. H. 61364

K. TDLNHENLK.G 6442673676677678679680681683687691694

K. GYTLPPHCSR.G 672673676
K.SEEEYPDLSK.H 728730731

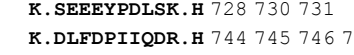

79750751752753754755756757758759760761762764765766767768769770771772773774775777778

K.GQSIDDMIPAQR.

K.GGDDLDPHYVLSSR.V $885887888889890891892893894895896897898899900902903904905906907908909910911912913914916917918920 \mathrm{~g}$

K. SFLVWVNEEDHLR.V 951952953955956957958959960961962963964965966967968969970971975979980981

C. K. R.GTGGVDTAAVGSVFDISNADR,LL=T>1095 10961098109911001101110211031104110511061107110811091110111111121113111411151116111711

K. SMTEOEOOOLIDDHFLFDKPVSPLLTASGMAR, D $<=$ TT $>1179$ 
2. gi|125304 Mass: 43=01 Score: 168 =B>Matches: $15(2)$ Sequences: $6(1)$ \&n=sp; emPAI: 0.11 RecName: Full=Creatine kinase M-type; AltName: Full=Creatine kinase M chain; AltName: =ull=M-CK $\begin{array}{lllllll}\text { Query } & \text { observed } & \text { Mr (expt) } & \text { Mr (calc) } & \text { Delta Miss Score Expect Rank Unique Peptide } \\ 113 & 759.3526 & 758.3453 & 758.3347 & 0.0106 & 0 & 36\end{array}$

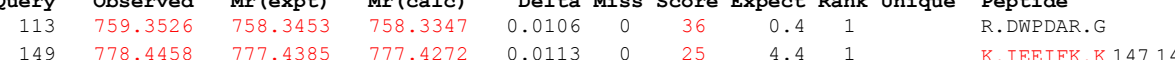

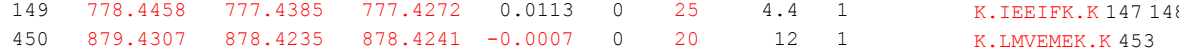

$\begin{array}{llllllllll}607 & 983.4736 & 982.4663 & 982.4621 & 0.0042 & 0 & 43 & 0.047 & 1 & \text { R.GIWHNDNK.T } 608609610611\end{array}$

$\begin{array}{llllllllll}645 & 1083.5530 & 1082.5457 & 1082.5356 & 0.0101 & 0 & 30 & 0.86 & 1 & \text { R. TDLNHENLK.G } 644\end{array}$

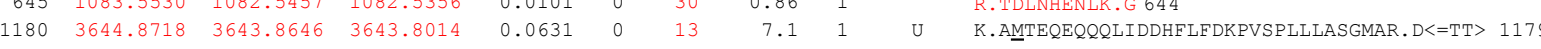

3. gi|125310 Mass: $42=47$ Score: $153 \quad=$ B>Matches: $35(11)$ Sequences: 4 (1) $\&=b s p$; emPAI: 0.23

RecName: Full=Creatine kinase M-type; AltName: Full=Creatine kinase M chain; AltName: Full=M-CK; AltName: =ull=Nu-2 protein

Query observed Mr(expt) Mr(calc) Delta Miss Score Expect Rank Unique Peptide

$\begin{array}{llllllllll}879.4307 & 878.4235 & 878.4241 & -0.0007 & 0 & 20 & 12 & 1 & \text { K. LMVEMEK.R } 453\end{array}$

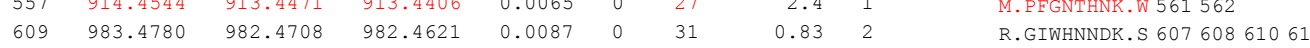

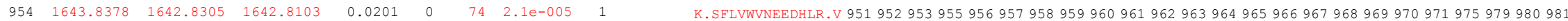

4. gi|125293 Mass: $42=44$ Score: 138 =B>Matches: 12 (3) Sequences: $4(2)$ sn=sp;emPAI: 0.23

RecName: Full=Creatine kinase B-type; AltName: =ull=B-CK; Altwame: Full=Creatine kinase B =hain

$\begin{array}{cccccc}\text { Query } & \text { Observed } & \text { Mr (expt) } & \text { Mr (calc) } & \text { Delta Miss Score Expect Rank Unique Peptide } \\ 113 & 759.3526 & 758.3453 & 758.3347 & 0.0106 & 0\end{array}$

$\begin{array}{llllllllll}113 & 759.3526 & 758.3453 & 758.3347 & 0.0106 & 0 & 36 & 0.4 & 1 & \text { R. DWPDAR.G } \\ 607 & 983.4736 & 982.4663 & 982.4621 & 0.0042 & 0 & 43 & 0.047 & 1 & R . G I W H N D N . T 608609610611\end{array}$

$\begin{array}{lllllllllll}824 & 1302.6368 & 1301.6296 & 1301.6285 & 0.0010 & 0 & 49 & 0.011 & 2 & \text { U } & \text { K.GQSIDDLMPAQK. }-821825\end{array}$

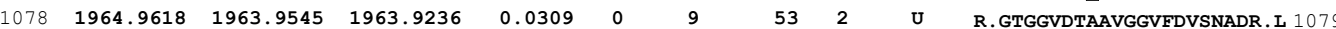

5. gi|3183536 Mass: $4=054$ Score: 68 =nbsp;Matches: $6(0)$ Sequences: $2(0)$

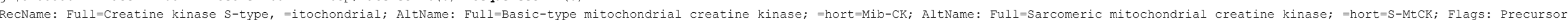
Query Observed $\operatorname{Mr}$ (expt) $\operatorname{Mr}$ (calc) Delta Miss Score Expect Rank Unique Peptide

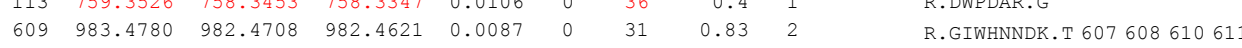

Proteins matching the same set of peptides:
gi $\mid 268370038$ Mass: $=47068 \quad$ Score: $68 \quad$ nnbs=; Matches: $6(0)$ Sequences: $2(0)\langle=T$ TT $\rangle$

creatine kinase S-type, mitochondrial [Gallus gallus]

Mascot: http://www.matrixscience.com/= 